\title{
Consenso argentino sobre diagnóstico y tratamiento de la esquizofrenia resistente al tratamiento
}

\author{
Argentine consensus on the diagnosis and therapeutics of treatment resistant schizophrenia
}

\author{
Alejo Corrales', Manuel Vilapriño Duprat ${ }^{2}$, Carlos Benavente Pinto ${ }^{3}$, Cristian Garay ${ }^{4}$, Ri- \\ cardo Corral ${ }^{5}$, Pedro R. Gargoloff', Aníbal Goldchluk ${ }^{7}$, Guillermo Hönig ${ }^{8}$, Gabriela Jufe', \\ Fabián Lamaison ${ }^{10}$, Eduardo A. Leiderman ", Carlos Morra ${ }^{12}$, Federico Rebok ${ }^{13}$, Pedro \\ Damián Gargoloff ${ }^{14}$
}

\section{Resumen}

Aproximadamente el $30 \%$ de los pacientes con diagnóstico de esquizofrenia no responden al tratamiento con antipsicóticos produciendo una importante carga de la enfermedad. La Esquizofrenia Resistente al Tratamiento (ERT) se define como la falta de respuesta a dos antipsicóticos de diferente clase, administrados en dosis adecuada durante 6 semanas. La clozapina es el único fármaco aprobado para tratar la ERT, sin embargo, uno de cada tres pacientes no responde a este fármaco. Existen algunas estrategias disponibles para el tratamiento de los pacientes con ERT que no responden a la clozapina, pero la evidencia de estas estrategias continua siendo escasa y de mala calidad. En este consenso presentamos el resultado de un trabajo conjunto de expertos pertenecientes a las principales asociaciones científicas de Argentina bajo el auspicio de la Asociación Argentina de Psiquiatría Biología (AAPB). El objetivo de este trabajo es desarrollar un consenso con recomendaciones sobre el tratamiento de la ERT. Para ello se llevó a cabo una revisión formal de la literatura científica y luego el panel de expertos respondió 35 preguntas sobre los temas más importantes en relación a ERT. Una modificación del método Delphi fue usado para consensuar los aspectos más relevantes sobre ERT, en función de ambas actividades y de la experiencia del panel de expertos, luego se analizaron y se discutieron los resultados obtenidos. Como corolario se elaboró un documento consensuado con recomendaciones sobre los principales puntos de la ERT, el mismo estará disponible para la comunidad científica y para cualquier otro organismo público o privado relacionado con esta problemática de salud.

\footnotetext{
RECIBIDO 29/10/2021 - ACEPTADO 26/II/202I

'.Departamento de Psiquiatría y Salud Mental, Facultad de Medicina (UNT). Presidente de la Asociación Argentina de Psiquiatría Biológica (AAPB).

2.Médico Especialista Universitario en Psiquiatría. Docente del Departamento de Neurociencias de la Fac. de Ciencias Médicas de la Univ. Nac. de

Cuyo. Presidente de la Asociación de Psiquiatras Argentinos (APSA).

3. Director Médico de la Residencia Psiquiátrica Teresa de Calcuta, Tandil.

4. Doctor en Psicología, Profesor Regular, Facultad de Psicología, Universidad de Buenos Aires.

5.Docencia e Investigación Hospital “José T Borda”. Presidente de AAP.

6. Médico especialista en Psiquiatría y Psicología Médica. Asociación de Ayuda de Familiares de Personas que padecen Esquizofrenia (AAFE).

7. Médico Psiquiatra. Ex Jefe de Servicio de Consultorios Externos del Hospital Borda.

8.Médico Psiquiatra UBA. Magister en Psiconeurofarmacología (UF). Jefe de Servicio 25 B Hospital “J.T. Borda”, GCABA.

9.Médica Especialista en Psiquiatría. Docente, Instituto Superior de Formación de Posgrado de la Asociación de Psiquiatras Argentinos (APSA).

10. Médico Psiquiatra. Especialista Jerarquizado. Investigador Principal. Profesor Adjunto UNLP (ULP).

"Médico especialista en psiquiatría. Doctor en psicología. Médico de planta del Hospital de Emergencias Psiquiátricas "T. de Alvear". Uiversidad de Buenos Aires. Profesor Titular Universidad de Palermo Argentina.

12. Director del Sanatorio Morra, Córdoba. Universidad Nacional de Córdoba, Argentina.

13.Médico especialista en Psiquiatría y Medicina Legal. Jefe del Servicio de Emergencia, Hospital “Dr. Braulio A. Moyano”. Investigador Asociado, Carrera del Investigador, GCBA.

14.Vicepresidente del Capítulo de Psicofarmacología de APSA. Jefe de Sala del Hospital “Alejandro Korn”, La Plata, Argentina.
}

Autor de referencia

Alejo Corrales

alejocorrales@hotmail.com

Lugar de realización del trabajo:Asociación Argentina de Psiquiatría Biológica (AAPB). 
Palabras claves: Esquizofrenia - Esquizofrenia resistente al tratamiento - Consenso de expertos - Recomendaciones de tratamiento - Intercesiones psicosociales - Antipsicóticos - Antipsicóticos de primera generación - Antipsicóticos de segunda generación - Clozapina - Terapia electro convulsiva.

\begin{abstract}
Approximately $30 \%$ of people with schizophrenia fail to respond to first-line antipsychotic treatment which impacts the burden of the disease. Treatment-resistant schizophrenia denotes patients with failure to respond to at least two adequate trials of different antipsychotics. Clozapine is a unique drug approved for treating treatment-resistant schizophrenia, however I/3 of patients fail to respond to clozapine. Even though different strategies have been proposed for treating clozapine-resistant schizophrenia, the evidence is very limited, unclear, and of poor quality. A formal literature search was conducted and then, panel members were asked to complete 35 questions addressing different aspects of ERT. A modified Delphi method was used to unify expert opinion and achieve consensus. The expert consensus in diagnostic and treatment of TRS is the result of experts from the main national scientific societies under the organization of the Argentine Association of Biological Psychiatric AAPB. The consensus statement aims to guide on diagnosis and treatment.
\end{abstract}

Keywords: Schizophrenia - Treatment-resistant schizophrenia - Expert consensus - Treatment recommendation - Psychosocial intervention - Antipsychotics - First generation antipsychotics - Second generation antipsychotics- ClozapineElectroconvulsive therapy.

\section{Introducción}

Entre junio y septiembre del 2021 y bajo el auspicio de la Asociación Argentina de Psiquiatría Biológica (AAPB), el grupo de integrantes del panel de expertos se encargó de revisar de manera exhaustiva la literatura publicada sobre Esquizofrenia Resistente al Tratamiento (ERT). Para tal fin, cada uno de los expertos se aboco al análisis de un aspecto en particular de esta patología, tales como: prevalencia y epidemiología, definiciones de respuesta, remisión, recaída y recurrencia en esquizofrenia, utilización de escalas clínicas, criterios diagnósticos de la ERT, comorbilidades en esquizofrenia y el concepto de pseudo-resistencia al tratamiento, la aplicación de métodos complementarios y los abordajes terapéuticos farmacológicos y no farmacológicos, así como las respectivas secuencias de tratamiento a seguir, entre los tópicos más relevantes. Como resultado de ese trabajo individual preliminar, el múltiple intercambio por vía electrónica y la discusión abierta, se realizó una reunión virtual del panel de expertos con la ayuda de un coordinador general y de la redactora médica científica, donde se logró arribar a este trabajo final que tiene como objetivo principal poner al alcance de los especialistas en psiquiatría y demás agentes de salud una revisión comprensiva y adaptada al contexto local sobre la ERT.

\section{Metodología}

A partir de la aceptación de los integrantes del panel para participar en el consenso, se llevó a cabo la tarea de distribuir los temas a ser revisados y analizados por cada uno durante un periodo de tres meses (junio a septiembre 2021). Posteriormente, una redactora médica científica especializada se encargó de preparar y adaptar cada sección particular y sus referencias en un formato estilístico común unificado. Luego de su aprobación, se hizo circular este primer documento del consenso por vía electrónica a todos los integrantes del panel de expertos, se utilizó una modificación del método Dephi para aunar la opinión de los participantes y arribar a un consenso (Lacalle Remigio et al., 1996; Martínez-Sahuquillo Amuedo, \& Echevarría Ruiz De Vargas, 2001).

Para ello se procedió a enviar un cuestionario de 35 preguntas a través de la plataforma de Google (https:// drive.google.com), las mismas fueron respondidas en forma anónima y posteriormente fueron discutidas en el debate que se realizó en forma virtual.

El primer documento común fue revisado por todos los integrantes del consenso con un mes de anticipación y posteriormente se llevó a cabo una reunión el 12 de agosto de 2021 por medio de un sistema electrónico para múltiples participantes (https://zoom.us). Allí se analizó y discutió la evidencia publicada en la literatura internacional, se realizaron comentarios respecto 
a cada una de las secciones y, conjuntamente con los resultados de las respuestas del cuestionario enviadas por los expertos, se logró consenso sobre aquellos puntos en los que existían controversias. De este encuentro general surgió un segundo documento, preparado por la redactora científica, quien lo envió a cada uno de los participantes del panel para una segunda ronda de revisión. Luego de insertar los comentarios y sugerencias particulares de los expertos de esta segunda revisión del documento, se realizó una tercera ronda por vía electrónica a fin de obtener una revisión y aprobación final por parte de todos los autores en octubre de 2021. El documento definitivo fue enviado para su publicación en la única revista argentina de revisión por pares e indexado de nuestra especialidad.

\section{Selección del panel de expertos}

Siguiendo igual metodología aplicada para la producción de consensos anteriores realizados por la AAPB (Corrales et al., 2020), los expertos invitados a participar fueron elegidos de acuerdo a los siguientes criterios: 1) acreditación de experiencia clínica amplia en el diagnóstico y manejo de la esquizofrenia y otros trastornos psicóticos y 2) presentación de antecedentes académicos y de investigación relevantes vinculados al tema en discusión. De un número mayor de profesionales que cumplían estos criterios de inclusión se eligió un grupo menor que fuese representativo de las principales agrupaciones nacionales de especialistas en psiquiatría de nuestro medio (AAPB, APSA y AAP).

\section{Generalidades: prevalencia y epide- miologia de la esquizofrenia}

La esquizofrenia es una de las enfermedades psiquiátricas más representativas, es considerada uno de los principales problemas médicos a nivel mundial, a pesar de su relativamente baja incidencia (American Psychiatric Association, 2013). Es una enfermedad potencialmente incapacitante que afecta a jóvenes y a sus familias y que persiste durante muchos años, requiriendo a menudo, costosas y prolongadas intervenciones farmacológicas y no farmacológicas (Chong et al., 2016).

$\mathrm{Su}$ diagnóstico implica una serie de manifestaciones muy variadas a nivel del pensamiento (cognición), afectividad y comportamiento entre otros y a pesar de que existen muchos enfoques diagnósticos, solo los manuales como el DSM-5 e ICD-11 lograron aceptación mundial.

Estas clasificaciones multidimensionales, utilizando metodología basada en el consenso de expertos, separaron los trastornos en grupos, basándose en manifestaciones clínicas comunes, algunos factores etiológicos o mecanismos patogénicos, pero fueron severamente criticados por no incluir biomarcadores como criterio de diagnóstico para muchos trastornos, incluida la esquizofrenia (American Psychiatric Association, 2013; Nemeroff et al., 2013; World Health Organization, 2019).

El concepto moderno de esquizofrenia se remonta al momento de la introducción del término démence précoce, atribuido a Benedict Morel (Morel, 1860) y su adopción por parte de Emil Kraepelin (Dementia Praecox), quien agrupó en dicha entidad a la hebefrenia (Hecker, 1871), la catatonia (Kahlbaum, 2012) y las demencias paranoides (Kraepelin, 1883). Posteriormente, Eugen Bleuler (1911), introdujo el término "esquizofrenia" y propuso diagnosticar la enfermedad por la presencia de síntomas básicos (las cuatro A de Bleuler) afirmando que la esquizofrenia no era una entidad única, sino un grupo de enfermedades que aún no eran accesibles al diagnóstico (Bleuler, 1911).

Luego, Karl Leonhard (1957), basado en los marcos conceptuales de Carl Wernicke (1899) y Karl Kleist (1923), propuso dos grupos de esquizofrenia: no sistemática y sistemática (continua versus episódica); este último se dividió en tres grupos en función de las manifestaciones clínicas predominantes (afectivas, ideativas o motoras), que podían discriminarse con éxito utilizando los resultados de los biomarcadores (Jablensky, 2006; Kleist, 1923; Leonhard, 1957; Wernicke, 1899).

Con base en las manifestaciones clínicas y en las neuroimágenes, Crow (1980) y Andreassen (1982) discriminaron, respectivamente, síntomas positivos $\mathrm{y}$ negativos $\mathrm{y}$ formas positivas, negativas y mixtas de esquizofrenia (Andreasen, 1982; Crow, 1980), sus contribuciones sirvieron de base para el concepto de "dominios" en la esquizofrenia. Podemos admitir que el concepto actual de esquizofrenia se ve seriamente limitado por su heterogeneidad en cuanto a los factores clínicos, neurobiológicos y etiológicos, y muchos autores lo cuestionan por la falta de coherencia en sus resultados (Tsuang \& Faraone, 1995).

La historia natural y el pronóstico de la esquizofrenia es también muy variable, descrita clásicamente como una enfermedad de deterioro crónico con un funcionamiento que disminuye gradualmente luego de cada episodio psicótico, no siendo el único curso y resultado posibles, ni el más frecuente (Carpenter \& Kirkpatrick, 1988). Por su parte, John Kane (1988), introdujo el término de Esquizofrenia Resistente al 
Tratamiento (ERT) para referirse a una población de pacientes en los que habían fallado tres tratamientos previos y en los que se estudió la respuesta de la clozapina, siendo considerado el primer estudio que evaluó específicamente esta población (Kane et al., 1988). Sin embargo, aún coexisten varias definiciones de ERT que dificultan la evaluación situacional de este problema (Gillespie et al., 2017).

\section{Epidemiología de la esquizofrenia}

El riesgo relativo de padecer esquizofrenia es relativamente bajo, con una incidencia media de 15.2 cada 100.000 personas por año (McGrath et al., 2004). Sin embargo, los datos de incidencia de la enfermedad son muy variables aunque se considera, en general, que su prevalencia de por vida es del 0,7\% (American Psychiatric Association, 2013). Cabe aclarar que se observan variaciones regionales en la frecuencia de presentación como en el caso de los EE. UU., cuyas estimaciones varían desde un $0.33 \%$ y un $0.75 \%$ (Moreno-Küstner et al., 2018; Saha et al., 2005).

En cuanto a los porcentajes de pacientes que presen$\tan$ ERT, son muy variables, ya que los criterios aplicados para definirla son también muchos y variados. De acuerdo con Libermann solo una pequeña proporción de pacientes (10\% a 15\%) son resistentes al tratamiento al inicio de la enfermedad; sin embargo, entre el 30\% y el $60 \%$ de los pacientes pueden volverse, eventualmente, resistentes al tratamiento o solo responder parcialmente (Lieberman et al., 1993). Posteriormente, Agid y col. (2011), afirmaron que si bien los pacientes presentan durante el primer episodio una elevada tasa de respuesta que es cercana al $70 \%$, en aquellos individuos que requieren incorporar un nuevo tratamiento, la tasa de respuesta cae hasta aproximadamente un 20\% (Agid et al., 2011). Sin embargo, es común que se describa la resistencia al tratamiento en un tercio de los pacientes diagnosticados (Elkis \& Buckley, 2016).

\section{La carga de la esquizofrenia}

La esquizofrenia es una de las enfermedades psiquiátricas más representativas que tiene un fuerte impacto en los presupuestos de atención médica en todo el mundo (American Psychiatric Association, 2013). La esquizofrenia es considerada una enfermedad potencialmente incapacitante que afecta a los adultos jóvenes y a sus familias y que persiste durante muchos años, requiriendo a menudo intervenciones farmacológicas y no farmacológicas costosas con costos indirectos adicionales que pueden superar marcadamente a los directos (estos representan del 50 al 85\% del costo total). En los EE. UU.
Esto representa una carga económica que oscila entre \$25.452 y \$102.396 millones (dólares estadounidenses) por año (Chong et al., 2016). El costo de la ERT alcanza a ser 3 a 11 veces mayor que el costo de la esquizofrenia que responde al tratamiento, ya que se ha visto asociada a un mayor índice de hospitalizaciones y estadías más prolongadas, mayor consumo de psicotrópicos, abuso de sustancias y menor índice de recuperación funcional (Kennedy et al., 2014; Nucifora et al., 2019; Wimberley et al., 2016).

En un estudio realizado en la Argentina se demostró que un tercio de los costos directos en salud mental (hospitalizaciones, dispositivos comunitarios, consulta con profesionales de salud mental, dispositivos de atención ambulatoria, tratamientos farmacológicos y manejo de efectos adversos) y dos tercios de los costos indirectos en salud mental (pérdida de productividad de los pacientes debida a la enfermedad o muerte, pérdida de productividad de la familia que no concurre al trabajo por estar a cargo del paciente) están destinados a la esquizofrenia (Gargoloff, 2005).

\section{Definiciones de respuesta, remisión, recaída y recuperación}

\section{a. Respuesta}

La definición clásica de respuesta en la esquizofrenia fue propuesta en el estudio de Kane y col. (1988), y se obtiene cuando se observa una reducción del 20\% en la Escala Breve de Evaluación Psiquiátrica (Brief Psychiatric Rating Scale, BPRS) más un valor de $\leq 3$ en la Escala de Impresión Clínica Global de Severidad (Clinical Global impresión Severity, CGI-S) o un puntaje total en BPRS $\leq 35$ post tratamiento. Este estudio demostró que la clozapina resultó más eficaz que la clorpromazina en el tratamiento de la esquizofrenia resistente. Sin embargo, este criterio ha sido usado también para episodios agudos en esquizofrenia no resistente (Leucht et al., 2007). En otras investigaciones se han establecido valores de corte diferentes en reducción del puntaje total basal de la BPRS para determinar respuesta, tales como una disminución del $30 \%, 40 \%$ y $50 \%$ (Leucht, 2014).

Las mejorías clínicas más sustanciales se han asociado con reducciones de alrededor del 50\% en el puntaje de las escalas BPRS o en la Escala de Sindrome Positivo y Negativo (Positive and Negative Syndrome Scale, PANSS), que se correlacionan bien con un puntaje en la Escala de Impresión Clínica Global de mejoría (Clinical Global Impression Severity Improvement, 
CGI-I) $\leq 2$. Por ello, los estudios que evalúan la respuesta en episodios agudos de esquizofrenia deberían usar un valor de corte de reducción del puntaje basal de al menos $50 \%$, en lugar de $20 \%$ o $30 \%$, pues estos representan mínimos cambios (Leucht et al., 2005a). Sin embargo, en el caso de la esquizofrenia resistente, podría ser una mejor opción un valor de corte del $25 \%$, dado que estos cambios mínimos (CGI-I $\leq 3$ ) pueden ser clínicamente significativos.

Es importante destacar, que en la definición de respuesta, la reducción del porcentaje es un mejor parámetro que la reducción absoluta del puntaje. Esto se debe a una mayor facilidad para la interpretación de las tasas de respuesta y los cambios de porcentajes, respecto de los cambios de puntajes en una escala por parte de los médicos especialistas clínicos que hacen asistencia y no investigación (Leucht, 2014).

Para hacer el cálculo del porcentaje de reducción se debe restar al puntaje total 1 punto (valor que expresa ausencia de severidad) por cada uno de todos los ítems de la PANSS (Wimberley et al., 2016) o BPRS (Andreasen, 1982). De no hacerlo se subestimaría el efecto de una intervención, por ejemplo, para reducir de 120 a 60 puntos en la PANSS, hay que restar los 30 puntos del puntaje mínimo de esta escala, por lo que este descenso de 60 puntos significa un cambio del $67 \%$, y no del 50\% (Leucht et al., 2007). Otro aspecto relevante en el uso de escalas es que la severidad de un síntoma/ítem, refleja cuatro aspectos: la intensidad o magnitud, la duración, la frecuencia en un determinado lapso y el impacto funcional.

En el estudio Schizophrenia Outpatients Health Outcomes (SOHO) la "respuesta" se determinó como una disminución de la CGI-S $\geq 2$ puntos si el puntaje basal era $\geq 4$ o una disminución $\geq 1$ si el puntaje basal era $\leq 3$ (Gargoloff et al., 2009).

En la mayoría de las definiciones de respuesta no se incluye la variable temporal. No obstante, Lee y col., han considerado que el tiempo estimado para decidir la respuesta al tratamiento en un primer episodio estaría entre 2 y 6 semanas, con mayor consenso para las 4 semanas (Lee et al., 2020). En general las publicaciones hacen referencia al tiempo transcurrido hasta que se cumple el criterio de cambio en los síntomas, ya sea en la reducción de un porcentaje del puntaje basal en una escala (ej. 50\% en la PANSS), o un valor absoluto final del puntaje de una escala (ej. CGI-S $\leq 3$ ). Así, es común encontrar que tal porcentaje de pacientes alcanzó la respuesta en tal semana.

\section{b. Remisión}

La definición más utilizada hasta la actualidad es la proveniente del grupo de trabajo de remisión en esquizofrenia (Remission in Schizophrenia Working Group RSWG) (Andreasen et al., 2005). La definición consta de dos criterios: para considerar una remisión completa deben cumplirse concomitantemente la severidad de los síntomas y la duración de los mismos; para considerar una remisión sintomática se requiere una puntuación en severidad $\leq 3$ (leve o menos) en cada uno de los ocho síntomas claves de la PANSS agrupados para esta definición en tres dimensiones según este grupo de trabajo: síntomas negativos (N1 afecto aplanado, N4 evitación social pasiva, N6 falta de espontaneidad), desorganización (P2 desorganización conceptual, G5 manierismos y posturas) y psicoticismo (P1 ideas delirantes, G9 contenido inusual del pensamiento, P3 conducta alucinatoria). El criterio temporal para remisión requiere que el criterio de severidad se haya alcanzado y sostenido por más de 6 meses. Alcanzar y mantener estos puntajes en la PANSS es necesario para hablar de remisión.

Se ha utilizado como criterio de remisión adicional el valor de corte en CGI-S $\leq 3$, que refleja una severidad leve de la enfermedad (Lieberman et al., 2003).

La desventaja de esta definición es que no refleja el cambio en los síntomas, por lo que en estudios con bajos niveles basales de síntomas, muchos pacientes pueden alcanzar la remisión con mínimos cambios en la sintomatología global. Otra limitación de la definición es que el tiempo de 6 meses podría ser muy estricto y quizás 3 meses podría ser mejor (Leucht, 2014).

Para la determinación del concepto de remisión no se recomienda usar un puntaje de corte sobre el total de una escala, como en el caso de depresión, pues en esquizofrenia los síntomas son variados y su ocurrencia cambia con el tiempo, siendo que en la fase aguda puede predominar inicialmente la reducción de la severidad de los síntomas positivos y luego los negativos. Por otro lado, usar como criterio de severidad un valor muy bajo en la CGI-S, por ejemplo 1 (síntomas ausentes) o 2 (síntomas muy leves, en el límite de la normalidad), dejaría muchos pacientes fuera del criterio de remisión.

\section{c. Recaída}

No existe una definición definitiva de lo que se considera recaída en la esquizofrenia, como se evidencia en una revisión sistemática que encontró 54 definiciones diferentes en los 81 estudios incluidos (Moncrieff et al., 2020). La recurrencia de síntomas 
psicóticos, particularmente los positivos, y los cambios significativos en el funcionamiento o la conducta, son los criterios que cuentan con mayor consenso a la hora de definir recaída en esquizofrenia.

Se han utilizado incrementos entre 10 y 30 puntos en el puntaje total de la PANSS, o un aumento del $30 \%$ en la misma escala como puntos de corte para definir recaída (Moncrieff et al., 2020). Podría señalarse un incremento en la PANSS de 10 puntos (San et al., 2015) o un 25\% (Alphs et al., 2016; Lee et al., 2020) como los valores de corte más frecuentes. Tal como se señaló en la definición de respuesta, el cambio de porcentaje es mejor parámetro que el incremento absoluto del puntaje en esta escala, por ser de más fácil interpretación clínica.

El criterio de cambio en la definición de recaída puede ser expresado por una CGI-I $\geq 6$ (mucho peor) (Lee et al., 2020; Saito et al., 2020; San et al., 2015), mientras que la severidad por una CGI-S $\geq 4$ (moderadamente enfermo).

Son pocas las veces que se utilizan medidas específicas de funcionamiento para definir la recaída, como podría ser una reducción $\geq 20$ puntos en la Escala de Evaluación de la Actividad Global (Global Assessment of Functioning, GAF) según algunas recomendaciones (San et al., 2015).

Otros componentes que se han incorporado en algunas definiciones de recaída incluyen la utilización de recursos sanitarios, las re hospitalizaciones, la conducta violenta que conlleva daño clínicamente significativo a otros o a la propiedad, ideación suicida $\mathrm{u}$ homicida, intento de suicidio (Alphs et al., 2016) y, finalmente, las que diferencian las recaídas entre aquellos pacientes en remisión completa y quienes presentan síntomas crónicos (Gleeson et al., 2010).

Pocas definiciones incorporan una duración mínima, como por ejemplo siete días (Wunderink et al., 2007) o catorce días (Craig et al., 2004) en el caso de estudios de prevención de recaídas en primeros episodios. Parece necesario incorporar la variable temporal en futuras definiciones, para tener en consideración fluctuaciones sintomáticas breves y leves que no necesariamente se interpreten como recaídas, tanto en primeros como en múltiples episodios.

\section{d. Recuperación}

El objetivo final del tratamiento de la esquizofrenia es la recuperación, concepto que apunta principalmente a aspectos funcionales con participación social y ocupacional. No existe un consenso en los aspectos íntimos de la definición (Leucht et al., 2007), pero si lo hubiera debería incluir: 1) algún grado de estabilización sintomática (como $\leq 4 \mathrm{o} \leq 3$ puntos en todos los ítems de la BPRS o PANSS), 2) una mejoría en el funcionamiento (mantener un empleo o estudio, o la sociabilización del paciente) y 3) durante un tiempo (de 2 a 5 años) (Leucht, 2014). En el estudio SOHO se definió claramente el concepto de recuperación como alcanzar y mantener por 2 años, simultáneamente, los criterios de remisión sintomática sostenida, remisión funcional sostenida y calidad de vida adecuada sostenida. Remisión sintomática sostenida entendida como una Escala de Impresión Clínica Global de mejoría en esquizofrenia (Clinical Global Impression Severity-Schizophrenia, CGI-I-SCH) $\leq 4$ y sin hospitalizaciones. Remisión funcional sostenida se refería a un estado ocupacional/vocacional positivo (empleo parcial o completo remunerado o no, estudiante activo, ama de casa), vida independiente e interacciones sociales activas (más de un encuentro social al mes o tener pareja). Y, finalmente, calidad de vida adecuada sostenida se definió como $\geq 70$ puntos en la Escala analógica visual del Cuestionario europeo de calida de vida relacionada con la salud de 5 dimensiones y 5 niveles (EuroQol 5-dimensions-5 Levels, EQ-5D-5L) (47).

Jääskeläinen y col. realizaron la más exhaustiva estimación de recuperación en esquizofrenia a la fecha a través de una revisión sistemática de estudios naturalísticos. Para ello, utilizaron una definición de recuperación que incluyó dos dominios que debían cumplirse: remisión clínica sintomática (severidad leve o menos) y funcionamiento social y al menos uno de ellos durante dos años (Jääskeläinen et al., 2013).

Lee y col. desarrollaron una definición con criterios operacionales de recuperación para primer episodio en esquizofrenia, que también tiene en cuenta los aspectos psicopatológicos, de funcionamiento social y ocupacional y el tiempo (Lee et al., 2020). Diferenciaron remisión parcial de remisión total según: relaciones interpersonales apropiadas y empleo o algunas tareas del hogar versus funcionamiento social y ocupacional pleno; puntaje en ítems de PANSS o en la Escala de evaluación de síntomas negativos (Scale for the Assessment of Negative Symptoms, SANS) $\leq 3$ (leve o menos) vs. 1 (normal); CGI-S $\leq 3$ (leve o menos) vs. 1 (normal); uso de antipsicóticos ( $\leq 300 \mathrm{mg}$ equivalentes de clorpromazina) vs sin prescripción de antipsicóticos; Evaluación Global de Funcionamiento (GAF) vs Social and Occupational Functioning Scale (SOFAS) $\geq 61$ o $\geq 71$; en ambos casos por $\geq 1$ año.

En el Cuadro 1 se resumen los valores de los apartados anteriores. 
Cuadro I. Respuesta, remisión, recaída y recuperación

\begin{tabular}{ll}
\hline & En esquizofrenia no resistente: (Leucht et al., 2005a) \\
& reducción en PANSS/BPRS $\geq 50 \% \circ \mathrm{CGI}-\mathrm{I} \leq 2$ (mucho mejor) \\
& En esquizofrenia resistente: (Leucht, 20I4) \\
Respuesta & reducción en PANSS/BPRS $\geq 25 \% \circ \mathrm{CGI}-\mathrm{I} \leq 3$ (mínimamente mejor) \\
& Luego de $\geq 4$ semanas (Lee et al., 2020) \\
\hline \multirow{2}{*}{ Remisión } & $\leq 3$ en ítems 8 ítems clave de la PANSS (PI, P2, P3, NI, N4, N6, G5, G9) ० CGI-S $\leq 3$ (mínima- \\
& mente enfermo) (Andreasen et al., 2005; Leucht, 20I4; Lieberman et al., 2003) $\geq 3$ meses \\
\hline \multirow{2}{*}{ Recaída } & Aumento $\geq 10$ puntos o $\geq 25 \%$ en la PANSS \\
& CGI-I $\geq 6$ (mucho peor) (Alphs et al., 20I6; Lee et al., 2020; Saito et al., 2020; San et al., 20I5) \\
\hline Remisión sintomática sostenida: CGI-I-SCH $\leq 4$ y sin hospitalización \\
Remisión funcional sostenida: \\
estado ocupacional/vocacional positivo (empleo parcial o completo remunerado o no, estu- \\
diante activo, tareas del hogar) \\
vida independiente \\
con interacciones sociales activas (más de un encuentro social al mes o tener pareja) \\
Calidad de vida adecuada sostenida EQ5DVAS $\geq 70$ \\
$\geq 2$ años \\
\hline
\end{tabular}

\section{Concepto y definición de resistencia al tratamiento antipsicótico}

El concepto de ERT data de 1988 desde el histórico trabajo de Kane J. en el que se demostró la eficacia de la clozapina sobre la clorpromazina en pacientes que se encontraban sin respuesta al tratamiento en los últimos 5 años de evolución, es decir que no presentaban mejoría con al menos tres antipsicóticos con dosis equivalentes o mayores a $1000 \mathrm{mg} /$ día de clorpromazina, durante 6 semanas de tratamiento, presentaban síntomas de severidad y estaban moderadamente enfermos sin buen funcionamiento en esos 5 años (Kane et al., 1988).

En la práctica actual los parámetros de tratamiento antipsicótico en la esquizofrenia han variado sensiblemente en relación a la dosis y a la duración de los mismos; existen muchos trabajos que describen una disminución de la respuesta sintomática cuando se retarda la aplicación de un tratamiento que es eficaz (Agid et al., 2003; McIlwain et al., 2011).

La resistencia o refractariedad al tratamiento, implica una persistente falta de mejoría sintomática a pesar de la implementación de tratamientos adecuados.

Todas las guías y consensos tratan de definir que es un tratamiento antipsicótico adecuado basado en la actual evidencia científica, en la falta de respuesta al tratamiento y en la especificación de la entidad clínica y terapéutica de pacientes esquizofrénicos resistentes al tratamiento antipsicótico. Esta definición toma en cuenta distintas variables. La variable sintomática de respuesta, es un aspecto relativo que se refiere a la disminución porcentual sintomática, esta es medida antes y después de realizar el tratamiento con esca- las internacionales tales como la PANSS (Kay et al., 1987), la BPRS (Overall \& Gorham, 1962) y la CGI; es importante señalar que se toma como punto de corte de respuesta al menos una disminución de un $25 \%$ en las escalas PANSS y BPRS, esto equivale a una leve mejoría en la CGI-I (Leucht et al., 2005a; Leucht et al., 2005b; Leucht et al., 2006).

La variable sintomática en un aspecto de umbral no relativo sino absoluto en relación a la sintomatología, para definir falta de respuesta el paciente tiene que presentar en forma sostenida en el tiempo un valor absoluto de al menos moderada severidad sintomática medida con cualquiera de estas escalas (Leucht et al., 2006; Levine et al., 2008).

La variable temporal de un tratamiento adecuado evidencia cuánto tiempo se sostiene un tratamiento para la aparición de la respuesta o, en todo caso, para definir la resistencia al mismo. La actual evidencia presenta un amplio rango en las distintas guías y consensos que van de 2 a 8 semanas (Hasan et al., 2012; Howes et al., 2017; Lehman et al., 2004; National Institute for Health and Care Excellence, 2014).

En cuanto a la variable de cantidad de intentos terapéuticos con distintas drogas, toda la evidencia coincide en que deben ser al menos dos tratamientos adecuados (Hasan et al., 2012; Howes et al., 2017; Lehman et al., 2004; National Institute for Health and Care Excellence, 2014).

En cuanto a la variable tipo de drogas en los dos intentos terapéuticos, puede ser cualquier tipo de droga antipsicótica, pero si una de ellas es un antipsicótico típico el otro intento debe ser con un atípico (Hasan et 
al., 2012; Howes et al., 2017; Lehman et al., 2004; National Institute for Health and Care Excellence, 2014)

En lo concerniente a la variable de evaluación de los intentos terapéuticos, de ser posible la evaluación de ambos intentos debe ser prospectiva, es posible que uno de esos intentos sea prospectivo y el otro retrospectivo, pero ambos con comprobada fiabilidad de la consignación de las variables (Howes et al., 2017).

En lo concerniente a la variable cantidad de dosis suficiente para esperar una respuesta terapéutica, el consenso es de al menos una dosis equivalente a 600 $\mathrm{mg} /$ día de clorpromazina en los atípicos o dosis plena más eficaz para atípicos dentro de los rangos terapéuticos aprobados para cada droga (Leucht et al., 2014; Leucht et al., 2015). No se recomiendan dosis mayores al rango terapéutico aprobado pues no se evidenciaron mayores beneficios terapéuticos y si mayores efectos adversos y futura falta de adherencia al tratamiento (Agid et al. 2013).

En referencia a la variable funcional y cognitiva, algunos consensos sugieren que debe haber al menos una moderada discapacidad funcional medida por distintas escalas de evaluación como la Social and Occupational Functioning Scale (SOFAS) con un corte de $<60$ puntos u otras equivalentes (Howes et al., 2017; Suzuki et al., 2011). No hay un acuerdo claro en el corte de la alteración cognitiva en relación a la resistencia al tratamiento a pesar de los intentos internacionales de cuantificar y evaluar alteraciones cognitivas mediante la batería cognitiva de consenso MATRICS (MATRICS Consensus Cognitive Battery, MCCB) (Gray et al., 2014) u otras (Buchanan et al., 2011).

La variable de adherencia al tratamiento se investiga por reportes del mismo paciente o por sospecha clínica del médico tratante, la forma más objetiva de evaluación es el conteo de píldoras, la observación directa de la toma y el control de concentración del antipsicótico a nivel plasmático, aunque esta última práctica es controversial para la mayoría de los antipsicóticos salvo para la clozapina (Taylor et al., 2015).

Tomando distintas guías internacionales y consensos de tratamiento, la esquizofrenia resistente al tratamiento puede ser definida como una situación en la cual no se demuestra mejoría clínica significativa, medida con escalas internacionales aceptadas (BPRS o PANSS) en las cuales no se demuestra una disminución de al menos un 25\% de la sintomatología, con un estado sintomático de al menos moderada severidad, a pesar de haber sido tratados con dos antipsicóticos, uno de los cuales al menos debe ser atípico y a dosis equivalente de al menos $600 \mathrm{mg} /$ día de clorpromazi- na para los antipsicóticos típicos o a dosis plena más eficaz para antipsicóticos atípicos. De estos estudios al menos uno debe ser prospectivo y el retrospectivo de comprobada fiabilidad: al menos 6 semanas de tratamiento, tiempo contado desde que la droga está con dosis plena, con adherencia al tratamiento probada y además el paciente debe presentar discapacidad funcional moderada o mayor.

\section{Evaluación y escalas aplicables a la ERT}

¿Cuáles son las evaluaciones que se recomiendan en personas que podrían satisfacer el criterio de ERT? Entre las escalas o instrumentos de evaluación clínica, ¿cuáles se recomiendan en la práctica clínica diaria para el diagnóstico y abordaje de personas que padecen ERT?

\section{a. Evaluaciones}

Las evaluaciones recomendadas en las guías, consensos y otros documentos, cuyo objetivo es determinar si la persona que padece esquizofrenia se considera resistente al tratamiento con antipsicóticos (ERT) se vinculan a la persona, a los fármacos y al contexto (Buckley \& Gaughran, 2014; Nucifora et al., 2019; Farooq et al., 2013; Howes et al., 2017; Kane et al., 2019; Lally \& Gaughran, 2019; Pharoah et al., 2010; Van Sant \& Buckley, 2011; Verdoux \& Quiles, 2020)

\section{Factores relacionados con la persona y la esquizofrenia:}

En esta sección se encuentran la exploración de enfermedades físicas y comorbilidades con otros trastornos mentales, además de las características de la esquizofrenia en cuanto a su severidad e impacto funcional.

- Reevaluar y certificar el diagnóstico de esquizofrenia

- Explorar comorbilidades, particularmente el consumo de cannabis.

- Características de la enfermedad, como la severidad de la sintomatología y su impacto funcional son las variables centrales, debiendo ser ambas determinadas mediante escalas de evaluación.

- Examen físico, ya que factores generales de salud física pueden modificar la farmacocinética de los fármacos.

- Estudios complementarios: que descarten variables de pseudo ERT, como estudios de imágenes del SNC, evaluación neurológica y neurocognitiva, laboratorio, dosaje de cannabis/cocaína. También para el seguimiento del tratamiento de ERT 
es necesario realizar un examen cardiovascular y ECG con determinación del QTc, determinación de circunferencia de cintura e IMC y laboratorio para síndrome metabólico, entre otras determinaciones.

- Escalas complementarias: si bien hay numerosas variables que podrían contribuir a la definición de ERT, no suelen ser incluidas rutinariamente en los estudios de investigación, a pesar de ser de potencial utilidad en la práctica clínica habitual (ver escalas complementarias en este capítulo).

\section{Factores dependientes del tratamiento:}

Hay tres variables a explorar para determinar ERT que dependen del tratamiento: criterios que se establecen cuando un ensayo es apropiado, los antipsicóticos prescriptos, cuál es la respuesta a los antipsicóticos, cómo ha sido la adherencia al tratamiento y la existencia de factores vinculados a la farmacocinética.

- Determinar que antipsicóticos recibió el paciente y explorar dosis y tiempo de administración de fármacos.

- El criterio de respuesta requiere, además del punto anterior, determinar los cambios en la severidad de la sintomatología, funcionalidad y cognición, con valores de corte establecidos con escalas, explorar la adherencia y la farmacocinética.
3. Factores relacionados con el contexto: estrés, escaso apoyo social, emoción expresada y psicoeducación familiar.

\section{b. Escalas aplicables a la ERT}

Las escalas de evaluación o instrumentos de evaluación clínica son procedimientos de observación estructurada, compuestas por un conjunto de ítems que representan las manifestaciones nucleares del concepto a evaluar, expresadas por medio de conductas pasibles de ser medidas objetivamente y en forma estandarizada (condiciones controladas con reglas), empleando entrevistas clínicas o por medio de autoevaluación, con pautas de interpretación de los resultados.

\section{Instrumentos de evaluación clínica básicos aplicables para el diagnóstico de ERT:}

En psicopatología: la recomendación es emplear la PANSS y CGI, ambas validadas en Argentina.

- PANSS: evalúa la psicopatología de la esquizofrenia, con 30 preguntas que exploran síntomas positivos y negativos (7 de cada uno) y 14 síntomas generales. La versión abreviada de 6 ítems está compuesta por los síntomas positivos 1 (delirios, Cuadro 2), 2 (desorganización conceptual), 3 (comportamiento alucinatorio, Cuadro 3), 6 (suspicacia) y 7 (hostilidad) y el ítem de psicopatología general 8 (falta de cooperación).

Cuadro 2. Ítem Delirios de la PANSS

\begin{tabular}{lll}
\hline \multicolumn{1}{c}{ Clasificación } & Criterios \\
\hline I & Ausente & La definición no es aplicable. \\
\hline 2 & Mínimo & Patología cuestionable; puede hallarse en el extremo superior de los límites normales. \\
\hline 3 & Leve & $\begin{array}{l}\text { Presencia de uno o dos delirios vagos que no se cristalizan y no prevalecen tenazmente. Los deli- } \\
\text { rios no interfieren con el pensamiento, las relaciones humanas o el comportamiento. }\end{array}$ \\
\hline 4 & Moderado & $\begin{array}{l}\text { Presencia tanto de varios delirios, pobremente formados e inestables, como de unos pocos deli- } \\
\text { rios bien formados que ocasionalmente interfieren con el pensamiento, las relaciones sociales o el } \\
\text { comportamiento. }\end{array}$ \\
\hline 5 & Moderadamente severo & $\begin{array}{l}\text { Presencia de numerosos delirios que se mantienen tenazmente y que ocasionalmente interfieren } \\
\text { con el pensamiento, las relaciones sociales o el comportamiento. }\end{array}$ \\
\hline 6 & Severo & $\begin{array}{l}\text { Presencia de un conjunto estable de delirios que se cristalizan, posiblemente en forma sistemática, } \\
\text { que se retienen tenaz y evidentemente interfieren con el pensamiento, las relaciones sociales y el } \\
\text { comportamiento. }\end{array}$ \\
\hline & Extremo & $\begin{array}{l}\text { Presencia de un conjunto estable de delirios que se hallan altamente sistematizados o son muy } \\
\text { numerosos y dominan las facetas más importantes de la vida del paciente. Esto frecuentemente } \\
\text { conlleva a acciones inadecuadas o irresponsables que hasta pueden llegar a poner en peligro la } \\
\text { seguridad de los mismos pacientes o de otras personas. }\end{array}$ \\
\hline
\end{tabular}


Cuadro 3. Ítem Alucinaciones de la PANSS

\begin{tabular}{|c|c|c|}
\hline & Clasificación & Criterios \\
\hline I & Ausente & La definición no es aplicable. \\
\hline 2 & Mínimo & Patología cuestionable; puede hallarse en el extremo superior de los límites normales. \\
\hline 3 & Leve & $\begin{array}{l}\text { Una o dos alucinaciones bien formadas pero infrecuentes, o si no, una cantidad de percepciones } \\
\text { anormales vagas que conducen a distorsiones del pensamiento y/o de la conducta. }\end{array}$ \\
\hline 4 & Moderado & $\begin{array}{l}\text { Las alucinaciones ocurren frecuentemente, pero no en forma continua y el pensamiento y con- } \\
\text { ducta del paciente se ven afectadas solo en un grado menor. }\end{array}$ \\
\hline 5 & Moderadamente severo & $\begin{array}{l}\text { Las alucinaciones son frecuentes y pueden involucrar más de una modalidad sensorial, y tienden a } \\
\text { distorsionar el pensamiento y/o alterar el comportamiento. Los pacientes pueden tener interpre- } \\
\text { taciones alucinatorias de estas experiencias y pueden reaccionar emocionalmente, y en ocasiones } \\
\text { también verbalmente, ante ellas. }\end{array}$ \\
\hline 6 & Severo & $\begin{array}{l}\text { Las alucinaciones están presentes casi continuamente, provocando alteraciones del pensamiento y } \\
\text { del comportamiento. Los pacientes perciben estas alucinaciones como reales y su desempeño se } \\
\text { ve impedido por frecuentes reacciones emocionales y verbales ante las mismas. }\end{array}$ \\
\hline
\end{tabular}

- CGI-S y CGI-I: CGI-S, (Cuadro 4) y CGI-I (Cuadro 5) son evaluaciones que realiza un profesional de salud mental para determinar la severidad de la enfermedad y el cambio de ésta desde el inicio del tratamiento. Es útil para la práctica clínica habitual por las restricciones de tiempo para las consultas, al ser una herramienta de medición breve, simple y tomar menos de 2 minutos para administrarlas. Hay versiones autoaplicadas y para el cuidador. Ver Cuadros 4 y 5 con niveles de severidad y pautas de anclaje (Busner \& Targum, 2007).

- SANS y Escala de evaluación de síntomas positivos (Scale for the Assessment of Positive Symptoms, SAPS).

Cuadro 4. Impresión clínica global de severidad (CGI-S)

\section{Escalas complementarias aplicables para la determinación y el seguimiento de ERT:}

- Psicopatología: Brief Psychiatric Rating Scale BPRS. Escala de evaluación de alucinaciones auditivas (Auditory Hallucinations Rating Scale, AHRS). Escala de evaluación de depresión de Calgary (Calgary Depression Rating Scale, CDR). Entrevista estructurada para estados prodrómicos (Structurated Interview for Prodromal States, SIPS). Escala de síntomas de primer orden de Schneider (Schneider First-Rank Symptoms Scale, S-FRSS). Escala del Síndrome Deficitario (Schedule for the Déficit Syndrome, SDS).
I Mucho mejor

2 Moderadamente mejor

3 Levemente mejor

\section{Sin cambios}

5 Levemente peor

6 Moderadamente peor

7 Mucho peor
Casi todo mejor; buen nivel de funcionamiento; síntomas mínimos que representan un cambio muy sustancial.

Notablemente mejor con una reducción significativa de los síntomas; incremento del nivel de funcionamiento pero algunos síntomas persisten.

Un poco mejor, con poca o nada de atenuación de los síntomas; reducción clínicamente no significativa de los síntomas; muy pocos cambios en el estado clínico basal, el nivel de cuidados o la capacidad funcional.

Los síntomas permanecen esencialmente sin cambios.

Un poco peor, aunque puede no ser clínicamente significativo; pueden implicar muy pocos cambios en la situación clínica o de la capacidad funcional.

Aumento clínicamente significativo de los síntomas y disminución del funcionamiento.

Exacerbación severa de los síntomas y pérdida del funcionamiento. 
Cuadro 5. Impresión clínica global de mejoría (CGI-I)

\begin{tabular}{lll}
\hline I & Normal, no enfermo & Los síntomas o la enfermedad no ha estado presente en los últimos siete días. \\
\hline 2 & Dudosamente enfermo & Enfermedad sospechosa, sutil o en el límite. \\
\hline 3 & Levemente enfermo & $\begin{array}{l}\text { Los síntomas están claramente presentes, con mínimo/ausente estrés o deterioro en su desempeño } \\
\text { ocupacional y social. }\end{array}$ \\
\hline 4 & Moderadamente enfermo & Los síntomas son evidentes y causan un notable, aunque modesto, deterioro funcional o estrés. \\
\hline 5 & Marcadamente enfermo & $\begin{array}{l}\text { Síntomas intrusivos que claramente dificultan su funcionamiento social y ocupacional; síntomas } \\
\text { que causan importantes niveles de estrés. }\end{array}$ \\
\hline 6 & Gravemente enfermo & $\begin{array}{l}\text { Patología disruptiva; la conducta y el funcionamiento están frecuentemente influenciados por los } \\
\text { síntomas; pueden requerir ayuda de terceros. }\end{array}$ \\
\hline $\begin{array}{l}\text { Entre los pacientes } \\
\text { más extremadamente } \\
\text { enfermos }\end{array}$ & La patología drásticamente interfiere en muchas áreas de la vida; puede estar hospitalizado. \\
\hline
\end{tabular}

- Funcionalidad: Inventario de Discapacidad de Sheehan (Sheehan Disability Inventory, SDI). Escala de desempeño personal y social (Personal and Social Performance scale, PSP). Escala de funcionamiento ocupacional social (Social Occupational Functioning Scale, SOFS).

- Insight: Escala para evaluar la falta de conciencia en trastornos mentales-versión abreviada (Scaleto Assess Unawareness of Mental Disorder-abbreviated version, SUMD-abbreviated version). Cuestionario de percepción de la enfermedad en esquizofrenia (Illness Perception Questionnaire for Schizophrenia, IPQS). Cuestionario de conciencia de enfermedad $\mathrm{y}$ actitudes hacia el tratamiento (Insight and Treatment Attitudes Questionnaire, ITAQ).

- Cognición: Escala de evaluación cognitiva en esquizofrenia (Schizophrenia Cognition Rating Scale, SCoRS). MCCB. Torre de Londres (Tower of London, ToL). Experiencia reportada por el paciente de deterioro cognitivo en esquizofrenia (Patient Reported Experience of Cognitive Impairment in Schizophrenia, PRECIS).

- Funcionalidad: Evaluación global de desempeño (Global Assessment of Functioning, GAF). Escala de evaluación funcional (Functional Assessment Staging, FAST). Herramienta de evaluación de la capacidad funcional de realidad virtual (Virtual Reality Functional Capacity Assessment Tool, VRFCAT). Escala de valoracion de necesidades y satisfaccion del paciente (Two-Way Communication Checklist, 2-COM Cheklist).

- Recuperación, remisión, rehabilitación: Entrevista clínica estructuarada para síntomas de remisión (Structured Clinical Interview for Symptoms of Re- mission, SCI-SR). Escala de remisión funcional general de esquizofrenia (Functional Remission of General Schizophrenia, FROGS). Evaluación de recaída en pacientes con esquizofrenia (Relapse Assessment for Schizophrenia Patients, RASP). Evaluación de rehabilitación vocacional (Individual Placement and Support to vocational rehabilitation, IPSVR). Instrumento de evaluación para pacientes psiquiátricos crónicos (Assessment instrument for chronic psychiatric patients, REHAB).

- Otras variables clínicas: Escala de evaluación de severidad del suicidio de Columbia, inicial y siguientes visitas (Columbia-Suicide Severity $R a$ ting Scale initial, since last visit, C-SSRS). Escala de Agresividad Manifiesta-modificada (Overt Aggression Scale-Modified, OAS-M). EQ-5D-5L. Escala Pronóstica para la Esquizofrenia de Strauss y Carpenter (Prognostic Scale for Schizophrenia Strauss-Carpenter, S-CS). Escala de evaluación de clínicos para Trastornos por el uso del alcohol (Clinitian' Rating Scales for Alcohol Use Disorder, CRSAUS). Escala de evaluación del clínico trastornos por uso de drogas (Clinitian' Rating Scales for Drug Use Disorder, CRS-DUS).

- Medicación: Cuestionario de Satisfacción con el tratamiento de 9 ítems (Treatment Satisfaction Questionnaire for Medication-9 items, TSQM-9). Cuestionario de Satisfacción médica (Medical Satisfaction Questionnaire, MSQ). Inventario de Actitudes hacia la Medicación (Drug Attitude Inventory, DAI). Escala de Acatisia de Barnes (Barnes Akathisia Rating Scale, BARS). Escala de Acatisia de Simpson-Angus (Simpson-Angus Scale, SAS). 
Escala de Movimientos Involuntarios Anormales (Abnormal Involuntary Movement Scale, AIMS). Escala de evaluación de síntomas extrapitramidales de Chouinard (Extrapyramidal Symptom Rating Scale Chouinard, ESRS). Cuestionario de antipsicóticos y funcionamiento sexual) (Antipsychotics and Sexual Functioning Questionnaire, ASFQ). Escala de Efectos Secundarios (Udvalg für Kliniske Undersogelser, UKU).

Listado de chequeo de síntomas de discontinuación del clínico (Physician With drawal Checklist, PWC20). Escala de síntomas y signos de emergentes por la discontinuación del tratamiento (Discontinuation-Emergent Signs and Symptoms Scale, DESS).

- Familiar y cuidador: Cuestionario de Carga del familiar (Schizophrenia Caregiver Questionnaire, SCQ). Cuestionario de precepción de enfermedad para familiares en esquizofrenia (Illness Perception Questionnaire for Schizophrenia by Relatives, IPQS-Relatives). Entrevista de evaluación de carga familiar subjetiva y objetiva (Subjective and Objective Family Burden Interview, EFCO). Cuestionario de calidad de vida del cuidador en esquizofrenia (Schizophrenia Care Giver Quality of Life Questionnaire, S-CGQoL). Escala de apoyo profesional percibido por cuidadores de Ribe (Professional Support Scale perceived by caregivers Ribe, EAP-C). Entrevista de conocimiento acerca de la esquizofrenia para cuidadores (Knowledge About Schizophrenia Interview for caregivers, KASI). Satisfacción familiar con el sistema y utilización de recursos de Navarro Gomez (Family Satisfaction with the System and the Resources Utilization-Navarro Gomez, FSSRU). Escala de emoción expresada (Expressed Emotion Scale, EES).

- Otros Resultados: Escala de utilización de recursos para el cuidado de la salud (Healthcare Resource Utilization, HCRU). Escala de preferencias sobre resultados del tratamiento en esquizofrenia para gestores de políticas públicas, consumidores, familiares y proveedores de Shumway (Preferences for Schizophrenia Treatment Outcomes for Public Policy Makers, Consumers, Families and Providers-Shumway, PSTO)

\section{Detalles de algunas escalas de la sección previa aplicables a ERT:}

- La Escala de Limitaciones de Sheehan SDS es una autoevaluación del impacto funcional del paciente con trastorno mental, con 3 ítems referidos a trabajo/estudio, vida social, vida familiar y responsabilidades en el hogar.
- La Escala de Desempeño Personal y Social PSP evalúa el grado de disfunción en 4 dominios, actividades socialmente útiles, relaciones personales y sociales, autocuidado y comportamiento agresivo.

- La batería cognitiva de consenso MATRICS MCCB está compuesta por 10 pruebas que evalúan 7 dominios cognitivos (velocidad de procesamiento, atención/vigilancia, memoria de trabajo, aprendizaje verbal, aprendizaje visual, razonamiento y resolución de problemas y cognición social).

- La escala de Evaluación Cognitiva en Esquizofrenia SCoRS contiene 20 preguntas que evalúa los déficits cognitivos y el grado en el que estos afectan el funcionamiento diario.

- El Cuestionario de Satisfacción con el tratamiento TSMQ-9 es una autoevaluación de las preferencias del paciente que consta de 9 ítems, sobre el tratamiento y el valor que le asigna, el riesgo de una escasa adherencia y el impacto de los efectos adversos.

- El Cuestionario de Carga del familiar SCQ evalúa el impacto global que implica el cuidado de una persona con esquizofrenia.

Una ampliación de información sobre los instrumentos de evaluación clínica puede consultarse en:

https://eprovide.mapi-trust.org/catalog

https://www.academia.edu/22398150/Banco Instrumentos_Psiquiatricos

\section{Predictores de ERT}

La identificación temprana de los síntomas que pueden predecir la ERT podría ayudar a los médicos a evitar retrasos en la terapia con clozapina, ya que es el único medicamento con aprobación regulatoria para el tratamiento de dicha sintomatología (Nielsen et al., 2016). A pesar de ser muy poco utilizado debido a sus efectos adversos, la clozapina es el único antipsicótico recomendado para ERT y es más eficaz que otros antipsicóticos para aliviar los síntomas psicóticos en pacientes con ERT (Taylor, 2017). Lamentablemente, la evidencia sugiere que la ERT a menudo no se reconoce rápidamente y que la clozapina se indica después de algunos años, Howes (Howes et al., 2012) informa de una demora promedio de 3 a 9 años, lo que sugiere que existe un margen considerable para acortar este período de tratamiento inadecuado.

Predecir quién se beneficiaría del uso de clozapina tendría un impacto clínico significativo, es por eso que el tratamiento oportuno para ERT es una necesidad, pero, lamentablemente, la ERT todavía se diagnostica tras una prueba terapéutica, por lo tanto, son deseables 
herramientas clínicas basadas en síntomas de alerta temprana para el diagnóstico en la práctica habitual.

Algunos estudios han examinado posibles predictores clínicos y sociales de la respuesta al tratamiento con clozapina. La mejor combinación para predecir ERT fue la suma de tres ítems de PANSS de línea base: desorganización conceptual (P2), dificultad en el pensamiento abstracto (N5), contenido de pensamiento inusual (G9), retraso motor (G7), género femenino y edad de inicio más temprana fueron predictores de ERT. En una muestra de pacientes ambulatorios, la precisión predictiva del modelo P2 + N5 + G9 para ERT estuvo solo en el rango de "aceptable", aunque en general, este modelo corresponde al constructo del trastorno del pensamiento formal compuesto por pensamiento desorganizado, pensamiento concreto y pensamiento bizarro-idiosincrásico. Los niveles pronunciados de estos síntomas son fácilmente identificables en la práctica clínica y pueden ser una estrategia factible en la predicción de ERT (Ortiz et al., 2020).

La falta de respuesta de los antipsicóticos en pacientes que potencialmente desarrollaran una ERT también se puede predecir a través de la observación minuciosa de la sintomatología que expresan los pacientes en forma temprana. Aquellos que antes de ser medicados expresan una mirada estuporosa, leve predominio de movimientos de la línea media del cuerpo, semi flexión de miembros superiores (en algunos casos se puede expresar el fenómeno de rueda dentada), espasmos musculares, iteraciones, blefaroespasmo, constipación y perdida de la sensibilidad (Klingelhoefer \& Reichmann, 2015), asociados a la perdida de incentivo y aumento de esfuerzo psíquico al realizar actividades de la vida diaria con pérdida de su autocuidado (Walton \& Bouret, 2019), con alteración en el lenguaje con tendencia a la hipofonía y mutismo (Barbas et al., 2013), junto a un pobre apoyo psicosocial, tendrán mayor riesgo de resistencia farmacológica, por lo que dichos síntomas son predictores de la respuesta a la clozapina (Köhler-Forsberg et al., 2017). Esto es de importancia ya que un estudio reciente ha destacado datos de varios estudios observacionales que apoyan estos marcadores como pronóstico de la enfermedad (Shah et al., 2018).

Varios estudios informaron predictores clínicos de ERT, el realizado por T. Wimberley y colaboradores (2016) es quizás el estudio más extenso, basado en el seguimiento de hasta 15 años en una muestra 8624 participantes; el mismo señala que los predictores significativos fueron una edad más temprana de inicio, menor nivel educativo, vivir en zonas rurales, subtipo paranoico (aunque no controlado por los otros subtipos), trastorno de personalidad, consumo de sustancias e intento de suicidio previo.

El objetivo de proporcionar una base empírica para mejorar la identificación temprana de ERT basada en la presentación psicopatológica, ayudaría a los médicos a anticipar el inicio del tratamiento con clozapina, aunque si bien la identificación temprana es clínicamente importante, actualmente tenemos un conocimiento muy limitado de sus predictores.

\section{Pseudoresistencia en esquizofrenia}

El fenómeno de pseudoresistencia en la esquizofrenia no ocurre debido a la falta de acción farmacodinámica del antipsicótico (Altamura et al., 2005) sino que, por el contrario, está mediada por causas clínicas o factores farmacocinéticos del tratamiento, entre los cuales caben destacar (Potkin et al., 2020):

- Diagnóstico incorrecto.

- Dosis inadecuada del antipsicótico.

- Duración inadecuada del tratamiento antipsicótico.

- Niveles plasmáticos insuficientes del antipsicótico.

- Escasa adherencia al tratamiento antipsicótico (hasta la mitad de los pacientes no toman la medicación de forma correcta) (Goff \& Freudenreich, 2010).

- Efectos adversos que enmascaran la respuesta al antipsicótico (ej.: acatisia, parkinsonismo).

- Condiciones médicas comórbidas que enmascaran la respuesta al antipsicótico.

- Comorbilidades psiquiátricas y psicosis gatillada por el consumo de sustancias.

\section{Comorbilidades}

Más de la mitad de las personas con esquizofrenia tienen al menos una condición clínica comórbida, debido a que las comorbilidades tienen un impacto negativo en el curso de la esquizofrenia, la detección y el tratamiento óptimo de las mismas son importantes para un desenlace favorable (Pratt et al., 2020).

\section{a. Depresión y esquizofrenia}

Se estima que más del $70 \%$ de los pacientes con esquizofrenia pueden presentar síntomas depresivos y aproximadamente uno de cada cuatro cumplirá criterios para trastorno depresivo mayor en algún momento de sus vidas (Castle \& Buckley, 2015). Los síntomas depresivos pueden presentarse en todas las etapas de la esquizofrenia y, si bien se ha considerado que la presencia de síntomas afectivos durante el episodio psicótico es un indicador pronóstico positivo, la presencia 
de depresión durante las remisiones se ha asociado a peores resultados (Upthegrove et al., 2017). La depresión está asociada con suicidios consumados, riesgo de recaídas, re internaciones, peor funcionamiento, peor calidad de vida, violencia y no adherencia al tratamiento (Pratt et al., 2020). Los síntomas depresivos pueden confundirse con los síntomas negativos (aplanamiento afectivo, alogia, abulia, anhedonia y asocialidad) o con efectos adversos medicamentosos (sedación, acinesia, parkinsonismo) (Pratt et al., 2020). Las características principales de la depresión mayor que la distinguen de los síntomas negativos incluyen la presencia de humor depresivo, culpa no delirante y síntomas neurovegetativos (Castle \& Buckley, 2015; Pratt et al., 2020).

\section{b. Esquizofrenia y suicidio}

Aproximadamente el 5\% de los pacientes con esquizofrenia consuman suicidio (Hor \& Taylor, 2010), siendo más frecuente en hombres que en mujeres y posicionándose como causa principal de muerte en personas con esquizofrenia entre los 15 y los 24 años (Lin et al. 2018). Entre los principales factores de riesgo se destacan la presencia de síntomas depresivos, alucinaciones e ideas delirantes activas, tentativas previas, consumo de sustancias y la presencia de insight (Hor \& Taylor, 2010).

\section{c. Esquizofrenia y ansiedad}

Los síntomas ansiosos son frecuentes en personas con esquizofrenia, presentando una prevalencia mayor que en la población general (Achim et al., 2011) y ocurriendo hasta en el 65\% de los pacientes (Temmingh \& Stein, 2015). Los niveles elevados de ansiedad o la presencia de un trastorno de ansiedad se han asociado con síntomas positivos más graves, aislamiento social, depresión, desesperanza, incremento en las tasas de suicidio y un funcionamiento más deficitario (Braga et al., 2005; Lysaker \& Salyers, 2007). La presencia de síntomas de ansiedad se ha asociado con el género femenino, edades tempranas, niveles más elevados de educación y matrimonio (Dixon et al., 2001). Los síntomas de ansiedad deben ser diferenciados de las ideas de autoreferencia, las reacciones a los delirios, la agitación, la acatisia, los síntomas relacionados con sustancias (ej. intoxicación por cocaína, abstinencia al alcohol) y los síntomas depresivos (Zisook et al., 1999).

La presencia de síntomas de pánico se encuentran asociados con una mayor gravedad psicopatológica, incremento en el riesgo y la conducta suicida y un aumento en la vulnerabilidad al consumo de sustancias; mientras que la ansiedad social comórbida se ha aso- ciado con un peor pronóstico, mayores posibilidades de una recaída temprana y mayores niveles de discapacidad social (Buckley et al., 2009; McEnery et al., 2019).

La presencia de un antecedente de trauma infantil incrementa el riesgo para el desarrollo de psicosis (Varese et al., 2012). La prevalencia a lo largo de la vida para desarrollar un trastorno por estrés postraumático en personas con esquizofrenia oscila entre el 14 al 53\% (Pratt et al., 2020) y este se asocia a una mayor alteración en el funcionamiento social, mayor riesgo de consumo de sustancias, una psicosis más severa y un incremento del riesgo suicida en comparación con pacientes que solo padecen esquizofrenia (Pratt et al., 2020).

Mientras que hasta el 30\% de los pacientes con esquizofrenia pueden presentar síntomas obsesivo-compulsivos (Mariné et al., 2015; Swets et al., 2014), solo del 12 al 14\% cumplen criterios diagnósticos para TOC (Swets et al., 2014); asociándose ambas instancias, con una edad menor al momento del inicio de la esquizofrenia, depresión comórbida, ideación y tentativas suicidas. Además, dichos pacientes tienen evoluciones más desfavorables, con un mayor aislamiento y una menor respuesta al tratamiento que los pacientes esquizofrénicos sin síntomas obsesivo-compulsivos. Estos pueden preceder el inicio de la psicosis, comenzar al momento de inicio o luego del inicio de la misma, u ocurrir en forma transitoria (Zink, 2014). Asimismo, el uso de antipsicóticos como la clozapina y la olanzapina puede empeorar los síntomas obsesivo-compulsivos en una minoría de pacientes (Fonseka et al., 2014).

\section{d. Esquizofrenia y consumo de sustancias}

Las personas con esquizofrenia tienen el doble de chance de presentar un trastorno por consumo de sustancias que la población general (Regier et al., 1990).

A pesar de que el uso de tabaco ha disminuido considerablemente en la población general, más de la mitad de los pacientes con esquizofrenia son tabaquistas (Correll et al., 2014), como los hidrocarburos pueden inhibir los CYP 1A1, 1A2 y 2E1, los cambios entre el estado de consumo y abstinencia al tabaco pueden generar cambios en los niveles plasmáticos de algunos antipsicóticos (ej. clozapina, olanzapina y haloperidol), complicando las transiciones entre internaciones y tratamientos ambulatorios (Lowe \& Ackman, 2010).

Existe, asimismo, gran abuso en el consumo de alcohol, seguido de cannabis y estimulantes (87), el consumo de sustancias complica el curso y el tratamiento de la esquizofrenia y genera exacerbaciones sintomáticas y un mayor riesgo de internaciones, desamparo, victimización y suicidio, el uso de cannabis, 
especialmente durante la adolescencia temprana, se asocia con un inicio más temprano y un mayor riesgo de desarrollar esquizofrenia (Pratt et al., 2020).

En la Tabla 1 se detallan las comorbilidades mencionadas y los abordajes terapéuticos recomendados (ver Tabla 1).

\section{Neurobiología y estudios comple- mentarios en ERT}

La posibilidad de que la esquizofrenia resistente al tratamiento sea una entidad diferente entre el grupo de las esquizofrenias es un desafío dentro de la neurobiología de esta enfermedad. Las actuales hipótesis de las bases biológicas en la ERT se enfocan sobre alteraciones en el funcionamiento de diferentes neurotransmisores (ej. dopamina y glutamato). Algunos estudios reportaron que los pacientes con esquizofrenia que responden al tratamiento antipsicótico presentan, aumento de la liberación de dopamina (DA), altos niveles de DA basales y también elevada capacidad de síntesis de DA a nivel del cuerpo estriado, comparado con controles sanos (Demjaha et al., 2012).

Es conocido que entre el 65 y $80 \%$ de la ocupación de los receptores de DA D2 por los antipsicóticos es suficiente para alcanzar la respuesta clínica, sin embargo los estudios llevados a cabo en pacientes diagnosticados con ERT, evidenciaron que la resistencia al tratamiento se presentaba a pesar de que la ocupación de los receptores de DA D2 fuera del 95\%. Así también algunos pacientes con ERT mostraron niveles normales de la actividad dopaminérgica o incluso un nivel bajo de esta. Por lo tanto la ocupación de los receptores de DA D2 no garantiza suficientemente la respuesta en un grupo de pacientes, estos resultados en conjunto, nos permiten realizar una hipótesis sobre un subtipo de esquizofrenia no-dopaminérgica (Howes et al., 2012; Howes \& Kapur, 2014).

Kim et al. (Kim et al., 2017) realizaron un estudio en pacientes que habían respondido a la clozapina, en este estudio los pacientes con ERT respondedores a la clozapina también mostraron bajos niveles de capacidad de síntesis de DA comparado con los respondedores a otros antipsicóticos, sugiriendo que esto podría ser parte de la fisiopatología de la ERT y no un marcador de estado relacionado con la severidad de los síntomas.

La hipótesis de psicosis por supersensibilidad a la DA (PSD) propone que el bloqueo sostenido de los receptores dopaminérgicos D2 que inducen cambios dopaminérgicos (regulación hacia arriba de los receptores D2), sería la causa de la aparición de síntomas o brotes que no revierten con las dosis iniciales de tratamiento. Esta teoría propuesta por Chouinard, con el nombre de psicosis por supersensibilidad inducida por neurolépticos, sitúa al tratamiento con antipsicóticos a largo plazo, como un aspecto negativo dentro del tratamiento de la esquizofrenia (Kanahara et al., 2021; Nakata et al., 2017).

Algunos autores han propuesto que la PSD podría estar relacionada con la progresión hacia la ERT, en otras palabras, que la PSD podría ser un subtipo de ERT, ellos sostienen que una vez desarrollada la supersensibilidad a la DA en el cerebro de pacientes con esquizofrenia, la eficacia de una dosis determinada de antipsicóticos (que fue previamente efectiva) disminuye, y eso implica que los síntomas se vuelvan re-

Tabla I. Comorbilidades psiquiátricas en esquizofrenia (modificado de Pratt et al., 2020)

\begin{tabular}{cl}
\hline Comorbilidad & \multicolumn{1}{c}{ Abordaje terapéutico recomendado } \\
Depresión & $\begin{array}{l}\text { Rotar a antipsicóticos de segunda generación. } \\
\text { Agregar antidepresivo. } \\
\text { Agregar intervenciones psicosociales para la depresión. }\end{array}$ \\
\hline Trastorno de pánico & Agregar medicación para el pánico y terapia cognitivo-conductual. \\
\hline Fobia social & Agregar antidepresivo y terapia cognitivo-conductual. \\
\hline Trastorno por estrés postraumático & Agregar antidepresivo y terapia cognitivo-conductual. \\
\hline Trastorno obsesivo-compulsivo & Agregar un inhibidor de la recaptación de serotonina y terapia cognitivo-conductual. \\
\hline Trastorno por uso de tabaco & $\begin{array}{l}\text { Agregar medicaciones para cesación tabáquica aprobadas por la FDA- } \\
\text { Agregar tratamiento conductual para mantener la motivación y habilidades de } \\
\text { afrontamiento. }\end{array}$ \\
\hline Trastorno por uso de sustancias & $\begin{array}{l}\text { Rotar a un antipsicótico de segunda generación (mayor evidencia para clozapina) } \\
\text { Agregar medicaciones para el trastorno por uso de sustancias. }\end{array}$ \\
\hline
\end{tabular}


fractarios. Aproximadamente la mitad de los casos de ERT podrían estar etiológicamente relacionados con PSD (Chouinard et al., 2017; Suzuki et al., 2015). Si bien esta hipótesis postula que la ERT estaría relacionada con la duración del tratamiento antipsicótico, existe una controversia ya que los síntomas positivos disminuyen con la edad y no se incrementan tal cómo lo enuncia la hipótesis de psicosis por supersensibilidad a la DA (Potkin et al., 2020).

Otro importante desafío es conocer en qué momento de la enfermedad comienza la resistencia al tratamiento. En un estudio reciente se encontró diferencias en la capacidad de síntesis de DA entre los respondedores y los no respondedores desde el inicio de la enfermedad, sugiriendo así que habría subtipos tempranos de ERT (Jauhar et al., 2019).

Hay evidencias que una anormalidad en la regulación del glutamato podría específicamente jugar un papel en la ERT, esta anormalidad podría originarse en una hipofunción de los receptores NMDA en las células piramidales y en las neuronas gabaérgicas. Normalmente el glutamato es el responsable de regular el tono inhibitorio en el cerebro a través de la unión a los receptores NMDA de las interneuronas gabaérgicas. Los mecanismos estructurales que podrían producirse a causa de una hipofunción de los receptores NMDA en los pacientes con ERT, podrían conducir a una desinhibición de las neuronas piramidales y de las vías excitatorias, por subestimulación a las interneuronas inhibitorias gabaérgicas. Consecuentemente, la señalización descendente que se origina en las ínterneuronas gabaérgicas, puede causar un incremento en la liberación del glutamato en las neuronas piramidales y unirse a los receptores AMPA y kainato; este estado de exceso de glutamato inicia la entrada de calcio a las neuronas y desencadena la toxicidad celular, la cual con el tiempo puede ser perjudicial para la red neuronal (Potkin et al., 2020; Uno \& Coyle, 2019).

Los estudios de neuroimágenes han encontrado aumentos de los niveles de glutamato en la corteza cingulada anterior (CCA) en pacientes con ERT comparado con controles sanos y con pacientes respondedores al tratamiento. En la ERT la estimulación excitatoria de las neuronas piramidales en los circuitos de la CCA podría también estar desinhibida, ocasionando un aumento de la liberación de glutamato, lo que ocasiona el bloqueo de los receptores D2 en los tratamientos convencionales. Es así que la "excito toxicidad" mediada por glutamato podría ser la responsable de una variedad de anormalidades y severidad de los síntomas presentes en la ERT. Así como también la perdida de las espigas dendríticas y la disminución en la longitud de las dendritas podrían ser secundarias a una disfunción glutamatérgica (Mouchlianitis et al., 2016b).

En modelos animales, la clozapina es el estándar de oro en el tratamiento de la ERT, muestra una alta afinidad por los receptores de dopamina D4, y el bloqueo de estos receptores regula hacia arriba la expresión de los receptores AMPA, mejorando la neurotransmisión glutamatérgica (Veerman et al., 2014). La clozapina también puede aumentar la liberación de L-glutamina y D-serina, lo que resulta en una regulación hacia arriba del número de receptores NMDA expresados (Yamamori et al., 2014).

Los estudios genéticos también aportaron datos sobre la ERT: El interés de estos reportes está en la posibilidad de predecir cuáles pacientes pueden presentar resistencia al tratamiento en sus aspectos farmacogenéticos y farmacogenómicos.

Algunos estudios sugieren que la ERT es una forma familiar de esquizofrenia ya que los índices de esquizofrenia entre los parientes de primer grado de pacientes con ERT son mayores que entre respondedores al tratamiento y los controles sanos, esto indica que la historia familiar de psicosis sería un predictor de ERT (Joober et al., 2005).

La mayoría de los estudios de genética molecular se enfocaron en el análisis de genes que codifican para proteínas relacionadas con los sistemas dopaminérgico, serotoninérgico, glutamatérgico, así como también en genes que intervienen en los mecanismos infamatorios y en el estrés oxidativo.

Una posible combinación ocurre entre la variante del gen transportador de DA (número variable de repeticiones en tándem -VNTR- de 40 pares de bases) y el gen transportador de serotonina (VNTR en el intrón 2) que han sido relacionados con ERT, los polimorfismos en el gen del receptor de dopamina D2 podrían afectar a pacientes en riesgo de desarrollar supersensibilidad a la DA, ERT o la probabilidad que el paciente responda a algún antipsicótico distinto de clozapina (Bilic et al., 2014).

Otros genes que fueron reportados con la ERT fueron el gen del factor neurotrófico derivado del cerebro -BDNF- (Val66Met o C207T polimorfismo), 5-HT2A (T102C polimorfismo), triptofano hidroxilasa (polimorfismo $\mathrm{C} / \mathrm{A}$ ), repeticiones de CCG en el gen de la reelina y el alelo A1 del HLA (Pisanu \& Squassina, 2019). Ruderfer y col., reportaron que un conjunto de genes relacionados con el tratamiento antipsicótico y con el riesgo de desarrollar enfermedad (por ej. CACNA1C, 
GRIN2A, AKT3, HCN1), estaban relacionados con la respuesta al tratamiento (Ruderfer et al., 2016).

Los estudios que se enfocaron sobre el potencial valor del análisis del índice de riesgo poligénico (PRS) surgidos de los reportes del Consorcio internacional de genética de esquizofrenia (PCG), encontraron que aquellos pacientes con baja carga poligénica tienen más probabilidad de responder a las 12 semanas del tratamiento antipsicótico, comparado con los pacientes con alto índice de riesgo poligénico (Ruderfer et al., 2016; Vita et al., 2019).

Un estudio de variación del número de copias $(\mathrm{CNV})$ encontró que los pacientes que portaban de novo CNVs tenían más probabilidad de tener ERT, en este estudio no solo se replicaron hallazgos anteriores que encontraron este tipo de variante (CNVs) en genes implicados en la señalización del calcio, gen de la proteína del retardo metal del cromosoma X frágil (FMPR) y genes relacionados con la sinapsis, sino que también se identificaron nuevas CNVs en genes que están relacionados con la repuesta al estrés oxidativo, a la integridad genómica, a las quinasas, a la regulación de la expresión genética y GTPasas (Kushima et al., 2017).

Estos resultados, aunque controvertidos, sostienen la hipótesis de que al menos algunos de los genes que confieren susceptibilidad para desarrollar esquizofrenia podrían explicar también parte de la variabilidad interindividual en la respuesta a los antipsicóticos y el riesgo para desarrollar ERT (Vita et al., 2019).

Si bien no existen en la actualidad estudios complementarios de diagnóstico con utilidad clínica para la ERT, los estudios de neuroimágenes reportaron algunos hallazgos en estos pacientes; así, una significativa disminución de la sustancia gris (en particular en las áreas frontales) fue encontrada en pacientes con ERT comparada con pacientes esquizofrénicos no resistentes y con controles sanos, esta reducción parece ser más severa en pacientes con esquizofrenia ultra-resistente (Anderson et al., 2015a; Quarantelli et al., 2014). Los estudios realizados en pacientes que evolucionaban desfavorablemente y no respondían al tratamiento, presentaban alargamiento de los ventrículos cerebrales y disminución de la sustancia blanca (Mitelman et al., 2010). Estas anormalidades podrían reflejar un continuo entre pacientes respondedores y resistentes al tratamiento y definir de forma más amplia el concepto de ERT (Mouchlianitis et al., 2016a).

La pérdida de elementos neuronales que ocasiona los síntomas de ERT y de esquizofrenia ultra resistente al tratamiento (EURT) podría ser más sustancial que en aquellos pacientes que responden a los antipsicóti- cos. Estudios volumétricos, de tensor de difusión en resonancia magnética (DTI) y de resonancia magnética funcional (RMNf) han examinado la morfología intracerebral regional, la integridad de los circuitos interregionales de sustancia blanca y la conectividad funcional en la ERT y han identificado alteración en las regiones frontales y temporales y en los principales haces de fibra que los conectan (Holleran et al., 2014; McNabb et al., 2020; Mitelman \& Buchsbaum, 2007; Nakajima et al., 2015).

A través de las neuroimágenes funcionales como el PET se reportaron altos niveles de síntesis de DA en el cuerpo estriado en pacientes esquizofrénicos respondedores al tratamiento, en comparación con pacientes con ERT que presentaban niveles de síntesis de DA equivalente a los controles (Demjaha et al., 2012), por resonancia magnética espectroscópica, se reportaron altos niveles de glutamato y glutamina en la CCA en la ERT comparado con pacientes respondedores al tratamiento (Egerton et al., 2010; Egerton et al., 2021; Mouchlianitis et al., 2016a).

En un estudio en el cual se evaluó la eficiencia de la conectividad local y global de las redes cerebrales en individuos con ERT, comparado con controles, los pacientes con ERT mostraron reducida conectividad funcional, que fue más pronunciada en el lóbulo temporal. El decrecimiento de la conectividad en el área del lóbulo frontal y temporal es un circuito particularmente vulnerable, alteraciones en estas áreas han sido reportadas en estudios previos de esquizofrenia y ERT (Ganella et al., 2017).

\section{ERT y cognición}

Los trastornos cognitivos en los pacientes con esquizofrenia han sido descriptos desde las primeras caracterizaciones del trastorno (Kraepelin, 1996), aunque en las últimas décadas su estudio ha tomado renovado vigor (O'Carroll, 2000; Sheffield et al., 2018). Se sabe que las personas aquejadas de esquizofrenia muy frecuentemente tienen alteraciones cognitivas, sobre todo en la atención, memoria, funciones ejecutivas, resolución de problemas, velocidad de procesamiento y cognición social (Keefe \& Fenton, 2007). El desempeño suele estar por debajo de uno o dos desvíos estándar de los sujetos normales siendo las alteraciones cuantitativamente más severas que en otras enfermedades psiquiátricas, tales como el trastorno bipolar (Bortolato et al., 2015; Li et al., 2020). Se ha observado que los déficits cognitivos están asociados específicamente con la sintomatología negativa, y que podrían estar correlacionados con la severidad sintomatológi- 
ca (Braw et al., 2012; Ventura et al., 2009). Las alteraciones cognitivas han sido asociadas significativamente a la evolución funcional, la calidad de vida y la capacidad laboral y de rehabilitación de los pacientes con esquizofrenia (Green, 1996; 2016).

Los déficits cognitivos han sido descriptos también en niños y adolescentes que fueron diagnosticados en años posteriores con esquizofrenia y en familiares de primer grado de estos pacientes (Keefe et al., 1994; Reichenberg et al., 2010).

Desde hace casi dos décadas se han comenzado a estudiar las diferencias de funcionamiento cognitivo entre los pacientes con esquizofrenia según su respuesta al tratamiento (Joober et al., 2002), adicionando una nueva variable clínica a la distinción entre estos dos grupos. Hasta la actualidad han aparecido ocho trabajos de comparación entre estos dos grupos de pacientes (Anderson et al., 2015b; Bourque et al., 2013; De Bartolomeis et al., 2013; Frydecka et al., 2015; Gilbert et al., 2014; Iasevoli et al., 2016; Joober et al., 2002; Kravariti et al., 2019). Estos estudios, lamentablemente, se han realizado con muestras pequeñas y gran heterogeneidad en los tests empleados, criterios de resistencia, síntomas, funcionalidad y tratamientos entre los grupos estudiados; sin embargo, salvo uno (Anderson et al., 2015b), todos los estudios restantes han demostrado diferencias significativas en algunas funciones cognitivas, siendo los pacientes con ERT los que se desempeñaban peor en las pruebas. Los dominios cognitivos en los que se han hallado diferencias han sido la memoria visual (Bourque et al., 2013; Gilbert et al., 2014; Joober et al., 2002), la memoria verbal (De Bartolomeis et al., 2013; Gilbert et al., 2014; Iasevoli et al., 2016; Joober et al., 2002), el aprendizaje verbal (Joober et al., 2002), la habilidad verbal (Joober et al., 2002), la atención selectiva (Frydecka et al., 2015), la velocidad de procesamiento (Frydecka et al., 2015; Gilbert et al., 2014), la fluencia verbal (Frydecka et al., 2015; (Kravariti et al., 2019), la inteligencia verbal (Kravariti et al., 2019) y la memoria de trabajo (Gilbert et al., 2014). Dos estudios observaron una correlación entre las alteraciones cognitivas y los síntomas negativos (De Bartolomeis et al., 2013; Frydecka et al., 2015).

Kravariti et al. (2019) siguieron durante diez años a un grupo de pacientes de 16 a 65 años testeado cognitivamente durante su primer episodio psicótico en el marco del estudio AESOP-10. Los pacientes esquizofrénicos, tanto refractarios como no refractarios al tratamiento (clasificados de esta forma 10 años después de su primer episodio), tuvieron peor desempeño en tests de fluencia verbal, memoria, aprendi- zaje e inteligencia verbal, habilidad visuo espacial y funciones ejecutivas en relación a los controles. A su vez, los pacientes con esquizofrenia refractaria tuvieron más déficits en la fluencia y la inteligencia verbal que los respondedores al tratamiento. Gilbert et al. (2014) dividieron una muestra de 112 pacientes con esquizofrenia en 3 grupos según sus desempeños neuropsicológicos en memoria verbal, memoria visual, velocidad de procesamiento y memoria de trabajo y distinguieron a un grupo casi normal, uno alterado selectivamente en la memoria visual y la velocidad de procesamiento y otro alterado en los cuatro dominios. Este último, mayoritariamente, fue el que tuvo peor respuesta al tratamiento medicamentoso. Con el establecimiento del uso de la clozapina como tratamiento de elección en el paciente con ERT, se comenzó a estudiar el efecto de la misma en los déficits cognitivos. Algunos estudios no hallaron cambios cognitivos con el uso de la clozapina a pesar de las mejorías clínicas en síntomas positivos y negativos (Goldberg et al., 1993; Lindenmayer et al., 1998; Zahn et al., 1994), sosteniendo el dominio cognitivo como un dominio independiente de la sintomatología. Inclusive un estudio (Zahn et al., 1994) observó un empeoramiento en la velocidad de respuesta a los estímulos visuales. Sin embargo, la mayoría de los estudios demostraron mejorías en las alteraciones neurocognitivas tras un tratamiento con clozapina luego de un corto plazo (Lee et al., 1999; Meyer-Lindenberg et al., 1997; Purdon et al., 2001), así como también posterior a un año (Breier et al., 1994; Fuji et al., 1997; Grace et al., 1996; Lee et al., 1999; Purdon et al., 2001). Las mejorías se observaron en la atención y velocidad psicomotriz (Grace et al., 1996; Lee et al., 1999), la fluencia verbal y la memoria visuo espacial (Buchanan et al., 1994; Grace et al., 1996; Lee et al., 1999), la memoria de trabajo, la función ejecutiva (Buchanan et al., 1994; Fuji et al., 1997; Grace et al., 1996) y la cognición social (Verma et al., 2020). El estudio de Grace et al. (1996) observó mejorías en la cognición a lo largo de 3 años, aunque es difícil adjudicar esta mejoría sólo a la medicación, ya que los pacientes se encontraban realizando un programa de rehabilitación psicosocial. Una revisión de 12 estudios de Mc Gurk (2000), concluyó que el tratamiento con clozapina produce mejorías en la atención y la fluencia verbal y un efecto beneficioso limitado en la memoria y el aprendizaje verbal con poca eficacia en la memoria de trabajo y en la función ejecutiva.

Un dato interesante de los últimos años es que la alteración de la cognición en los pacientes medicados con clozapina estaría asociada a la tasa clozapina/ 
norclozapina (metabolito activo de la clozapina) existente en el plasma sanguíneo (Dal Santo et al., 2020; McArdle et al., 2019; Park et al., 2020; Rajji et al., 2010). Se especula que esta relación se debería al efecto antagonista muscarínico de la clozapina en relación al efecto agonista de la norclozapina (Rajji et al., 2010). Esta correlación negativa entre la tasa clozapina/norclozapina y funcionamiento cognitivo se observó específicamente para la atención, vigilancia, memoria del trabajo y cognición social (Park et al., 2020).

Se han estudiado los efectos cognitivos de la adición de distintas drogas al tratamiento de la clozapina con resultados positivos con la ziprasidona (Muscatello et al., 2014a), la lamotrigina (Zoccali et al., 2007), la lurasidona (Meltzer et al., 2020), la minociclina (Kelly et al., 2015) y la memantina (De Lucena et al., 2009; Veerman et al., 2016), y resultados negativos con el aripiprazol (Muscatello et al., 2011a), la lamotrigina (Vaygǵsoğlu et al., 2013), la d-serina (Tsai et al., 1999), el topiramato (Muscatello et al., 2011b), la roziglitazona (Yi et al., 2012), la duloxetina (Mico et al., 2011) y el modafinilo (Freudenreich et al., 2009). De todas maneras, estos estudios han sido realizados con muestras muy pequeñas de pacientes, lo que no permite realizar aún recomendaciones. Actualmente se está realizando un estudio para evaluar el efecto cognitivo de la adición de n-acetil cisteína al tratamiento de clozapina en pacientes esquizofrénicos refractarios (Rossell et al., 2016).

\section{IX.Tratamientos psicosociales}

Los tratamientos no biológicos o psicosociales para los pacientes con esquizofrenia se iniciaron con las intervenciones familiares (Garay \& Sabatés, 2018). Las intervenciones psicoeducativas buscaron reducir el estigma asociado al problema y el estrés de la familia sobre el paciente. La teoría de la emoción expresada postuló que las emociones negativas que expresan los familiares sobre el paciente (agresión, culpa, etc.) incrementan el estrés recibido por este, empeorando el curso de la enfermedad. Posteriormente, la psicoeducación familiar ayudó con el objetivo de incrementar la adherencia al tratamiento farmacológico, en la medida en que los datos mostraron una disminución de la deserción de los pacientes en el largo plazo (Keegan \& Garay, 2007).

El entrenamiento en habilidades sociales se basó en los principios del aprendizaje social (modelado, etc.) para ayudar a los pacientes con esquizofrenia a desarrollar las habilidades necesarias para favorecer su integración social, incrementar su autonomía, manejar situaciones sencillas como realizar las compras, solicitar un turno médico y aquellas tareas más complejas, como la inclusión en contextos menos estructurados, como la vida social o afectiva.

La terapia cognitivo-conductual (TCC) designa una familia de intervenciones basadas en el estudio de los trastornos mentales, centrándose en los factores de mantenimiento de los mismos así como ocupándose de los procesos psicopatológicos estudiados (Garay et al., 2016). Al aplicarse a los pacientes con esquizofrenia, las intervenciones cognitivo-conductuales enfatizan elementos de la psicoeducación, focalizándose inicialmente en los contenidos de las ideas delirantes así como también en el manejo de contextos que incrementan o disminuyen las experiencias alucinatorias. Las técnicas son muy variadas y el tratamiento puede implementarse de forma individual pero también grupal o incluso bajo la forma de autoayuda.

El entrenamiento meta cognitivo (Garay, 2018) busca reducir los sesgos cognitivos propios de la esquizofrenia mediante diferentes ejercicios tendientes a la flexibilización de la cognición. Los modelos más contextuales, enfatizaron la relación de los pacientes con sus síntomas más que los contenidos de los mismos (Garay \& Korman, 2018).

La terapia forma parte de un trabajo interdisciplinario en el que se incluyen intervenciones comunitarias, terapia ocupacional, asistencia social, arteterapia, musicoterapia, tratamientos farmacológicos, etc., con el objetivo de reducir deserción, recaídas, reinternaciones, y mantener a los pacientes en tratamientos prolongados y complejos.

El estudio de intervenciones psicosociales en pacientes con ERT se ha realizado más recientemente. A continuación se mencionan los estudios controlados y aleatorizados más relevantes de su aplicación, destacando que no difieren en esencia de aquellas estudiadas en pacientes con esquizofrenia. De acuerdo al estudio multicéntrico de Newcastle y Manchester (Sensky et al., 2000; Turkington et al., 2002), en el cual 90 sujetos de entre 16 y 60 años, que tenían síntomas persistentes de esquizofrenia, durante más de 6 meses realizaron un tratamiento farmacológico adecuado; el grupo de pacientes que recibió terapia cognitivo conductual (TCC) obtuvo mejores puntajes en la psicopatología global y en los síntomas positivos y negativos de esquizofrenia, la diferencia se mantuvo a los 5 años y los pacientes que recibieron TCC tuvieron menos de la mitad de días de internación durante ese período (1323 versus 2947 días).

El estudio de Carolina del Norte y Pennsylvania (Penn et al., 2009) incluyó 65 pacientes con esquizofre- 
nia y alucinaciones auditivas resistentes al tratamiento farmacológico. El grupo tratado con TCC grupal tuvo menos síntomas positivos y negativos, en general, que el grupo control, a los 12 meses de seguimiento.

El estudio multicéntrico de Amsterdam, Groningen y Utrecht (van der Gaag et al., 2012) incluyó 186 sujetos con diagnóstico de esquizofrenia o desorden esquizoafectivo tratados con medicación antipsicótica y con síntomas persistentes. El grupo que recibió TCC mostró una mayor cantidad de días de funcionamiento normal en el seguimiento de 18 meses. El estudio FOCUS (Focusing on Clozapine Unresponsive Symptoms) (Morrison et al., 2018) incluyó 485 pacientes con síntomas persistentes. El grupo tratado con TCC mostró resultados similares a la potenciación farmacológica pero se observaron menores efectos colaterales y mayor calidad de la reducción sintomática al final de tratamiento.

Existe también evidencia sobre la eficacia de la TCC en el tratamiento de autoayuda (Naeem et al., 2016), muy relevante cuando no se disponen de profesionales entrenados en su administración. Los principales tratamientos psicosociales investigados se encuentran dentro de las TCC, habiéndose estudiado en pacientes con síntomas persistentes y resistentes a los tratamientos farmacológicos de primera línea (Sabatés \& Garay, 2016). La inclusión de estas intervenciones puede reducir la sintomatología positiva, negativa, mejorar la calidad de vida y reducir el tiempo de internación de los pacientes con ERT, destacándose la importancia de incluir dichas intervenciones en la asistencia global de esta población

\section{Tratamiento farmacológico de pri- mera línea en ERT}

La indicación de clozapina en la ERT nace del estudio crucial de Kane (Kane et al., 1988), el cual demostró la superioridad de este agente sobre el antipsicótico clorpromazina en una población rigurosamente definida como resistente al tratamiento. Mientras sólo el 4\% respondió a clorpromazina, el 30\% lo hizo a clozapina.

Al Estudio de Kane le siguieron otros que mostraron resultados similares aunque con diferencias menos espectaculares, en 2009 se publicó una revisión de Cochrane (Essali et al., 2009) sobre el tema que incluyó 52 estudios con 4746 participantes. Si bien mencionan que estos estudios tienen una duración promedio baja (13 semanas) y presentan sesgos metodológicos, la evaluación de los mismos revela que clozapina tiene una mayor efectividad que los antipsicóticos de primera generación (APG) en reducir los síntomas de la esquizofrenia, en posponer recaídas y lograr una mayor satisfacción en los pacientes; pero agregan, sin embargo, que la clozapina no mostró superioridad en el funcionamiento global o en el mantenimiento de una ocupación. Estas ventajas deben ser sopesadas con los efectos secundarios que produce.

La cuestión siguiente es la eficacia comparativa de clozapina con antipsicóticos de segunda generación (ASG), los datos más sólidos provienen de estudios también cruciales en este campo como son el CATIE y el CUTLASS (Lewis et al., 2006; McEvoy et al., 2006), llevados a cabo con una metodología que no es la de los estudios controlados aleatorizados (RCT por sus siglas en inglés), pero que refleja de mejor manera la eficacia y tolerancia de los tratamientos en el mundo real.

El estudio CATIE (McEvoy et al., 2006) usó la discontinuación como objetivo primario, asignando a los pacientes que habían fracasado a un AP anterior a clozapina, risperidona, quetiapina u olanzapina; clozapina demostró un mayor tiempo hasta la discontinuación por cualquier causa que risperidona o quetiapina, aunque no con olanzapina. Sin embargo, en la discontinuación exclusivamente por falta de resultados terapéuticos, clozapina fue superior a olanzapina. A los 3 meses, además, clozapina había mostrado un descenso en el score de la PANSS superior a risperidona y quetiapina, aunque no con respecto a olanzapina.

El estudio CUTLASS, con una metodología similar al CATIE asignó a los pacientes que habían fracasado en responder a 2 o más AP a clozapina, olanzapina, risperidona, quetiapina o amisulprida. La clozapina mostró una superioridad estadísticamente significativa en un año en la PANSS sobre sus competidores, además, en la semana 12 los pacientes tratados con clozapina expresaron una mayor satisfacción con su estado mental comparado con los otros AP.

No obstante esto, corresponde mencionar que en 2008 Meltzer y colaboradores (2008) publicaron un estudio en el que reportaban una eficacia similar entre la clozapina y la olanzapina en dosis inusualmente altas (promedio de olanzapina fue de $34 \mathrm{mg} /$ día) en ERT, aunque estos datos hay que relativizarlos dado que la muestra fue muy pequeña. Incluso, más adelante Souza y otros (2013) publicaron un metanálisis de 7 RCT que compararon ambas drogas en la ERT concluyendo que la clozapina mostró superioridad significativa sobre la olanzapina en resultados reflejados en PANSS tanto positiva como negativa.

Reuniendo esta serie de datos, la conclusión basada en la bibliografía es que la clozapina es el fármaco de elección para ERT y eso está reflejado en las diferentes 
guías de tratamiento (Barnes et al., 2011; Buchanan et al., 2010; Hasan et al., 2012; Lehman et al., 2004).

Más recientemente esto fue ratificado por la Guía de Tratamiento de Esquizofrenia del 2020 por la American Psychiatric Association (Keepers et al., 2020). En ella se incluyen las siguientes recomendaciones prácticas: a) lenta titulación para desarrollar tolerancia; b) monitoreo atento de los efectos secundarios; c) llegar a dosis promedio de 300 a $500 \mathrm{mg}$ y d) medir la concentración de clozapina y norclozapina. Mientras la eficacia clínica de clozapina se halla más a menudo con una concentración de $350 \mathrm{mcg} / \mathrm{ml}$ o más (aunque hay resultados positivos con una concentración menor), el valor de la ratio clozapina/norclozapina sirve para medir cumplimiento y saturación de las vías metabólicas. Dado que la norclozapina tiene una vida media más larga, un cociente menor a 0.5 estaría indicando falta de cumplimiento reciente y un cociente superior a 3 estaría indicando saturación de las vías metabólicas.

Si bien el efecto secundario más publicitado de la clozapina y lo que ha dado lugar a los programas de monitoreo mandatorios para su uso es la neutropenia y agranulocitosis, muchos otros deben ser observados, tales como la miocarditis y la cardiomiopatía que conllevan riesgo de muerte.

Fuera de estos, una serie de efectos secundarios pueden presentarse y afectar la calidad de vida y el cumplimiento (Iqbal et al., 2020): sedación, constipación, aumento de peso, síndrome metabólico, convulsiones, mareos, agitación, hipersalivación, cefaleas y taquicardia.

No obstante estos efectos secundarios, la clozapina presenta una mayor adherencia y satisfacción comparado con otros AP (Siskind et al., 2017).

Queda por aclarar que clozapina alcanza una respuesta de 30 a $40 \%$ de pacientes con ERT, lo cual deja una proporción significativa de individuos que requieren su potenciación con otros recursos.

Además de los datos que aporta la bibliografía, es de utilidad agregar la experiencia, en el año 2015 en un servicio de consultorios externos, el 38\% de los pacientes con diagnóstico de esquizofrenia o trastorno esquizoafectivo estaban siendo tratados con clozapina. El siguiente es un resumen de esa experiencia:

1. La clozapina tiene una eficacia diferencial comparado con cualquier otro AP o combinación de AP en ERT. En algunos casos, esa eficacia es sorprendente y se refleja en cambios notables en la capacidad de convivencia, en el desempeño funcional, en la calidad de vida y en la satisfacción del paciente y de su familia.
2. Sin embargo esto se aplica a un grupo de pacientes ya que otros tampoco responden a la clozapina $y$ requieren potenciación con otros recursos.

3. La clozapina, aun con su notable eficacia, es un fármaco con limitaciones en su uso porque presenta dificultades en su tolerancia. Más allá de los efectos secundarios amenazantes para la vida, otros como la sedación, la sialorrea o la constipación afectan el bienestar y la adherencia.

\section{Tratamientos farmacológicos. Aso- ciación con antipsicoticos (AP)}

En las personas con esquizofrenia, la respuesta parcial y la resistencia al tratamiento condicionan también la funcionalidad y plantean la necesidad de mejorar el acceso a la atención lo más precozmente posible, optimizar los métodos de diagnostico y los tratamientos disponibles (Jones et al., 2006).

Ante esta situación clínica la combinación de antipsicóticos se viene utilizando con mucha frecuencia en la práctica clínica, los informes de la prevalencia de la combinación de antipsicóticos en los EE. UU. varían del 7\% al 50\%. En un estudio realizado en centros de Europa, Canadá y Latinoamérica se encontró que la utilización de un solo un AP fue del $36.2 \%$, dos AP $24.6 \%$, tres AP $17.3 \%$, cuatro AP 9.4\% y cinco AP $11.9 \%$, en este estudio sólo un tercio de los pacientes reciben exclusivamente un antipsicótico en lo que podríamos llamar evidencia clínica en el mundo real (Haro et al., 2018).

Si bien se ha criticado la falta de fundamento farmacológico para combinar antipsicóticos con el mismo mecanismo de acción (bloqueo del receptor D2), también tenemos que reconocer que existe una comprensión incompleta y limitada de la farmacodinamia de las moléculas antipsicóticas debido a los múltiples efectos sobre los receptores y neurotransmisores (Ure et al., 2018). Sin embargo, la combinación de antipsicóticos sigue siendo una práctica común y controvertida debido a que no existe evidencia suficiente que respalde su eficacia, son importantes también las preocupaciones sobre la seguridad de estos fármacos a largo plazo, la mortalidad que podrían ocasionar y el aumento del costo (Correll et al., 2007; Stahl, 2002).

Además, pocos ensayos controlados aleatorios (ECA) usan combinación de antipsicóticos citados en este contexto e implican el uso de clozapina con un antipsicótico de alta afinidad por dopamina.

Tomando en cuenta los metaanálisis de estudios realizados en diferentes momentos durante las tres 
décadas pasadas en diversos centros a lo largo de $\mathrm{Eu}-$ ropa, Asia, Sudamérica y Norteamérica, se encontró que la combinación de antipsicóticos da una respuesta clínicamente significativa definida como una reducción de al menos un 50\% de PANSS o BPRS o al menos "mucho mejor" en CGI-I (Correll et al., 2009). En los estudios incluidos en el metaanálisis no se encontraron en ningún grupo diferencias para los siguientes eventos adversos: trastornos del movimiento, uso de anticolinérgicos, efectos adversos cardiovasculares, endocrinológicos, gastrointestinales, aumento de peso y hematológicos. En cambio, se evidenció un incremento de los niveles de prolactina en los grupos donde se utilizó sulpirida o risperidona con el tratamiento continuado con clozapina (Correll et al., 2009).

Como conclusión podemos decir que estos datos sugieren que bajo determinadas circunstancias, la combinación de antipsicóticos puede ser superior a la monoterapia antipsicótica, particularmente en casos de exacerbación aguda. En aquellos pacientes en los cuales se inicia la terapéutica con combinación de antipsicóticos y se benefician con ello, dicho beneficio no parece ser directamente proporcional al bloqueo de dopamina resultante. Sin embargo, es importante señalar que los resultados fueron heterogéneos, lo que sugiere que existe la influencia de múltiples variables y posiblemente haya sesgos de publicación. Es importante señalar que se requiere de más estudios de investigación, ya que la base de datos es demasiado limitada para determinar los efectos de combinaciones específicas, con la excepción de los beneficios que se muestran al incluir clozapina. Tampoco está claro si los beneficios potenciales en pacientes se limitan a combinaciones que incluyen clozapina o que incluyen clozapina combinada con un antipsicótico típico o atípico (de primera o de segunda generacion) y cuáles son los riesgos potenciales a corto plazo y en particular, a largo plazo de las combinaciones de antipsicóticos.

\section{Combinaciones farmacológicas con clozapina}

A pesar de las buenas respuestas a la clozapina que se pueden obtener en varios pacientes con ERT, este fármaco no es una panacea. Se calcula que sólo un 40\% de las personas con ERT responderá favorablemente (Siskind et al., 2017). Para mayor desaliento, los metanálisis y revisiones que evalúan las estrategias farmacológicas de combinación o potenciación de clozapina después de una respuesta insuficiente a la monoterapia con ese fármaco, indican sólo beneficios margina- les y/o incluyen estudios de baja calidad. Uno de los problemas que se observan es la falta de una definición consistente de esquizofrenia resistente a la clozapina en los ensayos clínicos, lo que compromete la posibilidad de replicar los resultados y también su aplicabilidad en la práctica clínica (Wagner et al., 2019). Por lo tanto, es de enorme importancia no considerar que haya falta de respuesta a la clozapina sin tener la seguridad de que se la ha utilizado de manera óptima.

Uno de los puntos a considerar es la duración del ensayo con este antipsicótico. Para Remington et al. un tratamiento de 8 , pero preferiblemente de 12 semanas, a una dosis de $400 \mathrm{mg} / \mathrm{d}$ sería un ensayo adecuado (Remington et al., 2017). Pero el tema es también sujeto de debate, ya que en opinión de algunos autores la eficacia puede evidenciarse en un plazo de 6 meses. Se ha identificado incluso una subpoblación de pacientes cuyas respuestas aparecen después de un año de tratamiento (Muscatello et al., 2014b).

Otro punto es el nivel plasmático de la clozapina, antes de tomar decisiones respecto de si potenciarla o hacer un cambio de medicación, se aconseja realizar una medición de niveles plasmáticos, sobre todo si hay dudas acerca de la adherencia al tratamiento, si aparecieron más o menos efectos adversos que lo esperado, por la posible existencia de interacciones o de otros factores que puedan estar influyendo (Remington et al., 2017). Aunque existe una variación sustancial entre individuos, los niveles de clozapina generalmente serán mayores en los no fumadores, en los consumidores de mucha cafeína, en las mujeres y en los individuos más ancianos (Ismail et al., 2012). Los cambios entre marcas de clozapina pueden generar variaciones de $5 \%$ a $10 \%$ en los niveles plasmáticos. La muestra de sangre se debe extraer una vez alcanzado el estado estacionario (3 o más días después de un cambio de dosis) y en un valle en los niveles de medicación (aproximadamente 12 horas después de la última toma) (Keepers et al., 2020). Al igual que con los resultados de cualquier prueba de laboratorio, su interpretación debe tener en cuenta el contexto clínico. Si el nivel obtenido es mucho mayor de lo esperado, se deberán evaluar efectos secundarios relacionados con la dosis y evidencia clínica de toxicidad. Si el estado clínico del paciente no sugiere toxicidad, habrá que determinar el momento en que se obtuvo el nivel (por ejemplo, pico o valle) e identificar cualquier posibilidad de interacciones farmacológicas, cambios en el estado de tabaquismo o etiquetado incorrecto de las muestras. Si los niveles son mucho más bajos de lo es- 
perado, se deberá pensar en factores como la mala adherencia, el metabolismo rápido, las interacciones con medicamentos o los cambios en el nivel de tabaquismo (Keepers et al., 2020). Se postula que se alcancen niveles plasmáticos de $350 \mathrm{ng} / \mathrm{ml}$ para la dosificación una vez al día y de $250 \mathrm{ng} / \mathrm{ml}$ para la dosificación en tomas repartidas (Remington et al., 2017).

Si se llega a la conclusión de que el tratamiento con clozapina está correctamente realizado y aun así no se ha obtenido la respuesta deseada, una opción será combinarla con otro fármaco. En 2006 se publicó el primer artículo que hablaba de "esquizofrenia ultrarresistente" (Mouaffak et al., 2006). La preferencia actual es llamarla "esquizofrenia resistente a la clozapina” y no está claro si este grupo representa una forma distinta de la enfermedad.

Se ha evaluado una amplia gama de posibles asociaciones con la clozapina, pero ninguna intervención ha demostrado efectos sólidos y repetidos que justifiquen su identificación como el tratamiento de elección (Remington et al., 2017). Si se lleva a cabo un ensayo de potenciación, es fundamental considerar los posibles efectos aditivos en los efectos secundarios y el potencial de interacciones. También es importante la revisión periódica del régimen de medicación del paciente para identificar y reducir o interrumpir los medicamentos que no son eficaces, que ya no son necesarios, o que están contribuyendo a una carga excesiva de efectos secundarios (Keepers et al., 2020).

En líneas generales, los agentes más eficaces como potenciadores para los síntomas psicóticos fueron aripiprazol, fluoxetina y valproato de sodio. Estudios individuales de ciertos antipsicóticos (penfluridol), antidepresivos (paroxetina, duloxetina), litio y ginkgo biloba mostraron efectos prometedores, aunque estos hallazgos preliminares requieren replicación (Siskind et al., 2018).

Una de las estrategias más utilizadas, aunque no existe un consenso con respecto a la misma, es la potenciación con un segundo antipsicótico (AP). Taylor y Smith (2009) concluyen que, aunque la eficacia del aumento con un AP es modesta, es posible alcanzar una mejoría clínica en algunos pacientes (Taylor \& Smith, 2009). Se ha presumido que los AP con alta potencia bloqueante D2 deberían aumentar la eficacia de la clozapina, cuyo mecanismo de acción se caracteriza por un débil antagonismo D2. Sin embargo, la risperidona demostró eficacia pobre agregada a clozapina (Porcelli et al., 2012). Cuando se añadieron a la clozapina fármacos como el aripiprazol (agonista parcial de D2), o la amisulprida (antagonista selectivo
D2 y antagonista D3, no disponible comercialmente en Argentina), se observó un cierto grado de mejoría de los síntomas, por lo que también se postula que el aumento de la ocupación D2 podría ser ineficaz o perjudicial en lugar de beneficioso. Con respecto al aripiprazol, los resultados favorables para este agente se ven atenuados por la mala calidad de la mayoría de los estudios (Siskind et al., 2018).

En el caso de los antidepresivos (AD), se observaron efectos sobre los síntomas negativos, pero los mismos podrían explicarse en parte porque en las escalas se pueden confundir síntomas negativos primarios con secundarios relacionados, entre otros factores, con síntomas depresivos. Además, los efectos de algunos $\mathrm{AD}$, como la fluoxetina y la paroxetina, podrían estar mediados por un aumento de los niveles séricos de clozapina a través de la inhibición del citocromo CYP2D6. La fluvoxamina, que es un importante inhibidor del CYP2D6, no se recomienda en asociación con clozapina debido a la interacción farmacocinética.

Entre los estabilizadores del estado de ánimo, el valproato de sodio y el litio mejoraron los síntomas de psicosis, aunque en estudios de baja calidad. Un estudio de alta calidad con topiramato mostró eficacia para los síntomas positivos y negativos, mientras que los estudios de alta calidad de lamotrigina no mostraron resultados significativos. La memantina fue eficaz para síntomas negativos, pero se requieren estudios adicionales para validar estos resultados (Siskind et al., 2018).

\section{Tratamientos no farmacológicos I Terapia electroconvulsiva}

Se cumplen 85 años de utilización de la Terapia Electro Convulsiva (TEC) (Sinclair et al., 2019), técnica que surgió, precisamente, focalizada en el tratamiento de la esquizofrenia y que consiste en la inducción de crisis convulsivas a partir de un estímulo eléctrico que se administra a través de electrodos, generalmente bilaterales, colocados en el cuero cabelludo.A este tipo de TEC, se la llama inmodificada. La TEC original fue modificada por el uso de miorrelajantes y de anestesia general, siendo ésta técnica la de más utilizada a nivel mundial. No obstante, existen situaciones donde todavía se utiliza la TEC inmodificada (vinculado a la dificultad en acceder a miorrelajantes y anestésicos) y sigue siendo indicada con el agregado que, en tales lugares y tal vez por la mayor efectividad del procedimiento o por el costo menor de los antipsicóticos, su uso resulta más frecuente que en países con mayor nivel de industrialización. 
En la última década se observa un interés mayor en la utilización de TEC para el tratamiento de la esquizofrenia en los EE.UU. y en algunos países europeos, el cual había disminuido considerablemente a partir de la llegada de los antipsicóticos, dando lugar a que la depresión sea la principal indicación de TEC en la actualidad (Sanghani et al., 2018). En el tratamiento de la esquizofrenia se ha limitado la indicacion de TEC a situaciones específicas tales como:

- ERT.

- Episodio de descompensación aguda con alta suicidabilidad (Chan et al., 2019).

- Esquizofrenia catatónica (Chan et al., 2019).

La ERT (existen diferentes acepciones que buscan definirla, utilizando en la mayoría de los estudios el criterio de falta de respuesta a por lo menos dos esquemas con fármacos antipsicóticos) (Nucifora et al., 2019), por la complejidad que implica desde el aspecto clínico-pronóstico y la severidad (persistencia de la neurotoxicidad), resulta una condición cuyo estudio e interés en investigarla se incrementa progresivamente y es aquí donde la TEC permanece como una indicación que conserva su vigencia (Fink \& Sackeim, 1996).

En relación a la indicación de TEC en la ERT, la evidencia muestra que tanto sola como asociada a fármacos antipsicóticos (Kaster et al., 2017), se observa que hay mayor respuesta a la TEC que a los antipsicóticos por separado (Sackeim, 2003; Zheng et al., 2016). La combinación de TEC más antipsicóticos resulta avalada por la evidencia, inclinándose más a la combinación con clozapina. En tal sentido, un meta análisis realizado por Lally y cols. (2016), encuentra que el $66 \%$ de los pacientes evaluados en cinco estudios respondieron a clozapina asociada a TEC, reportándose recaída sintomatológica en el $32 \%$ de los pacientes después de finalizada la TEC y efectos adversos, como trastornos en la memoria, en el 14\% de los pacientes. De los cinco estudios evaluados, solo el de Petrides y cols. (2015) fue realizado a doble ciego, siendo el mismo de tipo prospectivo y randomizado, de ocho semanas de duración. Esta última línea de investigación incluyó 39 pacientes resistentes al tratamiento con clozapina, que se dividieron en dos grupos: pacientes tratados con clozapina únicamente y pacientes tratados con clozapina más TEC bilateral (promedio 16 sesiones). En el primer grupo no se observó respuesta, mientras que en el segundo grupo la respuesta (reducción de más del 40\% de los síntomas, medidos con BPRS y CGI-S) fue del 50\%. (dato coincidente con la literatura previa). La mejoría fue evidente en los sín- tomas positivos, pero no en la sintomatología negativa; tampoco se encontraron diferencias en lo relativo a efectos adversos de tipo cognitivo, lo cual se encuentra a contramano de lo que muestran otras investigaciones, requiriéndose, por lo tanto, nuevos estudios (Chan et al., 2019) que profundicen en aspectos como la calidad de vida y la función cognitiva antes de determinar con certeza una u otra posibilidad. Los efectos adversos detectados no son, en general, de importancia ni sostenidos en el tiempo, caracterizándose por cefaleas, náuseas y leve excitación post TEC (Kim et al., 2018).

En cuanto a los factores predictores de respuesta al tratamiento, podemos decir que la escasa respuesta al tratamiento con TEC más antispicóticos, tiende a asociarse con mayor duración del episodio, ausencia de síntomas afectivos y más severidad de los síntomas negativos. Asimismo, como predictores de buena respuesta al mencionado tratamiento, encontramos: edad temprana, menor duración de la enfermedad o del episodio, más ingresos y poca historia familiar de esquizofrenia. En relación al sexo, los estudios informan que el sexo juega un rol crítico en determinar las características de la enfermedad y por ende, la predicción de la respuesta al tratamiento (Chanpattana et al., 1999).

El tiempo que demora en observarse mejoría signo sintomatológica con la aplicación de TEC variará en función de los estudios que se evalúen y probablemente, la población objeto de estudio (diferente composición racial) (Wang et al., 2015). En tal sentido, mientras el trabajo de Yi Wen Chan (Chan et al., 2019) objetiva que el $80 \%$ de los pacientes responden en las primeras seis sesiones (sugiriendo que un paciente que no evidencia evolución favorable después de la sexta sesión, existen menos posibilidades que lo haga posteriormente), Petrides y cols. (2015) postulan que tal respuesta alcanza su máximo entre las sesiones 12 y 16 .

Respecto a la técnica utilizada y la respuesta de la TEC en la ERT, la mayor parte de los estudios que hacen hincapié en tal aspecto, postulan que no existirían diferencia entre la técnica donde los electrodos se ubican bi frontalmente y aquella donde lo hacen bi temporalmente (Chan et al., 2019).

El riesgo de recaída tras un tratamiento exitoso con TEC es una condición posible, particularmente en pacientes con historia de resistencia a tratamientos previos. Las investigaciones postulan que un descenso gradual en las aplicaciones de TEC o su continuidad en el tiempo deben ser las estrategias terapéuticas utilizadas en este tipo de pacientes (Braga et al., 2019). En igual forma, la combinación de TEC con antipsicóticos disminuye más la factibilidad de recaída que la 
aplicación de TEC o la administración de antipsicóticos por separado (Chanpattana et al., 1999).

Por lo expuesto, y en función de la contundencia de la evidencia existente, este consenso recomienda la utilización de Terapia Convulsiva en ERT.

En relación a las intervenciones focalizadas en estimulación del SNC, numerosos estudios han sido direccionados en torno al tratamiento de la esquizofrenia resistente (Rajji et al., 2013) sin resultados concluyentes.La intervención de este tipo más estudiada ha sido la Estimulación Magnética Transcraneal (EMT), la cual se caracteriza por ser no invasiva e impactar en la funcionalidad del cerebro a través de inducir modificaciones de la corriente eléctrica, y por ende en la neurotransmisión específica, a partir de cambios rápidos en el campo magnético. En el tratamiento de la esquizofrenia su indicación ha sido propuesta teniendo en cuenta la refractariedad que puede ser observable a los tratamientos antipsicóticos habituales, como así también considerando los efectos adversos de los mismos. Existen líneas de investigación que apoyan la indicación de EMT principalmente en pacientes con esquizofrenia donde predominan los síntomas negativos (Zhuo et al., 2019), resaltando de todas formas la necesidad de ser avalado lo dicho por otros estudios que trabajen con muestras de mayor tamaño. En sintomatología productiva de corte alucinatoria, si bien existen estudios que muestran leve respuesta, carecen de solidez, consistencia y estandarización que los legitimen como evidencia segura (Dougall et al., 2015).

La EMT, tiene a su favor que no es invasiva y presenta un buen perfil de tolerancia. También cuenta con evidencia parcial de ser efectiva en la sintomatología negativa de la esquizofrenia (Valiengo et al., 2020), pero al igual que el resto de las técnicas (incluida la Estimulación Magneto Convulsiva) requiere de mayor aval de evidencia.

\section{Esquizofrenia ultrarresistente (es- quizofrenia resistente a clozapina)}

La clozapina es el fármaco de elección ante el diagnóstico de ERT. Aproximadamente el 30\% de los pacientes diagnosticados con ERT, tratados adecuadamente con clozapina, no responden al tratamiento. Estos pacientes son conocidos como "resistentes a la clozapina" (Barretto et al., 2009), "super-resistentes" (Henna Neto \& Elkis, 2007) o "ultrarresistentes" (Mouaffak et al., 2006). Esta escasa o parcial respuesta a la clozapina parece estar condicionada por los siguientes factores:
- Factores farmacogenéticos: variaciones genéticas de los enzimas CYP1A2, CYP3A4, CYP2D6 pueden desempeñar un importante papel en la eficacia de la clozapina.

- Factores farmacodinámicos: la respuesta inadecuada puede estar relacionada con polimorfismos de los genes que regulan en los receptores D1, D3, 5HT2a, 5HT2c, 5HT6 (Mancama et al., 2002).

- Factores neuroestructurales: existen discrepancias al considerar anormalidades estructurales como causa de alteraciones en la eficacia de la clozapina (Arango et al., 2003).

- Factores metabólicos: disminución del metabolismo cortical en áreas frontales, que podría estar asociado a una peor respuesta a clozapina (Potkin et al., 2003).

Desde hace años la esquizofrenia resistente a la clozapina o ultrarresistente ha sido objeto de múltiples estudios, la mayoría consistentes en pequeñas muestras en las que se observa la evolución de los pacientes tras diferentes estrategias de potenciación de la clozapina mediante la asociación de antipsicóticos, eutimizantes o antidepresivos entre otros, siendo estos pacientes los que podrían consumir más del $97 \%$ de los costes de la esquizofrenia (Davies \& Drummond, 1994).

La esquizofrenia ultrarresistente al tratamiento ha sido escasamente definida en la bibliografía consultada. Se han intentado realizar propuestas de definiciones entre las que destaca la propuesta realizada por Mouaffak (Mouaffak et al., 2006) que considera cuatro criterios:

A. Condición de refractariedad a la clozapina definida como al menos 8 semanas de tratamiento con clozapina con concentraciones plasmáticas mayores a $350 \mu \mathrm{g} / \mathrm{L}$ con mejoría menor al $20 \%$ del total de la BPRS.

B. Persistencia de síntomas psicóticos positivos caracterizados por puntuar mayor o igual a 4 (moderado) en al menos 2 de los 4 ítems positivos de la escala BPRS.

C. Presencia de enfermedad moderadamente severa con una puntuación total BPRS mayor o igual a 45 y una puntuación mayor o igual a 4 (moderada) en la escala CGI-S.

D. Persistencia de enfermedad sin periodos de mayor estabilidad o mejoría en el funcionamiento social u ocupacional puntuando en la Escala de Evaluación de la Actividad Global (EEAG) (Bodlund et al., 1994) menor o igual a 40.

Esta aproximación al concepto de esquizofrenia ultrarresistente al tratamiento aparece por la necesidad por parte de los investigadores de aunar criterios para 
evitar heterogeneidades metodológicas. Del mismo modo, algunos autores han centrado sus esfuerzos en describir predictores de resistencia al tratamiento tales como: síntomas severos, presencia de graves efectos secundarios como sintomatología extrapiramidal, temprana edad de inicio del trastorno, subtipo de esquizofrenia paranoide (Umbricht et al., 2002), sexo masculino y mayor número de hospitalizaciones (Murray \& Van Os, 1998). Sin embargo, no se han hallado predictores específicos de super o ultra-resistencia (Henna Neto \& Elkis, 2007).

Han existido intentos por tratar de diferenciar pacientes diagnosticados con esquizofrenia resistente al tratamiento y pacientes diagnosticados con esquizofrenia super resistente al tratamiento mediante el seguimiento durante 6 meses de tres grupos de pacientes con esquizofrenia resistente y ultra-resistente al tratamiento: (sin resistencia al tratamiento, resistentes y super-resistentes) (Henna Neto \& Elkis, 2007). Inicialmente no existen ni diferencias demográficas entre ambos grupos ni en el número de hospitalizaciones, aunque los síntomas presentados por el grupo de super-resistentes son más severos además de puntuar más bajo en escalas de calidad de vida. El tratamiento de la esquizofrenia súper resistente se basa en la potenciación de la clozapina mediante otros psicofármacos, siendo generalmente un segundo antipsicótico una estrategia altamente frecuente en la práctica clínica (Taylor \& Smith, 2009). Los resultados obtenidos por estos autores al realizar un meta-análisis donde se recogen los datos de potenciación de la clozapina con diversos psicofármacos durante un periodo comprendido entre las 6 a las 16 semanas de estudio, concluyen que los beneficios terapéuticos de la potenciación comparada con placebo son escasos, lo que conlleva importantes repercusiones en la práctica clínica, donde estas estrategias son frecuentes. Finalmente, cuando los intentos de potenciación de clozapina con otros antipsicóticos fallan, se ha propuesto el cambio de la clozapina a otro antipsicótico aunque esta estrategia ha demostrado un débil nivel de evidencia (Miller et al., 2004) y la olanzapina es el antipsicótico que se inicia con más frecuencia (Lindenmayer et al., 2002). La TEC (Tang \& Ungvari, 2003), la EMT (Rosa et al., 2007) y la terapia cognitivo conductual (Valmaggia et al., 2005) son otros tratamientos no farmacológicos indicados en el tratamiento de la ERT.

\section{Prevalencia, clínica y aspectos psicopa- tológicos}

Existen pocos datos en el momento actual centrados en los aspectos clínicos y psicopatológicos de la ERT y la esquizofrenia ultra resistente al tratamiento. Un meta análisis (Hegarty et al., 1994) de la literatura actual sobre el tratamiento de la esquizofrenia observa que, tras la introducción del tratamiento antipsicótico, sólo el $48 \%$ de los pacientes que padecen esquizofrenia tiene una evolución favorable; $y$ en un primer episodio, aproximadamente un $20 \%$ de los pacientes no responden de forma adecuada tras un año de tratamiento (Lieberman et al., 1993). Generalmente se acepta que entre el 20-30\% de los pacientes que padecen esquizofrenia no responden al tratamiento antipsicótico convencional, aunque en revisiones recientes esta cifra eleva hasta el 60\% (Meltzer \& Kostakoglu, 2001). La edad de inicio de la esquizofrenia difiere entre el varón, de 15 a 25 años de la mujer, de 25 a 35 años, observándose una influencia del sexo en la evolución de la enfermedad, más favorable y con menor deterioro en el caso de la mujer, a pesar de presentar la misma prevalencia. Estudios demográficos indican una diferencia de aproximadamente dos años respecto al inicio del trastorno en varones al comparar pacientes que padecen esquizofrenia no resistente al tratamiento con pacientes que padecen ERT (Meltzer et al., 1997), cuya media de edad en el inicio de la enfermedad ronda los 17 años (comparado con una media de 20 años en varones con esquizofrenia no resistente al tratamiento) (Henna Neto \& Elkis, 2007). Otros autores, en estudios retrospectivos centrándose en la edad de inicio del trastorno, observan datos similares en pacientes no resistentes al tratamiento. En este caso la edad de inicio de la enfermedad se encuentra entre los 21 y los 23 años y en pacientes con esquizofrenia resistente al tratamiento y tratados con clozapina una media de 18 años (Castro \& Elkis, 2007). En relación con el número de episodios de la enfermedad, tiempo de enfermedad no tratada, historia de abusos de tóxicos o complicaciones obstétricas, no se han encontrado diferencias significativas entre ambos grupos de pacientes (Lindenmayer et al., 2002), así como en la presencia de antecedentes familiares en pacientes refractarios al tratamiento (Meltzer et al., 1997). En conclusión, podemos indicar como factores demográficos típicos de le ERT el sexo masculino, edad de inicio del trastorno temprana y, por lo tanto, mayor duración del trastorno, incremento en número de descompen- 
saciones (Huber et al. 2008), pobre estado premórbido, importante tiempo de psicosis no tratada, historia familiar de esquizofrenia y ausencia de factores precipitantes del trastorno.

En relación con la psicopatología, algunos autores han intentado diferenciar a nivel psicopatológico a los pacientes incluidos en el grupo de ERT mediante la aplicación de numerosas escalas. Se realizaron varios intentos tratando de homogeneizar grupos de pacientes diagnosticados con ERT y medir posteriormente síntomas psicopatológicos con la finalidad de delimitar posibles patrones psicopatológicos en ellos. De esta forma, en un trabajo se evaluaron a 157 pacientes incluidos en el grupo de esquizofrenia resistente al tratamiento aplicando la escala PANSS, concluyen que no existen diferencias significativas en relación con pacientes incluidos en el grupo de no resistentes al tratamiento (Lindenmayer et al., 2002). Utilizando la escala BPRS el grupo de McMahon et al. (2002), realizan el primer estudio que intenta recoger la psicopatología de una muestra grande de pacientes resistentes al tratamiento que no responden a tratamiento convencional. Identifican un modelo sindrómico que incluye síntomas de distorsión de la realidad, desorganización y síntomas negativos, ya identificados por otros autores (Arndt et al., 1991) e incluyen el factor ansiedad/depresión. Este modelo se muestra invariable en estos pacientes tras seis meses de tratamiento correcto, mediante la administración de clozapina, lo que sugiere que la evaluación de los síntomas utilizando BPRS se mantiene estable incluso tras la administración del tratamiento indicado para estos pacientes. Posteriormente, otro grupo de investigadores, utilizando esta misma escala en una muestra de 96 pacientes diagnosticados de ERT, presentaron un modelo en el que, al igual que en modelos previos, se incluyen síntomas negativos/desorganización, depresión y síntomas positivos pero, este nuevo estudio, incluyeron hostilidad/tensión (Alves et al., 2003). Otros autores discuten si la disfunción cognitiva o la probabilidad de suicidio deberían también estar incluidos en las características clínicas de la ERT (Buckley \& Shendarkar, 2005).

En conclusión, podríamos afirmar que la evidencia es pobre debido a varios factores, entre ellos los múltiples dominios sintomáticos y esto podría determinar resistencia a los psicofármacos desde el inicio de la enfermedad. En el futuro, una estrategia que complemente el mapeo cognitivo, los neurocircuitos y la genética de los trastornos mentales podría producir una nueva clasificación de enfermedades, proporcionando un mejor marco para los estudios clínicos y posiblemente mejores objetivos de tratamiento. Se podría ar- gumentar que una nueva y más precisa definición de esquizofrenia ultrarresistente podría conducir a una estrategia de tratamiento mejor y más temprano y de esta forma disminuir la carga económica y de calidad de vida que conlleva esta enfermedad.

Las diferentes revisiones sistemáticas y meta análisis, muestran resultados dispares en los pacientes con esquizofrenia ultrarresistente o resistente a clozapina. Existe aún falta de consenso en la definición de este grupo y por lo tanto en la interpretación de los datos publicados, resulta imperiosa la necesidad de aunar esfuerzos y consensuar para continuar trabajando, dada la alta prevalencia y la escasa respuesta que ofrecemos a este importante grupo de pacientes, los cuales evolucionaran indefectiblemente a la cronicidad.

\section{Conclusiones}

Este es el primer consenso de expertos sobre ERT en Argentina. En el presente documento, se resume el resultado de una revisión de la bibliografía más relevante, y del debate posterior llevado a cabo por los miembros del grupo de expertos. De acuerdo con esta metodología, se arribó a un consenso por mayoría entre los miembros del panel. Las recomendaciones (Tabla 2) se basan en la evidencia disponible hasta el momento, y la experiencia de los autores en el tratamiento de pacientes con ERT. Las recomendaciones expuestas podrán ser de utilidad en los distintos ámbitos relacionados con el abordaje de las personas con esquizofrenia.

No obstante existen, todavía, limitaciones para llevar a cabo un consenso sobre la ERT. En primer lugar en lo relativo a la misma definición de ERT, ya que no están incluidos en ella ciertos especificadores clínicos (síntomas cognitivos y síntomas negativos) y no existen, hasta el momento, tratamientos efectivos para ellos. Una segunda limitación es la escasa evidencia científica sobre el tratamiento de los pacientes tratados con clozapina que presentan una respuesta parcial con persistencia de síntomas o falta de respuesta a la misma. En función de lo anterior, es necesario en un plazo de 3 años, revisar la nueva evidencia publicada y actualizar las recomendaciones, luego de un nuevo análisis y discusión.

Finalmente, este documento constituye un llamado de la atención sobre la problemática de la ERT tanto a nivel local como en el mundo. Es necesario, continuar con un trabajo interdisciplinario donde los distintos actores que intervienen, desde la atención primaria hasta los responsables de las políticas públicas, puedan colaborar con prácticas basadas en la evidencia, para mejorar la calidad de vida de las personas que sufren una ERT (ver Tabla 2). 
Tabla 2. Recomendaciones del Consenso de Expertos

\section{Comentarios y recomendaciones}

Falta de respuesta a dos antipsicóticos, uno de ellos de segunda generación (entre los de segunda generación risperidona, olanzapina, paliperidona, aripiprazol o brexipiprazol),

Definición de ERT durante 6 semanas, a dosis equivalentes iguales o mayores a $600 \mathrm{mg}$ de clorpromazina o a dosis plena si es un antipsicótico de segunda generación. Esta definición no incluye tratamientos psicosociales.

Especificadores clínicos Los especificadores clínicos son de gran importancia y deberían ser tenidos en cuenta en futuras definición de ERT (positivos, negativos y cognitivos).

Momento de aparición de la resistencia al tratamiento El momento de aparición de la resistencia al tratamiento podría influir en la clínica, en la fisiopatología, en el pronóstico y severidad, y en las decisiones terapéuticas.

Predictores de riesgo Aparición temprana de la enfermedad, sexo masculino, deterioro funcional global dentro de los primeros años, falta de respuesta temprana, duración de psicosis no tratada, recaída durante los primeros 6 meses, abuso de sustancias.

Pseudo-resistencia Evaluar dosis inadecuada, duración inadecuada del tratamiento, comorbilidades psiquiátricas.

Adherencia al tratamiento Para mejorar adherencia, se recomienda acompañantes terapéuticos, hospital de día o antipsicóticos de larga duración.

Comorbilidades Las comorbilidades medicas psiquiátricas podrían interferir sobre la mejoría clínica de los pacientes con ERT (ej. consumo de sustancias).

Escalas de evaluación Se recomienda el uso de escalas para evaluar síntomas, entre las escalas CGI, PANSS, BPRS, SANS para síntomas negativos y SAPS para síntomas positivos.

Estudios complementarios Se recomienda solicitar neuroimágenes, EEG, laboratorio analítico de rutina, perfil tiroideo, dosaje toxicológico, dosaje de niveles plasmáticos de antipsicóticos.

Tratamiento de la ERT La droga de elección para un paciente que fallo a dos antipsicóticos de diferente clase en tiempo y dosis adecuado es clozapina.

Aumentar los niveles plasmáticos de clozapina $\geq 350 \mathrm{ng} / \mathrm{ml}$.

Persistencia de síntomas positivos Combinar clozapina con otro antipsicótico de segunda generación. Esperar una respuesta tardía de la clozapina.

Aumentar los niveles plasmáticos de clozapina $\geq 350 \mathrm{ng} / \mathrm{ml}$.

Persistencia de síntomas negativos

Combinar con un fármaco no-antipsicótico.

Esperar una respuesta tardía de la clozapina.

Aumentar los niveles plasmáticos de clozapina $\geq 350 \mathrm{ng} / \mathrm{ml}$.

Persistencia de síntomas positivos y negativos

Combinar clozapina con otro antipsicótico de segunda generación.

Combinar con un fármaco no-antipsicótico.

Esperar una respuesta tardía de la clozapina.

TCC.

Aumentar los niveles plasmáticos de clozapina $\geq 350 \mathrm{ng} / \mathrm{ml}$.

Sin mejoría o experimenta un Combinar clozapina con otro antipsicótico de segunda generación. empeoramiento de la sintomatología con clozapina

Combinar con un fármaco no-antipsicótico.

Esperar una respuesta tardía de la clozapina.

TCC.

Combinar clozapina con otro antipsicótico de segunda o primera generación.

Agresión persistente Aumentación con estabilizadores del ánimo.

Aumentación con TEC.

Aumentación con antidepresivos.

Persistencia de ideación suicida

Aumentación con estabilizadores del ánimo.

Aumentación con TEC. 
Conflictos de intereses: los autores declaran no tener conflictos de intereses.

\section{Agradecimientos: los autores agradecen especialmente a la Dra. Valeria Gabiani, por su aporte como redactora científica.}

\section{Referencias bibliográficas}

Achim, A. M., Maziade, M., Raymond, E., Olivier, D., Mérette, C., \& Roy, M. A. (2011). How prevalent are anxiety disorders in schizophrenia? A meta-analysis and critical review on a significant association. Schizophrenia bulletin, 37(4), 811-821. https://doi.org/10.1093/schbul/sbp148

Agid, O., Arenovich, T., Sajeev, G., Zipursky, R. B., Kapur, S., Foussias, G., \& Remington, G. (2011). An algorithm-based approach to first-episode schizophrenia: response rates over 3 prospective antipsychotic trials with a retrospective data analysis. The Journal of clinical psychiatry, 72(11), 14391444. https://doi.org/10.4088/JCP.09m05785yel

Agid, O., Kapur, S., Arenovich, T., \& Zipursky, R. B. (2003). Delayed-onset hypothesis of antipsychotic action: a hypothesis tested and rejected. Archives of general psychiatry, 60(12), 1228-1235. https://doi.org/10.1001/ archpsyc.60.12.1228

Agid, O., Schulze, L., Arenovich, T., Sajeev, G., McDonald, K., Foussias, G., Fervaha, G., \& Remington, G. (2013). Antipsychotic response in first-episode schizophrenia: efficacy of high doses and switching. European neuropsychopharmacology : the journal of the European College of Neuropsychopharmacology, 23(9), 1017-1022. https://doi.org/10.1016/j. euroneuro.2013.04.010

Alphs, L., Nasrallah, H. A., Bossie, C. A., Fu, D. J., Gopal, S., Hough, D., \& Turkoz, I. (2016). Factors associated with relapse in schizophrenia despite adherence to long-acting injectable antipsychotic therapy. International clinical psychopharmacology, 31(4), 202-209. https://doi.org/10.1097/ $\underline{\text { YIC. } 0000000000000125}$

Altamura, A. C., Bassetti, R., Cattaneo, E., \& Vismara, S. (2005). Some biological correlates of drug resistance in schizophrenia: a multidimensional approach. The world journal of biological psychiatry : the official journal of the World Federation of Societies of Biological Psychiatry, 6 Suppl 2, 23-30. https://doi.org/10.1080/15622970510030027

Alves, T. M., Pereira, J. C., \& Elkis, H. (2005). The psychopathological factors of refractory schizophrenia. Revista brasileira de psiquiatria (Sao Paulo, Brazil : 1999), 27(2), 108-112. https://doi.org/10.1590/s151644462005000200007

American Psychiatric Association. (2013). Diagnostic and statistical manual of mental disorders (5ta. ed). https://doi.org/10.1176/appi. books.9780890425596

Anderson, V. M., Goldstein, M. E., Kydd, R. R., \& Russell, B. R. (2015a). Extensive gray matter volume reduction in treatment-resistant schizophrenia. The international journal of neuropsychopharmacology, 18(7), pyv016. https://doi.org/10.1093/ijnp/pyv016

Anderson, V. M., McIlwain, M. E., Kydd, R. R., \& Russell, B. R. (2015b). Does cognitive impairment in treatment-resistant and ultra-treatment-resistant schizophrenia differ from that in treatment responders?. Psychiatry research, 230(3), 811-818. https://doi.org/10.1016/j.psychres.2015.10.036 Andreasen, N. C. (1982). Negative symptoms in schizophrenia. Definition and reliability. Arch Gen Psychiatry; 39(7):784-788. doi:10.1001/archpsyc. 1982.04290070020005

Andreasen, N. C., Carpenter, W. T., Jr, Kane, J. M., Lasser, R. A., Marder, S. R., \& Weinberger, D. R. (2005). Remission in schizophrenia: proposed criteria and rationale for consensus. The American journal of psychiatry, 162(3), 441-449. https://doi.org/10.1176/appi.ajp.162.3.441

Arango, C., Breier, A., McMahon, R., Carpenter, W. T., Jr, \& Buchanan, R. W. (2003). The relationship of clozapine and haloperidol treatment response to prefrontal, hippocampal, and caudate brain volumes. The American journal of psychiatry, 160(8), 1421-1427. https://doi.org/10.1176/appi. ajp.160.8.1421
Arndt, S., Alliger, R. J., \& Andreasen, N. C. (1991). The distinction of positive and negative symptoms. The failure of a two-dimensional model. The British journal of psychiatry: the journal of mental science, 158, 317-322. https://doi.org/10.1192/bip.158.3.317

Barbas, H., García-Cabezas, M. Á., \& Zikopoulos, B. (2013). Frontal-thalamic circuits associated with language. Brain and language, 126(1), 49-61. https://doi.org/10.1016/j.bandl.2012.10.001

Barnes, T. R., Drake, R., Paton, C., Cooper, S. J., Deakin, B., Ferrier, I. N., Gregory, C. J., Haddad, P. M., Howes, O. D., Jones, I., Joyce, E. M., Lewis, S., Lingford-Hughes, A., MacCabe, J. H., Owens, D. C., Patel, M. X., Sinclair, J. M., Stone, J. M., Talbot, P. S., Upthegrove, R., ... Yung, A. R. (2020). Evidence-based guidelines for the pharmacological treatment of schizophrenia: Updated recommendations from the British Association for Psychopharmacology. Journal of psychopharmacology (Oxford, England), 34(1), 3-78. https://doi.org/10.1177/0269881119889296

Barretto, E. M., Kayo, M., Avrichir, B. S., Sa, A. R., Camargo, M. d., Napolitano, I. C., Nery, F. G., Pinto, J. A., Jr, Bannwart, S., Scemes, S., Di Sarno, E., \& Elkis, H. (2009). A preliminary controlled trial of cognitive behavioral therapy in clozapine-resistant schizophrenia. The Journal of nervous and mental disease, 197(11), 865-868. https://doi.org/10.1097/NMD.0b013e3181 be7422

Bilic, P., Jukic, V., Vilibic, M., Savic, A., \& Bozina, N. (2014). Treatment-resistant schizophrenia and DAT and SERT polymorphisms. Gene, 543(1), 125-132. https://doi.org/10.1016/j.gene.2014.03.050

Bleuler, E. (1911). Dementia Praecox oder Groupe der Schizophrenien. Deuticke.

Bodlund, O., Kullgren, G., Ekselius, L., Lindström, E., \& von Knorring, L. (1994). Axis V--Global Assessment of Functioning Scale. Evaluation of a self-report version. Acta psychiatrica Scandinavica, 90(5), 342-347. https://doi.org/10.1111/j.1600-0447.1994.tb01604.x

Bortolato, B., Miskowiak, K. W., Köhler, C. A., Vieta, E., \& Carvalho, A. F. (2015). Cognitive dysfunction in bipolar disorder and schizophrenia: a systematic review of meta-analyses. Neuropsychiatric disease and treatment, 11, 3111-3125. https://doi.org/10.2147/NDT.S76700

Bourque, J., Lakis, N., Champagne, J., Stip, E., Lalonde, P., Lipp, O., \& Mendrek, A. (2013). Clozapine and visuospatial processing in treatment-resistant schizophrenia. Cognitive Neuropsychiatry, 18(6), 615-630. https://doi. org/10.1080/13546805.2012.760917

Braga, R. J., John, M., Schooler, N. R., Bailine, S. H., Malur, C., Mendelowitz, A., \& Petrides, G. (2019). Continuation Electroconvulsive Therapy for Patients With Clozapine-Resistant Schizophrenia: A Pilot Study. The journal of ECT, 35(3), 156-160. https://doi.org/10.1097/YCT.0000000000000588

Braga, R. J., Mendlowicz, M. V., Marrocos, R. P., \& Figueira, I. L. (2005). Anxiety disorders in outpatients with schizophrenia: prevalence and impact on the subjective quality of life. Journal of psychiatric research, 39(4), 409-414. https://doi.org/10.1016/i.jpsychires.2004.09.003

Braw, Y., Benozio, A., \& Levkovitz, Y. (2012). Executive functioning during full and partial remission (positive and negative symptomatic remission) of schizophrenia. Schizophrenia Research, 2012;142(1-3), 122-128. https:// doi.org/10.1016/j.schres.2012.10.011

Breier, A., Buchanan, R. W., Kirkpatrick, B., Davis, O. R., Irish, D., Summerfelt, A., \& Carpenter, W. T., Jr (1994). Effects of clozapine on positive and negative symptoms in outpatients with schizophrenia. The American journal of psychiatry, 151(1), 20-26. https://doi.org/10.1176/ajp.151.1.20

Buchanan, R. W., Holstein, C., \& Breier, A. (1994). The comparative efficacy and long-term effect of clozapine treatment on neuropsychological test performance. Biological Psychiatry, 36(11), 717-725. https://doi. org/10.1016/0006-3223(94)90082-5

Buchanan, R. W., Keefe, R. S., Umbricht, D., Green, M. F., Laughren, T., \& Marder, S. R. (2011). The FDA-NIMH-MATRICS guidelines for clinical trial design of cognitive-enhancing drugs: what do we know 5 years later?. Schizophrenia bulletin, 37(6), 1209-1217. https://doi.org/10.1093/schbul/sbq038 
Buchanan, R. W., Kreyenbuhl, J., Kelly, D. L., Noel, J. M., Boggs, D. L., Fischer, B. A., Himelhoch, S., Fang, B., Peterson, E., Aquino, P. R., Keller, W., \& Schizophrenia Patient Outcomes Research Team (PORT) (2010). The 2009 schizophrenia PORT psychopharmacological treatment recommendations and summary statements. Schizophrenia bulletin, 36(1), 71-93. https://doi.org/10.1093/schbul/sbp116

Buckley, P. F., \& Gaughran, F. (Eds.). (2014). Treatment-refractory schizophrenia: A clinical conundrum. Springer-Verlag Publishing. https://doi. org/10.1007/978-3-642-45257-4

Buckley, P. F., \& Shendarkar, N. (2005). Treatment-refractory schizophrenia. Current opinion in psychiatry, 18(2), 165-173. https://doi. org/10.1097/00001504-200503000-00010

Buckley, P. F., Miller, B. J., Lehrer, D. S., \& Castle, D. J. (2009). Psychiatric comorbidities and schizophrenia. Schizophrenia bulletin, 35(2), 383-402. https://doi.org/10.1093/schbul/sbn135

Busner, J., \& Targum, S. D. (2007). The clinical global impressions scale: applying a research tool in clinical practice. Psychiatry (Edgmont ( $\mathrm{Pa}$. : Township)), 4(7), 28-37.

Carpenter, W. T. Jr., \& Kirkpatrick, B. (1988). The heterogeneity of the longterm course of schizophrenia. Schizophr Bull; 14(4):645-652. doi:10.1093/ schbul/14.4.645

Castle, D. J., \& Buckley, P. (2015). Schizophrenia. 2nd ed. Oxford University Press.

Castro, A. P., \& Elkis, H. (2007). Rehospitalization rates of patients with schizophrenia discharged on haloperidol, risperidone or clozapine. Revista brasileira de psiquiatria (Sao Paulo, Brazil : 1999), 29(3), 207-212. https://doi.org/10.1590/s1516-44462007000300004

Chan, C., Abdin, E., Seow, E., Subramaniam, M., Liu, J., Peh, C. X., \& Tor, P. C. (2019). Clinical effectiveness and speed of response of electroconvulsive therapy in treatment-resistant schizophrenia. Psychiatry and clinical neurosciences, 73(7), 416-422. https://doi.org/10.1111/pcn.12855

Chanpattana, W., Chakrabhand, M. L., Sackeim, H. A., Kitaroonchai, W., Kongsakon, R., Techakasem, P., Buppanharun, W., Tuntirungsee, Y., \& Kirdcharoen, N. (1999). Continuation ECT in treatment-resistant schizophrenia: a controlled study. The journal of ECT, 15(3), 178-192.

Chong, H. Y., Teoh, S. L., Wu, D. B., Kotirum, S., Chiou, C. F., \& Chaiyakunapruk, N. (2016). Global economic burden of schizophrenia: a systematic review. Neuropsychiatric disease and treatment, 12, 357-373. https://doi. org/10.2147/NDT.S96649.

Chouinard, G., Samaha, A. N., Chouinard, V. A., Peretti, C. S., Kanahara, N., Takase, M., \& Iyo, M. (2017). Antipsychotic-Induced Dopamine Supersensitivity Psychosis: Pharmacology, Criteria, and Therapy. Psychotherapy and psychosomatics, 86(4), 189-219. https://doi.org/10.1159/000477313

Corrales, A., Cetkovich-Bakmas, M., Corral, R., García Bonetto, G., Herbst, L., Lupo, C., Morra, C., Mosca, D., Strejilevich, S., Vilapriño, J. J., Vilapriño, M., Vázquez, G. (2020). Consenso Argentino sobre el diagnóstico y tratamiento del Trastorno depresivo mayor resistente al tratamiento (DRT). Vertex Rev Arg de Psiquiatr, Volumen XXXI, Suplemento especial segundo semestre 2020.

Correll, C. U., Frederickson, A. M., Kane, J. M., \& Manu, P. (2007). Does antipsychotic polypharmacy increase the risk for metabolic syndrome?. Schizophrenia research, 89(1-3), 91-100. https://doi.org/10.1016/j. schres.2006.08.017

Correll, C. U., Robinson, D. G., Schooler, N. R., Brunette, M. F., Mueser, K. T., Rosenheck, R. A., Marcy, P., Addington, J., Estroff, S. E., Robinson, J., Penn, D. L., Azrin, S., Goldstein, A., Severe, J., Heinssen, R., \& Kane, J. M. (2014). Cardiometabolic risk in patients with first-episode schizophrenia spectrum disorders: baseline results from the RAISE-ETP study. JAMA psychiatry, 71(12), 1350-1363. https://doi.org/10.1001/jamapsychiatry.2014.1314

Correll, C. U., Rummel-Kluge, C., Corves, C., Kane, J. M., \& Leucht, S. (2009). Antipsychotic combinations vs monotherapy in schizophrenia: a meta-analysis of randomized controlled trials. Schizophrenia bulletin, 35(2), 443-457. https://doi.org/10.1093/schbul/sbn018
Craig, T. K., Garety, P., Power, P., Rahaman, N., Colbert, S., Fornells-Ambrojo, M., \& Dunn, G. (2004). The Lambeth Early Onset (LEO) Team: randomised controlled trial of the effectiveness of specialised care for early psychosis. BMJ, 329(7474), 1067. https://doi.org/10.1136/bmj.38246.594873.7C

Crow, T. J. (1980). Positive and negative schizophrenic symptoms and the role of dopamine.Br J Psychiatry; 137:383-386.

Dal Santo, F., Jarratt-Barnham, I., González-Blanco, L., García-Portilla, M. P., Bobes, J., \& Fernández-Egea, E. (2020). Longitudinal effects of clozapine concentration and clozapine to $\mathrm{N}$-desmethylclozapine ratio on cognition: A mediation model. European Neuropsychopharmacology, 33, 158-163. https://doi.org/10.1016/j.euroneuro.2020.01.016

Davies, L. M., \& Drummond, M. F. (1994). Economics and schizophrenia: the real cost. BJP. Supplement, (25), 18-21.

De Bartolomeis, A., Balletta, R., Giordano, S., Buonaguro, E. F., Latte, G., \& Iasevoli, F. (2013). Differential cognitive performances between schizophrenic responders and non-responders to antipsychotics: Correlation with course of the illness, psychopathology, attitude to the treatment and antipsychotics doses. Psychiatry Research, 210(2), 387-395. https://doi.org/10.1016/j.psychres.2013.06.042

De Lucena, D., Fernandes, B. S., Berk, M., Dodd, S., Medeiros, D. W., Pedrini, M., Kunz, M., Gomes, F. A., Giglio, L. F., Lobato, M. I., Belmonte-de-Abreu, P. S., \& Gama, C. S. (2009). Improvement of negative and positive symptoms in treatment-refractory schizophrenia: A double-blind, randomized, placebo-controlled trial with memantine as add-on therapy to clozapine. Journal of Clinical Psychiatry, 70(10), 1416-1423. https://doi. org/10.4088/JCP.08m04935gry

Demjaha, A., Murray, R. M., McGuire, P. K., Kapur, S., \& Howes, O. D. (2012). Dopamine synthesis capacity in patients with treatment-resistant schizophrenia. The American journal of psychiatry, 169(11), 1203-1210. https://doi.org/10.1176/appi.ajp.2012.12010144

Dixon, L., Green-Paden, L., Delahanty, J., Lucksted, A., Postrado, L., \& Hall, J. (2001). Variables associated with disparities in treatment of patients with schizophrenia and comorbid mood and anxiety disorders. Psychiatric services (Washington, D.C.), 52(9), 1216-1222. https://doi.org/10.1176/ appi.ps.52.9.1216

Dougall, N., Maayan, N., Soares-Weiser, K., McDermott, L. M., \& McIntosh, A. (2015). Transcranial magnetic stimulation (TMS) for schizophrenia. The Cochrane database of systematic reviews, (8), CD006081. https:// doi.org/10.1002/14651858.CD006081.pub2

Egerton, A., Demjaha, A., McGuire, P., Mehta, M. A., \& Howes, O. D. (2010). The test-retest reliability of 18F-DOPA PET in assessing striatal and extrastriatal presynaptic dopaminergic function. Neuro Image, 50(2), 524-531. https://doi.org/10.1016/j.neuroimage.2009.12.058

Egerton, A., Murphy, A., Donocik, J., Anton, A., Barker, G. J., Collier, T., Deakin, B., Drake, R., Eliasson, E., Emsley, R., Gregory, C. J., Griffiths, K., Kapur, S., Kassoumeri, L., Knight, L., Lambe, E., Lawrie, S. M., Lees, J., Lewis, S., Lythgoe, D. J., ... Howes, O. D. (2021). Dopamine and Glutamate in Antipsychotic-Responsive Compared With Antipsychotic-Nonresponsive Psychosis: A Multicenter Positron Emission Tomography and Magnetic Resonance Spectroscopy Study (STRATA). Schizophrenia bulletin, 47(2), 505-516. https://doi.org/10.1093/schbul/sbaa128

Elkis, H., \& Buckley, P. F. (2016). Treatment-Resistant Schizophrenia. The Psychiatric clinics of North America, 39(2), 239-265. https://doi.org/10.1016/j.psc.2016.01.006

Essali, A., Al-Haj Haasan, N., Li, C., \& Rathbone, J. (2009). Clozapine versus typical neuroleptic medication for schizophrenia. The Cochrane database of systematic reviews, 2009(1), CD000059. https://doi. org/10.1002/14651858.CD000059.pub2

Farooq, S., Agid, O., Foussias, G., \& Remington, G. (2013). Using treatment response to subtype schizophrenia: proposal for a new paradigm in classification. Schizophrenia bulletin; 39(6), 1169-1172. https://doi. org/10.1093/schbul/sbt137

Fink, M., \& Sackeim, H. A. (1996). Convulsive therapy in schizophrenia?. Schizophrenia bulletin, 22(1), 27-39. https://doi.org/10.1093/sch$\underline{\mathrm{bul} / 22.1 .27}$ 
Fonseka, T. M., Richter, M. A., \& Müller, D. J. (2014). Second generation antipsychotic-induced obsessive-compulsive symptoms in schizophrenia: a review of the experimental literature. Current psychiatry reports, 16(11), 510. https://doi.org/10.1007/s11920-014-0510-8

Freudenreich, O., Henderson, D. C., Macklin, E. A., Evins, A. E., Fan, X., Cather, C., Walsh, J. P., \& Goff, D. (2009). CModafinil for Clozapine-Treated Schizophrenia Patients: A Double-Blind, Placebo-Controlled Pilot Trial. Journal of Clinical Psychiatry, 70(12), 1674-1680. https://doi. org/10.4088/JCP.08m04683.Modafinil

Frydecka, D., Beszłej, J. A., Gościmski, P., Kiejna, A., \& Misiak, B. (2015). Profiling cognitive impairment in treatment-resistant schizophrenia patients. Psychiatry Research, 235, 133-138. https://doi.org/10.1016/j.psychres.2015.11.028

Fujii, D. E., Ahmed, I., Jokumsen, M., \& Compton, J. M. (1997). The effects of clozapine on cognitive functioning in treatment-resistant schizophrenic patients. The Journal of neuropsychiatry and clinical neurosciences, 9(2), 240-245. https://doi.org/10.1176/jnp.9.2.240

Ganella, E. P., Bartholomeusz, C. F., Seguin, C., Whittle, S., Bousman, C., Phassouliotis, C., Everall, I., Pantelis, C., \& Zalesky, A. (2017). Functional brain networks in treatment-resistant schizophrenia. Schizophrenia research, 184, 73-81. https://doi.org/10.1016/j.schres.2016.12.008

Garay, C. J. (2018). Metacognición y psicoterapia. El enfoque metacognitivo en el abordaje de los trastornos emocionales. En: Garay, C. J., Korman, G. P. (Eds.). Innovaciones en los modelos cognitivo-conductuales (pp. 45-72). Akadia.

Garay, C. J., \& Sabatés, J. (2018). Panorama actual de los modelos cognitivo-conductuales para pacientes con esquizofrenia y otros trastornos psicóticos. En: Tolosa, D. (Ed.). Recursos psicoeducativos y cognitivo-conductuales para esquizofrenia. Akadia, p. 241-252.

Garay, C. J., Korman, G. K. (2018). Introducción. En: Garay, C. J., Korman, G. P. (Eds.). Innovaciones en los modelos cognitivo-conductuales (pp 13-20). Akadia.

Garay, C. J., Korman, G. P., \& Keegan, E. (2016). Terapia cognitivo-conductual contemporánea. En: Garay, C. J. (Ed.). Terapia cognitivo-conductual y Psicofarmacología. Una guía para combinar tratamientos en salud mental. (pp. 1-16). Akadia,

Gargoloff, P. (2005). Farmacoeconomía, Costos en Salud Mental. En: N. Marchand, \& A Monchablón. Tratado de Psiquiatría (pp. 1657-1676). Editorial Grupo Guía. Disponible en: https://es.scribd.com/document/430060407/Farmacoeconomia-Costos-en-Salud-Mental

Gargoloff, P., García-Bonetto, G., Galeno, R., Ortiz, E., Godino, A., Gris, E., \& Adrianzén C. (2009). Resultados clínicos de 3 años del estudio Schizophrenia Outpatients Health Outcomes (SOHO) en Argentina. Arch Neurocien, 14(3), 167-175. https://www.medigraphic.com/pdfs/arcneu/ ane-2009/ane093e.pdf

Gilbert, E., Mérette, C., Jomphe, V., Émond, C., Rouleau, N., Bouchard, R. H., Roy, M. A., Paccalet, T., \& Maziade, M. (2014). Cluster analysis of cognitive deficits may mark heterogeneity in schizophrenia in terms of outcome and response to treatment. European Archives of Psychiatry and Clinical Neuroscience, 264(4), 333-343. https://doi.org/10.1007/s00406-013-0463-7

Gillespie, A. L., Samanaite, R., Mill, J., Egerton, A., MacCabe, J. H. (2017). Is treatment-resistant schizophrenia categorically distinct from treatment-responsive schizophrenia? a systematic review. BMC Psychiatry; 17(1):12. doi:10.1186/s12888-016-1177-y

Gleeson, J. F., Alvarez-Jimenez, M., Cotton, S. M., Parker, A. G., \& Hetrick, S. (2010). A systematic review of relapse measurement in randomized controlled trials of relapse prevention in first-episode psychosis. Schizophrenia research, 119(1-3), 79-88. https://doi.org/10.1016/j.schres.2010.02.1073

Goff, D. C., Hill, M., \& Freudenreich, O. (2010). Strategies for improving treatment adherence in schizophrenia and schizoaffective disorder. The Journal of clinical psychiatry, 71 Suppl 2, 20-26. https://doi.org/10.4088/ JCP.9096sulcc.04
Goldberg, T. E., Greenberg, R. D., Griffin, S. J., Gold, J. M., Kleinman, J. E., Pickar, D., Schulz, S. C., \& Weinberger, D. R. (1993). The effect of clozapine on cognition and psychiatric symptoms in patients with schizophrenia. British Journal of Psychiatry, 162; 43-48. https://doi.org/10.1192/ bjp.162.1.43

Grace, J., Bellus, S. B., Raulin, M. L., Herz, M. I., Priest, B. L., Brenner, V., Donnelly, K., Smith, P., \& Gunn, S. (1996). Long-term impact of clozapine and psychosocial treatment on psychiatric symptoms and cognitive functioning. Psychiatric Services, 47(1), 41-45. https://doi.org/10.1176/ps.47.1.41 Gray, B. E., McMahon, R. P., Green, M. F., Seidman, L. J., Mesholam-Gately, R. I., Kern, R. S., Nuechterlein, K. H., Keefe, R. S., \& Gold, J. M. (2014). Detecting reliable cognitive change in individual patients with the MATRICS Consensus Cognitive Battery. Schizophrenia research, 159(1), 182187. https://doi.org/10.1016/j.schres.2014.07.032

Green M. F. (1996). What are the functional consequences of neurocognitive deficits in schizophrenia?. The American Journal of Psychiatry, 153(3), 321-330. https://doi.org/10.1176/ajp.153.3.321

Green, M. F. (2016). Impact of cognitive and social cognitive impairment on functional outcomes in patients with schizophrenia. Journal of Clinical Psychiatry, 77, 8-11. https://doi.org/10.4088/JCP.14074sulc.02

Haro, J. M., Altamura, C., Corral, R., Elkis, H., Evans, J., Krebs, M. O., Zink, M., Malla, A., Méndez, J. I., Bernasconi, C., Lalonde, J., \& Nordstroem, A. L. (2018). Understanding the course of persistent symptoms in schizophrenia: Longitudinal findings from the pattern study. Psychiatry research, 267, 56-62. https://doi.org/10.1016/j.psychres.2018.04.005

Hasan, A., Falkai, P., Wobrock, T., Lieberman, J., Glenthoj, B., Gattaz, W. F., Thibaut, F., Möller, H. J., \& World Federation of Societies of Biological Psychiatry (WFSBP) Task Force on Treatment Guidelines for Schizophrenia (2012). World Federation of Societies of Biological Psychiatry (WFSBP) Guidelines for Biological Treatment of Schizophrenia, part 1: update 2012 on the acute treatment of schizophrenia and the management of treatment resistance. The world journal of biological psychiatry : the official journal of the World Federation of Societies of Biological Psychiatry, 13(5), 318-378. https://doi.org/10.3109/15622975.2012.696143

Hecker, E. (1871). Die hebephrenie. Archiv für pathologische Anatomie und Physiologie und für klinische Medicin, 52(3), 394-429.

Hegarty, J. D., Baldessarini, R. J., Tohen, M., Waternaux, C., \& Oepen, G. (1994). One hundred years of schizophrenia: a meta-analysis of the outcome literature. The American journal of psychiatry, 151(10), 1409-1416. https://doi.org/10.1176/ajp.151.10.1409

Henna Neto, J., \& Elkis, H. (2007). Clinical aspects of super-refractory schizophrenia: a 6-month cohort observational study. Revista brasileira de psiquiatria, 29(3), 228-232. https://doi.org/10.1590/s1516-44462007000300007 Holleran, L., Ahmed, M., Anderson-Schmidt, H., McFarland, J., Emse1l, L., Leemans, A., Scanlon, C., Dockery, P., McCarthy, P., Barker, G. J., McDonald, C., \& Cannon, D. M. (2014). Altered interhemispheric and temporal lobe white matter microstructural organization in severe chronic schizophrenia. Neuropsychopharmacology : official publication of the American College of Neuropsychopharmacology, 39(4), 944-954. https:// doi.org/10.1038/npp.2013.294

Hor, K., \& Taylor, M. (2010). Suicide and schizophrenia: a systematic review of rates and risk factors. Journal of psychopharmacology (Oxford, England), 24(4 Suppl), 81-90. https://doi.org/10.1177/1359786810385490

Howes, O. D., \& Kapur, S. (2014). A neurobiological hypothesis for the classification of schizophrenia: type A (hyperdopaminergic) and type B (normodopaminergic). The British journal of psychiatry : the journal of mental science, 205(1), 1-3. https://doi.org/10.1192/bjp.bp.113.138578

Howes, O. D., Kambeitz, J., Kim, E., Stahl, D., Slifstein, M., Abi-Dargham, A., \& Kapur, S. (2012). The nature of dopamine dysfunction in schizophrenia and what this means for treatment. Archives of general psychiatry, 69(8), 776-786. https://doi.org/10.1001/archgenpsychiatry.2012.169 
Howes, O. D., McCutcheon, R., Agid, O., de Bartolomeis, A., van Beveren, N. J., Birnbaum, M. L., Bloomfield, M. A., Bressan, R. A., Buchanan, R. W., Carpenter, W. T., Castle, D. J., Citrome, L., Daskalakis, Z. J., Davidson, M., Drake, R. J., Dursun, S., Ebdrup, B. H., Elkis, H., Falkai, P., Fleischacker, W. W., ... Correll, C. U. (2017). Treatment-Resistant Schizophrenia: Treatment Response and Resistance in Psychosis (TRRIP) Working Group Consensus Guidelines on Diagnosis and Terminology. The American journal of psychiatry, 174(3), 216-229. https://doi.org/10.1176/appi. ajp.2016.16050503

Howes, O. D., Vergunst, F., Gee, S., McGuire, P., Kapur, S., \& Taylor, D. (2012). Adherence to treatment guidelines in clinical practice: study of antipsychotic treatment prior to clozapine initiation. The British journal of psychiatry: the journal of mental science, 201(6), 481-485. https://doi. org/10.1192/bjp.bp.111.105833

Huber, C. G., Naber, D., \& Lambert, M. (2008). Incomplete remission and treatment resistance in first-episode psychosis: definition, prevalence and predictors. Expert opinion on pharmacotherapy, 9(12), 2027-2038. https:// doi.org/10.1517/14656566.9.12.2027

Iasevoli, F., Giordano, S., Balletta, R., Latte, G., Formato, M. V., Prinzivalli, E., De Berardis, D., Tomasetti, C., \& de Bartolomeis, A. (2016). Treatment resistant schizophrenia is associated with the worst community functioning among severely-ill highly-disabling psychiatric conditions and is the most relevant predictor of poorer achievements in functional milestones. Progress in Neuro-Psychopharmacology and Biological Psychiatry, 65, 3448. https://doi.org/10.1016/j.pnpbp.2015.08.010

Iqbal, E., Govind, R., Romero, A., Dzahini, O., Broadbent, M., Stewart, R., Smith, T., Kim, C. H., Werbeloff, N., MacCabe, J. H., Dobson, R., \& Ibrahim, Z. M. (2020). The side effect profile of Clozapine in real world data of three large mental health hospitals. PloS one, 15(12), e0243437. https://doi. org/10.1371/journal.pone.0243437

Ismail, Z., Wessels, A. M., Uchida, H., Ng, W., Mamo, D. C., Rajji, T. K., Pollock, B. G., Mulsant, B. H., \& Bies, R. R. (2012). Age and sex impact clozapine plasma concentrations in inpatients and outpatients with schizophrenia. The American journal of geriatric psychiatry: official journal of the American Association for Geriatric Psychiatry, 20(1), 53-60. https://doi. org/10.1097/JGP.0b013e3182118318

Jääskeläinen, E., Juola, P., Hirvonen, N., McGrath, J. J., Saha, S., Isohanni, M., Veijola, J., \& Miettunen, J. (2013). A systematic review and meta-analysis of recovery in schizophrenia. Schizophrenia bulletin, 39(6), 1296-1306. https://doi.org/10.1093/schbul/sbs130

Jablensky, A. (2006). Subtyping schizophrenia: implications for genetic research.Mol Psychiatry; 11(9):815-836. doi:10.1038/sj.mp.4001857

Jauhar, S., Veronese, M., Nour, M. M., Rogdaki, M., Hathway, P., Turkheimer, F. E., Stone, J., Egerton, A., McGuire, P., Kapur, S., \& Howes, O. D. (2019). Determinants of treatment response in first-episode psychosis: an18F-DOPA PET study.Molecular psychiatry, 24(10), 1502-1512. https:// doi.org/10.1038/s41380-018-0042-4

Jones, P. B., Barnes, T. R., Davies, L., Dunn, G., Lloyd, H., Hayhurst, K. P., Murray, R. M., Markwick, A., \& Lewis, S. W. (2006). Randomized controlled trial of the effect on Quality of Life of second- vs first-generation antipsychotic drugs in schizophrenia: Cost Utility of the Latest Antipsychotic Drugs in Schizophrenia Study (CUtLASS 1). Archives of general psychiatry, 63(10), 1079-1087. https://doi.org/10.1001/archpsyc.63.10.1079

Joober, R., Rouleau, G. A., Lal, S., Bloom, D., Lalonde, P., Labelle, A., \& Benkelfat, C. (2005). Increased prevalence of schizophrenia spectrum disorders in relatives of neuroleptic-nonresponsive schizophrenic patients. Schizophrenia research, 77(1), 35-41. https://doi.org/10.1016/j. schres.2005.01.008

Joober, R., Rouleau, G. A., Lal, S., Dixon, M., O'Driscoll, G., Palmour, R., Annable, L., Bloom, D., Lalonde, P., Labelle, A., \& Benkelfat, C. (2002). Neuropsychological impairments in neuroleptic-responder vs. -nonresponder schizophrenic patients and healthy volunteers. Schizophrenia Research, 53(3), 229-238. https://doi.org/10.1016/S0920-9964(01)00279-1

Kahlbaum, K. (2012). La Catatonía o locura de tensión. "Die Katatonie oder das Spannungsirresein" [1874]. Extracto. Vertex Rev Arg de Psiquiatr, Volumen XXIII (104):312-320.
Kanahara, N., Kimura, H., Oda, Y., Ito, F., \& Iyo, M. (2021). Recent discussions on dopamine supersensitivity psychosis: Eight points to consider when diagnosing treatment-resistant schizophrenia.Current neuropharmacology, 10.2174/1570159X19666210125152815. Advance online publication. https://doi.org/10.2174/1570159X19666210125152815

Kane, J. M., Agid, O., Baldwin, M. L., Howes, O., Lindenmayer, J. P., Marder, S., Olfson, M., Potkin, S. G., \& Correll, C. U. (2019). Clinical Guidance on the Identification and Management of Treatment-Resistant Schizophrenia. The Journal of clinical psychiatry, 80(2), 18com12123. https:// doi.org/10.4088/ICP.18com12123

Kane, J., Honigfeld, G., Singer, J., Meltzer, H. (1988). Clozapine for the treatment-resistant schizophrenic. A double-blind comparison with chlorpromazine. Arch Gen Psychiatry; 45(9):789-796. doi:10.1001/archpsyc.1988.01800330013001

Kaster, T. S., Daskalakis, Z. J., \& Blumberger, D. M. (2017). Clinical Effectiveness and Cognitive Impact of Electroconvulsive Therapy for Schizophrenia: A Large Retrospective Study. The Journal of clinical psychiatry, 78(4), e383-e389. https://doi.org/10.4088/JCP.16m10686

Kay, S. R., Fiszbein, A., \& Opler, L. A. (1987). The positive and negative syndrome scale (PANSS) for schizophrenia. Schizophrenia bulletin, 13(2), 261-276. https://doi.org/10.1093/schbul/13.2.261

Keefe, R. S. E., Silverman, J. M., Lees Roitman, S. E., Harvey, P. D., Duncan, M. A., Alroy, D., Siever, L. J., Davis, K. L., \& Mohs, R. C. (1994). Performance of nonpsychotic relatives of schizophrenic patients on cognitive tests. Psychiatry Research, 53(1), 1-12. https://doi.org/10.1016/01651781(94)90091-4

Keefe, R. S., \& Fenton, W. S. (2007). How should DSM-V criteria for schizophrenia include cognitive impairment?. Schizophrenia bulletin, 33(4), 912-920. https://doi.org/10.1093/schbul/sbm046

Keegan, E., Garay, C. J. (2007). Terapia cognitivo-conductual de la esquizofrenia. Vertex Rev Arg de Psiquiatr, 18(76):423-427.

Keepers, G. A., Fochtmann, L. J., Anzia, J. M., Benjamin, S., Lyness, J. M., Mojtabai, R., Servis, M., Walaszek, A., Buckley, P., Lenzenweger, M. F., Young, A. S., Degenhardt, A., Hong, S. H., \& (Systematic Review) (2020). The American Psychiatric Association Practice Guideline for the Treatment of Patients With Schizophrenia. The American journal of psychiatry, 177(9), 868-872. https://doi.org/10.1176/appi.ajp.2020.177901

Kelly, D. L., Sullivan, K. M., McEvoy, J. P., McMahon, R. P., Wehring, H. J., Gold, J. M., Liu, F., Warfel, D., Vyas, G., Richardson, C. M., Fischer, B. A., Keller, W. R., Koola, M. M., Feldman, S. M., Russ, J. C., Keefe, R. S. E., Osing, J., Hubzin, L., August, S., ... Buchanan, R. W. (2015). Adjunctive Minocycline in Clozapine-Treated Schizophrenia Patients with Persistent Symptoms. Journal of Clinical Psychopharmacology, 35(4), 374-381. https://doi.org/10.1097/JCP.0000000000000345

Kennedy, J. L., Altar, C. A., Taylor, D. L., Degtiar, I., \& Hornberger, J. C. (2014). The social and economic burden of treatment-resistant schizophrenia: a systematic literature review. International clinical psychopharmacology, 29(2), 63-76. https://doi.org/10.1097/YIC.0b013e32836508e6

Kim, E., Howes, O. D., Veronese, M., Beck, K., Seo, S., Park, J. W., Lee, J. S., Lee, Y. S., \& Kwon, J. S. (2017). Presynaptic Dopamine Capacity in Patients with Treatment-Resistant Schizophrenia Taking Clozapine: An [18F]DOPA PET Study. Neuropsychopharmacology : official publication of the American College of Neuropsychopharmacology, 42(4), 941-950. https://doi.org/10.1038/npp.2016.258

Kim, J. H., Youn, T., Choi, J. G., Jeong, S. H., Jung, H. Y., Kim, Y. S., \& Chung, I. W. (2018). Combination of Electroconvulsive Therapy and Clozapine in Treatment-Resistant Schizophrenia. Psychiatry investigation, 15(8), 829-835. https://doi.org/10.30773/pi.2018.05.15

Kleist, K. (1923). Die auffassung der schizophrenien als systemkrankheiten. Klin J wochenschr, 2:962-965.

Klingelhoefer, L., \& Reichmann, H. (2015). Pathogenesis of Parkinson disease--the gut-brain axis and environmental factors. Nature reviews. Neurology, 11(11), 625-636. https://doi.org/10.1038/nrneurol.2015.197 
Köhler-Forsberg, O., Horsdal, H. T., Legge, S. E., MacCabe, J. H., \& Gasse, C. (2017). Predictors of Nonhospitalization and Functional Response in Clozapine Treatment: A Nationwide, Population-Based Cohort Study. Journal of clinical psychopharmacology, 37(2), 148-154. https://doi. org/10.1097/JCP.0000000000000649

Kraepelin, E. (1883). Compendium der psychiatrie. Barth.

Kraepelin, E. (1996). La demencia precoz. Editorial Polemos.

Kravariti, E., Demjaha, A., Zanelli, J., Ibrahim, F., Wise, C., MacCabe, J. H., Reichenberg, A., Pilecka, I., Morgan, K., Fearon, P., Morgan, C., Doody, G. A., Donoghue, K., Jones, P. B., Kaçar, A. Ş., Dazzan, P., Lappin, J., \& Murray, R. M. (2019). Neuropsychological function at first episode in treatment-resistant psychosis: Findings from the ÆsOP-10 study. Psychological Medicine, 49(12), 2100-2110. https://doi.org/10.1017/S0033291718002957

Kushima, I., Aleksic, B., Nakatochi, M., Shimamura, T., Shiino, T., Yoshimi, A., Kimura, H., Takasaki, Y., Wang, C., Xing, J., Ishizuka, K., Oya-Ito, T., Nakamura, Y., Arioka, Y., Maeda, T., Yamamoto, M., Yoshida, M., Noma, H., Hamada, S., Morikawa, M., ... Ozaki, N. (2017). High-resolution copy number variation analysis of schizophrenia in Japan. Molecular psychiatry, 22(3), 430-440. https://doi.org/10.1038/mp.2016.88

Lacalle Remigio, J. R., Pastor Torres, L., Reyes Domínguez, A., Pérez Lozano, M. J., Âlvarez Gil, R. (1996). Metodología Delphi aplicada a la evaluación de procedimientos diagnósticos y terapéuticos. En: Consenso en Medicina. Metodología de expertos. EASP, p. 53-69.

Lally, J., \& Gaughran, F. (2019). Treatment resistant schizophrenia - review and a call to action. Irish journal of psychological medicine, 36(4), 279-291. https://doi.org/10.1017/ipm.2018.47

Lally, J., Tully, J., Robertson, D., Stubbs, B., Gaughran, F., \& MacCabe, J. H. (2016). Augmentation of clozapine with electroconvulsive therapy in treatment resistant schizophrenia: A systematic review and meta-analysis. Schizophrenia research, 171(1-3), 215-224. https://doi.org/10.1016/j. schres.2016.01.024

Lee, B. J., Kim, S. W., Kim, J. J., Yu, J. C., Lee, K. Y., Won, S. H., Lee, S. H., Kim, S. H., Kang, S. H., Kim, E., Kim, K., Piao, Y. H., \& Chung, Y. C. (2020). Defining Treatment Response, Remission, Relapse, and Recovery in First-Episode Psychosis: A Survey among Korean Experts. Psychiatry investigation, 17(2), 163-174. https://doi.org/10.30773/pi.2019.0240

Lee, M. A., Jayathilake, K., \& Meltzer, H. Y. (1999). A comparison of the effect of clozapine with typical neuroleptics on cognitive function in neuroleptic-responsive schizophrenia. Schizophrenia Research, 37(1), 1-11. https://doi.org/10.1016/S0920-9964(98)00145-5

Lehman, A. F., Lieberman, J. A., Dixon, L. B., McGlashan, T. H., Miller, A. L., Perkins, D. O., Kreyenbuhl, J., American Psychiatric Association, \& Steering Committee on Practice Guidelines (2004). Practice guideline for the treatment of patients with schizophrenia, second edition. The American journal of psychiatry, 161(2 Suppl), 1-56.

Leonhard, K. (1957). Aufeilung den Endogenen Psychosen. Akademie.

Leucht, S. (2014). Measurements of response, remission, and recovery in schizophrenia and examples for their clinical application. J Clin Psychiatry;75 Suppl 1:8-14. doi:10.4088/JCP.13049su1c.02

Leucht, S., Davis, J. M., Engel, R. R., Kane, J. M., \& Wagenpfeil, S. (2007). Defining 'response' in antipsychotic drug trials: recommendations for the use of scale-derived cutoffs.Neuropsychopharmacology: official publication of the American College of Neuropsychopharmacology, 32(9), 1903-1910. https://doi.org/10.1038/sj.npp.1301325

Leucht, S., Kane, J. M., Etschel, E., Kissling, W., Hamann, J., \& Engel, R. R. (2006). Linking the PANSS, BPRS, and CGI: clinical implications. Neuropsychopharmacology : official publication of the American College of Neuropsychopharmacology, 31(10), 2318-2325. https://doi.org/10.1038/ sj.npp.1301147

Leucht, S., Kane, J. M., Kissling, W., Hamann, J., Etschel, E., \& Engel, R. R. (2005a). What does the PANSS mean?. Schizophrenia research, 79(2-3), 231-238. https://doi.org/10.1016/j.schres.2005.04.008
Leucht, S., Kane, J. M., Kissling, W., Hamann, J., Etschel, E., \& Engel, R. (2005b). Clinical implications of Brief Psychiatric Rating Scale scores. The British journal of psychiatry: the journal of mental science, 187, 366-371. https://doi.org/10.1192/bjp.187.4.366

Leucht, S., Samara, M., Heres, S., Patel, M. X., Furukawa, T., Cipriani, A., Geddes, J., \& Davis, J. M. (2015). Dose Equivalents for Second-Generation Antipsychotic Drugs: The Classical Mean Dose Method. Schizophrenia bulletin, 41(6), 1397-1402. https://doi.org/10.1093/schbul/sbv037

Leucht, S., Samara, M., Heres, S., Patel, M. X., Woods, S. W., \& Davis, J. M. (2014). Dose equivalents for second-generation antipsychotics: the minimum effective dose method. Schizophrenia bulletin, 40(2), 314-326. https://doi.org/10.1093/schbul/sbu001

Levine, S. Z., Rabinowitz, J., Engel, R., Etschel, E., \& Leucht, S. (2008). Extrapolation between measures of symptom severity and change: an examination of the PANSS and CGI. Schizophrenia research, 98(1-3), 318-322. https://doi.org/10.1016/j.schres.2007.09.006

Lewis, S. W., Barnes, T. R., Davies, L., Murray, R. M., Dunn, G., Hayhurst, K. P., Markwick, A., Lloyd, H., \& Jones, P. B. (2006). Randomized controlled trial of effect of prescription of clozapine versus other second-generation antipsychotic drugs in resistant schizophrenia. Schizophrenia bulletin, 32(4), 715-723. https://doi.org/10.1093/schbul/sbj067

Li, W., Zhou, F. C., Zhang, L., Ng, C. H., Ungvari, G. S., Li, J., \& Xiang, Y. T. (2020). Comparison of cognitive dysfunction between schizophrenia and bipolar disorder patients: A meta-analysis of comparative studies. Journal of affective disorders, 274, 652-661. https://doi.org/10.1016/j. jad.2020.04.051

Lieberman, J. A., Phillips, M., Gu, H., Stroup, S., Zhang, P., Kong, L., Ji, Z., Koch, G., \& Hamer, R. M. (2003). Atypical and conventional antipsychotic drugs in treatment-naive first-episode schizophrenia: a 52-week randomized trial of clozapine vs chlorpromazine. Neuropsychopharmacology : official publication of the American College of Neuropsychopharmacology, 28(5), 995-1003. https://doi.org/10.1038/sj.npp.1300157

Lieberman, J., Jody, D., Geisler, S., Alvir, J., Loebel, A., Szymanski, S., Woerner, M., \& Borenstein, M. (1993). Time course and biologic correlates of treatment response in first-episode schizophrenia. Archives of general psychiatry, 50(5), 369-376. https://doi.org/10.1001/archpsyc. 1993.01820170047006

Lin, J. J., Liang, F. W., Li, C. Y., \& Lu, T. H. (2018). Leading causes of death among decedents with mention of schizophrenia on the death certificates in the United States. Schizophrenia research, 197, 116-123. https://doi.org/10.1016/j.schres.2018.01.011

Lindenmayer, J. P., Czobor, P., Volavka, J., Lieberman, J. A., Citrome, L., Sheitman, B., Chakos, M., \& McEvoy, J. P. (2002). Olanzapine in refractory schizophrenia after failure of typical or atypical antipsychotic treatment: an open-label switch study. The Journal of clinical psychiatry,63(10), 931935. https://doi.org/10.4088/jcp.v63n1011

Lindenmayer, J.-P., Iskander, A., Park, M., Aspergi, F., Czobor, P., Smith, R., \& Allen, D. (1998). Clinical and neurocognitive effects of clozapine and risperidone in treatment-refractory schizophrenic patients: a prospective study. J Clin Psychiatry, 59(10), 521-527.

Lowe, E. J., \& Ackman, M. L. (2010). Impact of tobacco smoking cessation on stable clozapine or olanzapine treatment. The Annals of pharmacotherapy, 44(4), 727-732. https://doi.org/10.1345/aph.1M398

Lysaker, P. H., \& Salyers, M. P. (2007). Anxiety symptoms in schizophrenia spectrum disorders: associations with social function, positive and negative symptoms, hope and trauma history. Acta psychiatrica Scandinavica,116(4), 290-298. https://doi.org/10.1111/j.1600-0447.2007.01067.x

Mancama, D., Arranz, M. J., \& Kerwin, R. W. (2002). Genetic predictors of therapeutic response to clozapine: current status of research. CNS drugs, 16(5), 317-324. https://doi.org/10.2165/00023210-200216050-00004

Mariné, R., Creus, M., Solé, M., Cabezas, Á., Algora, M. J., Moreno, I., Izquierdo, E., Stojanovic-Pérez, A., \& Labad, J. (2015). Clinical correlates of obsessive-compulsive symptom dimensions in at-risk mental states and psychotic disorders at early stages. Psychiatry research, 228(3), 363-367. https://doi.org/10.1016/j.psychres.2015.05.083 
Martínez-Sahuquillo Amuedo, M. E., \& Echevarría Ruiz De Vargas, M. C. (2001). Métodos de consenso. Uso adecuado de la evidencia en la toma de decisiones. «Método RAND/UCLA». Rehabilitación, 35(6), 388-392. doi: $10.1016 /$ s0048-7120(01)73220-3

Mc Gurk, S. R. (2000). The effects of clozapine on cognitive functioning in schizophrenic patients. The Journal of Clinical Psychiatry, 61(suppl 6), 47-51. McArdle, P. A., De Mel, V., DeMonte, V., Winckel, K., Gore-Jones, V., Foley, S., Korman, N., Parker, S., Dark, F., \& Siskind, D. (2019). An investigation into the relationship between clozapine treatment and cognitive performance in patients with treatment resistant schizophrenia. Schizophrenia research, 206, 450-451. https://doi.org/10.1016/j.schres.2018.11.030

McEnery, C., Lim, M. H., Tremain, H., Knowles, A., \& Alvarez-Jimenez, M. (2019). Prevalence rate of social anxiety disorder in individuals with a psychotic disorder: A systematic review and meta-analysis. Schizophrenia research, 208, 25-33. https://doi.org/10.1016/j.schres.2019.01.045

McEvoy, J. P., Lieberman, J. A., Stroup, T. S., Davis, S. M., Meltzer, H. Y., Rosenheck, R. A., Swartz, M. S., Perkins, D. O., Keefe, R. S., Davis, C. E., Severe, J., Hsiao, J. K., \& CATIE Investigators (2006). Effectiveness of clozapine versus olanzapine, quetiapine, and risperidone in patients with chronic schizophrenia who did not respond to prior atypical antipsychotic treatment. The American journal of psychiatry, 163(4), 600-610. https:// doi.org/10.1176/appi.ajp.163.4.600

McGrath, J., Saha, S., Welham, J., El Saadi, O., MacCauley, C., Chant, D. (2004). A systematic review of the incidence of schizophrenia: the distribution of rates and the influence of sex, urbanicity, migrant status and methodology. BMC Med; 2:13. doi:10.1186/1741-7015-2-13

McIlwain, M. E., Harrison, J., Wheeler, A. J., \& Russell, B. R. (2011). Pharmacotherapy for treatment-resistant schizophrenia. Neuropsychiatric disease and treatment, 7, 135-149. https://doi.org/10.2147/NDT.S12769

McMahon, R. P., Kelly, D. L., Kreyenbuhl, J., Kirkpatrick, B., Love, R. C., \& Conley, R. R. (2002). Novel factor-based symptom scores in treatment resistant schizophrenia: Implications for clinical trials. Neuropsychopharmacology, 26(4), 537-545. https://doi.org/10.1016/S0893-133X(01)00387-6

McNabb, C. B., McIlwain, M. E., Anderson, V. M., Kydd, R. R., Sundram, F., \& Russell, B. R. (2020). Aberrant white matter microstructure in treatment-resistant schizophrenia. Psychiatry research. Neuroimaging, 305, 111198. https://doi.org/10.1016/j.pscychresns.2020.111198

Meltzer, H. Y., \& Kostakoglu, A. (2001). Treatment resistant schizophrenia. En: Lieberman, J., Murray, R. M. (eds.) Comprehensive care of schizophrenia. (pp.. 181-203).Martin Dunitz,

Meltzer, H. Y., Bobo, W. V., Roy, A., Jayathilake, K., Chen, Y., Ertugrul, A., Anil Yağcioğlu, A. E., \& Small, J. G. (2008). A randomized, double-blind comparison of clozapine and high-dose olanzapine in treatment-resistant patients with schizophrenia. The Journal of clinical psychiatry, 69(2), 274285. https://doi.org/10.4088/jcp.v69n0214

Meltzer, H. Y., Rabinowitz, J., Lee, M. A., Cola, P. A., Ranjan, R., Findling, R. L., \& Thompson, P. A. (1997). Age at onset and gender of schizophrenic patients in relation to neuroleptic resistance. The American journal of psychiatry, 154(4), 475-482. https://doi.org/10.1176/ajp.154.4.475

Meltzer, H. Y., Share, D. B., Jayathilake, K., Salomon, R. M., \& Lee, M. A. (2020). Lurasidone Improves Psychopathology and Cognition in Treatment-Resistant Schizophrenia. Journal of Clinical Psychopharmacology, 40(3), 240-249. https://doi.org/10.1097/JCP.0000000000001205

Meyer-Lindenberg, A., Gruppe, H., Bauer, U., Lis, S., Krieger, S., \& Gallhofer, B. (1997). Improvement of cognitive function in schizophrenic patients receiving clozapine or zotepine: Results from a double-blind study. Pharmacopsychiatry, 30(2), 35-42. https://doi.org/10.1055/s-2007-979481

Mico', U., Bruno, A., Pandolfo, G., Maria Romeo, V., Mallamace, D., D’Arrigo, C., Spina, E., Zoccali, R. A., \& Muscatello, M. R. A. (2011). Duloxetine as adjunctive treatment to clozapine in patients with schizophrenia: A randomized, placebo-controlled trial. International Clinical Psychopharmacology, 26(6), 303-310. https://doi.org/10.1097/YIC.0b013e32834bbc0d

Miller, A. L., Crismon, M. L., Rush, A. J., Chiles, J., Kashner, T. M., Toprac, M., Carmody, T., Biggs, M., Shores-Wilson, K., Chiles, J., Witte, B., Bow-Thomas, C., Velligan, D. I., Trivedi, M., Suppes, T., \& Shon, S. (2004).
The Texas medication algorithm project: clinical results for schizophrenia. Schizophrenia bulletin,30(3), 627-647. https://doi.org/10.1093/oxfordjournals.schbul.a007111

Mitelman, S. A., \& Buchsbaum, M. S. (2007). Very poor outcome schizophrenia: clinical and neuroimaging aspects. International review of psychiatry (Abingdon, England), 19(4), 345-357. https://doi. org/10.1080/09540260701486563

Mitelman, S. A., Canfield, E. L., Brickman, A. M., Shihabuddin, L., Hazlett, E. A., \& Buchsbaum, M. S. (2010). Progressive ventricular expansion in chronic poor-outcome schizophrenia. Cognitive and behavioral neurology: official journal of the Society for Behavioral and Cognitive Neurology, 23(2), 85-88. https://doi.org/10.1097/WNN.0b013e3181cfb52a

Moncrieff, J., Crellin, N. E., Long, M. A., Cooper, R. E., \& Stockmann, T. (2020). Definitions of relapse in trials comparing antipsychotic maintenance with discontinuation or reduction for schizophrenia spectrum disorders: A systematic review. Schizophrenia research, 225, 47-54. https:// doi.org/10.1016/j.schres.2019.08.035

Morel, B. A. (1860). Traité des Maladies Mentales. Masson.

Moreno-Küstner, B., Martín, C., Pastor, L. (2018). Prevalence of psychotic disorders and its association with methodological issues. A systematic review and meta-analyses. PLoS One; 13(4):e0195687. doi:10.1371/journal. pone.0195687

Morrison, A. P., Pyle, M., Gumley, A., Schwannauer, M., Turkington, D., MacLennan, G., Norrie, J., Hudson, J., Bowe, S. E., French, P., Byrne, R., Syrett, S., Dudley, R., McLeod, H. J., Griffiths, H., Barnes, T., Davies, L., Kingdon, D., \& FOCUS trial group (2018). Cognitive behavioural therapy in clozapine-resistant schizophrenia (FOCUS): an assessor-blinded, randomised controlled trial. The lancet. Psychiatry, 5(8), 633-643. https://doi. org/10.1016/S2215-0366(18)30184-6

Mouaffak, F., Tranulis, C., Gourevitch, R., Poirier, M. F., Douki, S., Olié, J. P., Lôo, H., \& Gourion, D. (2006). Augmentation strategies of clozapine with antipsychotics in the treatment of ultraresistant schizophrenia. Clinical neuropharmacology, 29(1), 28-33. https://doi.org/10.1097/00002826200601000-00009

Mouchlianitis, E., Bloomfield, M. A., Law, V., Beck, K., Selvaraj, S., Rasquinha, N., Waldman, A., Turkheimer, F. E., Egerton, A., Stone, J., \& Howes, O. D. (2016a). Treatment-Resistant Schizophrenia Patients Show Elevated Anterior Cingulate Cortex Glutamate Compared to Treatment-Responsive. Schizophrenia bulletin, 42(3), 744-752. https://doi. org $/ 10.1093 / \mathrm{schbul} / \mathrm{sbv} 151$

Mouchlianitis, E., McCutcheon, R., \& Howes, O. D. (2016b). Brain-imaging studies of treatment-resistant schizophrenia: a systematic review. The Lancet. Psychiatry, 3(5), 451-463. https://doi.org/10.1016/S22150366(15)00540-4

Murray, R. M., \& Van Os, J. (1998). Predictors of outcome in schizophrenia. Journal of clinical psychopharmacology, 18(2 Suppl 1), 2S-4S. https:// doi.org/10.1097/00004714-199804001-00002

Muscatello, M. R. A., Bruno, A., Pandolfo, G., Micò, U., Scimeca, G., Di Nardo, F., Santoro, V., Spina, E., \& Zoccali, R. A. (2011a). Effect of aripiprazole augmentation of clozapine in schizophrenia: A double-blind, placebo-controlled study. Schizophrenia Research, 127(1-3), 93-99. https:// doi.org/10.1016/j.schres.2010.12.011

Muscatello, M. R. A., Pandolfo, G., Micò, U., Lamberti Castronuovo, E., Abenavoli, E., Scimeca, G., Spina, E., Zoccali, R., \& Bruno, A. (2014a). Augmentation of clozapine with ziprasidone in refractory schizophrenia: A double-blind, placebo-controlled study. Journal of Clinical Psychopharmacology, 34(1), 129-133. https://doi.org/10.1097/JCP.0000000000000042 Muscatello, M. R., Bruno, A., De Fazio, P., Segura-Garcia, C., Pandolfo, G., \& Zoccali, R. (2014b). Augmentation strategies in partial responder and/or treatment-resistant schizophrenia patients treated with clozapine. Expert opinion on pharmacotherapy, 15(16), 2329-2345. https://doi.org/10 $.1517 / 14656566.2014 .956082$

Muscatello, M., Bruno, A., Pandolfo, G., Micò, U., Bellinghieri, P. M., Scimeca, G., Cacciola, M., Campolo, D., Settineri, S., \& Zoccali, R. (2011b). Topiramate augmentation of clozapine in schizophrenia: A double-blind, placebo-controlled study. Journal of Psychopharmacology, 25(5), 667-674. https://doi.org/10.1177/0269881110372548 
Naeem, F., Johal, R., McKenna, C., Rathod, S., Ayub, M., Lecomte, T., Husain, N., Kingdon, D., \& Farooq, S. (2016). Cognitive Behavior Therapy for psychosis based Guided Self-help (CBTp-GSH) delivered by frontline mental health professionals: Results of a feasibility study. Schizophrenia research, 173(1-2), 69-74. https://doi.org/10.1016/j.schres.2016.03.003

Nakajima, S., Takeuchi, H., Plitman, E., Fervaha, G., Gerretsen, P., Caravaggio, F., Chung, J. K., Iwata, Y., Remington, G., \& Graff-Guerrero, A. (2015). Neuroimaging findings in treatment-resistant schizophrenia: A systematic review: Lack of neuroimaging correlates of treatment-resistant schizophrenia. Schizophrenia research, 164(1-3), 164-175. https://doi.org/10.1016/j.schres.2015.01.043

Nakata, Y., Kanahara, N., \& Iyo, M. (2017). Dopamine supersensitivity psychosis in schizophrenia: Concepts and implications in clinical practice. Journal of psychopharmacology, 31(12), 1511-1518. https://doi. org/10.1177/0269881117728428

National Institute for Health and Care Excellence. (2014). Psychosis and schizophrenia. (NICE guideline CG178). https://www.nice.org.uk/guidance/cg178.

Nemeroff, C. B., Weinberger, D., Rutter, M., MacMillan, H. L., Bryant, R. A., Wessely, S., Stein, D. J., Pariante, C. M., Seemüller, F., Berk, M., Malhi, G. S., Preisig, M., Brüne, M., \& Lysaker, P. (2013). DSM-5: a collection of psychiatrist views on the changes, controversies, and future directions. BMC medicine, 11, 202. https://doi.org/10.1186/1741-7015-11-202

Nielsen, J., Young, C., Ifteni, P., Kishimoto, T., Xiang, Y. T., Schulte, P. F., Correll, C. U., \& Taylor, D. (2016). Worldwide Differences in Regulations of Clozapine Use. CNS drugs, 30(2), 149-161. https://doi.org/10.1007/ s40263-016-0311-1

Novick, D., Haro, J. M., Suarez, D., Vieta, E., \& Naber, D. (2009). Recovery in the outpatient setting: 36 -month results from the Schizophrenia Outpatients Health Outcomes (SOHO) study. Schizophrenia research, 108(1-3), 223-230. https://doi.org/10.1016/j.schres.2008.11.007

Nucifora, F. C., Jr, Woznica, E., Lee, B. J., Cascella, N., \& Sawa, A. (2019). Treatment resistant schizophrenia: Clinical, biological, and therapeutic perspectives. Neurobiology of disease, 131, 104257. https://doi.org/10.1016/j.nbd.2018.08.016

O'Carroll, R. (2000). Cognitive impairment in schizophrenia. Advances in Psychiatric Treatment, 6(3), 161-168. doi:10.1192/apt.6.3.161

Ortiz, B. B., Higuchi, C. H., Noto, C., Joyce, D. W., Correll, C. U., Bressan, R. A., \& Gadelha, A. (2020). A symptom combination predicting treatment-resistant schizophrenia - A strategy for real-world clinical practice. Schizophrenia research, 218, 195-200. https://doi.org/10.1016/j. schres.2020.01.002

Overall, J. E., \& Gorham, D. R. (1962). The Brief Psychiatric Rating Scale. Psychol Rep; 10:799-812.

Park, R., Kim, S., \& Kim, E. (2020). Relationship of change in plasma clozapine/n-desmethylclozapine ratio with cognitive performance in patients with schizophrenia. Psychiatry Investigation, 17(11), 1158-1165. https:// doi.org/10.30773/pi.2020.0306

Penn, D. L., Meyer, P. S., Evans, E., Wirth, R. J., Cai, K., \& Burchinal, M. (2009). A randomized controlled trial of group cognitive-behavioral therapy vs. enhanced supportive therapy for auditory hallucinations. Schizophrenia research, 109(1-3), 52-59. https://doi.org/10.1016/j.schres.2008.12.009 Petrides, G., Malur, C., Braga, R. J., Bailine, S. H., Schooler, N. R., Malhotra, A. K., Kane, J. M., Sanghani, S., Goldberg, T. E., John, M., \& Mendelowitz, A. (2015). Electroconvulsive therapy augmentation in clozapine-resistant schizophrenia: a prospective, randomized study. The American journal of psychiatry, 172(1), 52-58. https://doi.org/10.1176/appi.ajp.2014.13060787

Pharoah, F., Mari, J., Rathbone, J., \& Wong, W. (2010). Family intervention for schizophrenia. The Cochrane database of systematic reviews, (12), CD000088. https://doi.org/10.1002/14651858.CD000088.pub2

Pisanu, C., \& Squassina, A. (2019). Treatment-Resistant Schizophrenia: Insights From Genetic Studies and Machine Learning Approaches. Frontiers in pharmacology, 10, 617. https://doi.org/10.3389/fphar.2019.00617

Porcelli, S., Balzarro, B., \& Serretti, A. (2012). Clozapine resistance: augmentation strategies. European neuropsychopharmacology, 22(3), 165-182. https://doi.org/10.1016/i.euroneuro.2011.08.005
Potkin, S. G., Basile, V. S., Jin, Y., Masellis, M., Badri, F., Keator, D., Wu, J. C., Alva, G., Carreon, D. T., Bunney, W. E., Jr, Fallon, J. H., \& Kennedy, J. L. (2003). D1 receptor alleles predict PET metabolic correlates of clinical response to clozapine. Molecular psychiatry, 8(1), 109-113. https://doi. org/10.1038/sj.mp.4001191

Potkin, S. G., Kane, J. M., Correll, C. U., Lindenmayer, J. P., Agid, O., Marder, S. R., Olfson, M., \& Howes, O. D. (2020). The neurobiology of treatment-resistant schizophrenia: paths to antipsychotic resistance and a roadmap for future research. NPJ schizophrenia, 6(1), 1. https://doi. org/10.1038/s41537-019-0090-z

Pratt, S., Bennett, M., Brunette, M. F. (2020). Co-occurring Disorders and Conditions. En: Liberman, J. A., Stroup, T. S., Perkins, D. O., Dixon, L. B. (eds.). The American Psychiatric Association Publishing Textbook of Schizophrenia. 2nd ed. American Psychiatric Association Publishing.

Purdon, S. E., Labelle, A., \& Boulay, L. (2001). Neuropsychological change in schizophrenia after 6 weeks of clozapine. Schizophrenia Research, 48(1), 57-67. https://doi.org/10.1016/S0920-9964(00)00101-8

Quarantelli, M., Palladino, O., Prinster, A., Schiavone, V., Carotenuto, B., Brunetti, A., Marsili, A., Casiello, M., Muscettola, G., Salvatore, M., \& de Bartolomeis, A. (2014). Patients with poor response to antipsychotics have a more severe pattern of frontal atrophy: a voxel-based morphometry study of treatment resistance in schizophrenia. Bio Med research international, 2014, 325052. https://doi.org/10.1155/2014/325052

Rajji, T. K., Rogasch, N. C., Daskalakis, Z. J., \& Fitzgerald, P. B. (2013). Neuroplasticity-based brain stimulation interventions in the study and treatment of schizophrenia: a review. Canadian journal of psychiatry. Revue canadienne de psychiatrie, 58(2), 93-98. https://doi.org/10.1177/070674371305800206

Rajji, T. K., Uchida, H., Ismail, Z., Ng, W., Mamo, D. C., Remington, G., Pollock, B. G., \& Mulsant, B. H. (2010). Clozapine and global cognition in schizophrenia. Journal of Clinical Psychopharmacology, 30(4), 431-436. https://doi.org/10.1097/JCP.0b013e3181e69060

Regier, D. A., Farmer, M. E., Rae, D. S., Locke, B. Z., Keith, S. J., Judd, L. L., \& Goodwin, F. K. (1990). Comorbidity of mental disorders with alcohol and other drug abuse. Results from the Epidemiologic Catchment Area (ECA) Study. JAMA, 264(19), 2511-2518.

Reichenberg, A., Caspi, A., Harrington, H., Houts, R., Keefe, R. S. E., Murray, R. M., Poulton, R., \& Moffitt, T. E. (2010). Static and dynamic cognitive deficits in childhood preceding adult schizophrenia: A 30-year study. American Journal of Psychiatry, 167(2), 160-169. https://doi.org/10.1176/ appi.ajp.2009.09040574

Remington, G., Addington, D., Honer, W., Ismail, Z., Raedler, T., \& Teehan, M. (2017). Guidelines for the Pharmacotherapy of Schizophrenia in Adults. Canadian journal of psychiatry. Revue canadienne de psychiatrie, 62(9), 604-616. https://doi.org/10.1177/0706743717720448

Rosa, M. O., Gattaz, W. F., Rosa, M. A., Rumi, D. O., Tavares, H., Myczkowski, M., Sartorelli, M. C., Rigonatti, S. P., Elkis, H., Cabral, S. B., Teixeira, M. J., \& Marcolin, M. A. (2007). Effects of repetitive transcranial magnetic stimulation on auditory hallucinations refractory to clozapine. The Journal of clinical psychiatry, 68(10), 1528-1532. https://doi. org/10.4088/jcp.v68n1009

Rossell, S. L., Francis, P. S., Galletly, C., Harris, A., Siskind, D., Berk, M., Bozaoglu, K., Dark, F., Dean, O., Liu, D., Meyer, D., Neill, E., Phillipou, A., Sarris, J., \& Castle, D. J. (2016). N-acetylcysteine (NAC) in schizophrenia resistant to clozapine: A double blind randomised placebo controlled trial targeting negative symptoms. BMC Psychiatry, 16(1), 1-9. https://doi. org/10.1186/s12888-016-1030-3

Ruderfer, D. M., Charney, A. W., Readhead, B., Kidd, B. A., Kähler, A. K., Kenny, P. J., Keiser, M. J., Moran, J. L., Hultman, C. M., Scott, S. A., Sullivan, P. F., Purcell, S. M., Dudley, J. T., \& Sklar, P. (2016). Polygenic overlap between schizophrenia risk and antipsychotic response: a genomic medicine approach. The lancet. Psychiatry, 3(4), 350-357. https://doi. org/10.1016/S2215-0366(15)00553-2

Sabatés, J., \& Garay, C. J. (2016). Terapia cognitivo-conductual de la esquizofrenia: una revisión bibliográfica. Inv Psicol, 21(3):67-77.

Sackeim, H. A. (2003). Electroconvulsive therapy and schizophrenia. En: S. R. Hirsch, \& D. Weinberger, (Eds.). Schizophrenia. Blackwell. 
Saha, S., Chant, D., Welham, J., McGrath, J. (2005). A systematic review of the prevalence of schizophrenia. PLoS Med; 2(5):e141. doi:10.1371/journal.pmed.0020141

Saito, Y., Sakurai, H., Kane, J. M., Schooler, N. R., Suzuki, T., Mimura, M., \& Uchida, H. (2020). Predicting relapse with residual symptoms in schizophrenia: A secondary analysis of the PROACTIVE trial. Schizophrenia research, 215, 173-180. https://doi.org/10.1016/j.schres.2019.10.037

San, L., Serrano, M., Cañas, F., Romero, S. L., Sánchez-Cabezudo, Á., \& Villar, M. (2015). Towards a pragmatic and operational definition of relapse in schizophrenia: A Delphi consensus approach. International journal of psychiatry in clinical practice, 19(2), 90-98. https://doi.org/10.3109/1365 $\underline{1501.2014 .1002501}$

Sanghani, S. N., Petrides, G., \& Kellner, C. H. (2018). Electroconvulsive therapy (ECT) in schizophrenia: a review of recent literature. Current opinion in psychiatry, 31(3), 213-222. https://doi.org/10.1097/YCO.0000000000000418 Sensky, T., Turkington, D., Kingdon, D., Scott, J. L., Scott, J., Siddle, R., O'Carroll, M., \& Barnes, T. R. (2000). A randomized controlled trial of cognitive-behavioral therapy for persistent symptoms in schizophrenia resistant to medication. Archives of general psychiatry, 57(2), 165-172. https://doi.org/10.1001/archpsyc.57.2.165

Shah, P., Iwata, Y., Plitman, E., Brown, E. E., Caravaggio, F., Kim, J., Nakajima, S., Hahn, M., Remington, G., Gerretsen, P., \& Graff-Guerrero, A. (2018). The impact of delay in clozapine initiation on treatment outcomes in patients with treatment-resistant schizophrenia: A systematic review. Psychiatry research, 268, 114-122. https://doi.org/10.1016/j.psychres.2018.06.070

Sheffield, J. M., Karcher, N. R., \& Barch, D. M. (2018). Cognitive Deficits in Psychotic Disorders: A Lifespan Perspective. Neuropsychology review, 28(4), 509-533. https://doi.org/10.1007/s11065-018-9388-2

Sinclair, D. J., Zhao, S., Qi, F., Nyakyoma, K., Kwong, J. S., \& Adams, C. E. (2019). Electroconvulsive therapy for treatment-resistant schizophrenia. The Cochrane database of systematic reviews, 3(3), CD011847. https://doi. org/10.1002/14651858.CD011847.pub2

Siskind, D. J., Lee, M., Ravindran, A., Zhang, Q., Ma, E., Motamarri, B., \& Kisely, S. (2018). Augmentation strategies for clozapine refractory schizophrenia: A systematic review and meta-analysis. The Australian and New Zealand journal of psychiatry, 52(8), 751-767. https://doi. org/10.1177/0004867418772351

Siskind, D., Siskind, V., \& Kisely, S. (2017). Clozapine Response Rates among People with Treatment-Resistant Schizophrenia: Data from a Systematic Review and Meta-Analysis. Canadian journal of psychiatry. Revue canadienne de psychiatrie, 62(11), 772-777. https://doi. org/10.1177/0706743717718167

Souza, J. S., Kayo, M., Tassell, I., Martins, C. B., \& Elkis, H. (2013). Efficacy of olanzapine in comparison with clozapine for treatment-resistant schizophrenia: evidence from a systematic review and meta-analyses. CNS spectrums, 18(2), 82-89. https://doi.org/10.1017/S1092852912000806

Stahl S. M. (2002). Antipsychotic polypharmacy: evidence based or eminence based?. Acta psychiatrica Scandinavica, 106(5), 321-322. https://doi. org/10.1034/j.1600-0447.2002.2e011.x

Suzuki, T., Kanahara, N., Yamanaka, H., Takase, M., Kimura, H., Watanabe, H., \& Iyo, M. (2015). Dopamine supersensitivity psychosis as a pivotal factor in treatment-resistant schizophrenia. Psychiatry research, 227(2-3), 278-282. https://doi.org/10.1016/j.psychres.2015.02.021

Suzuki, T., Remington, G., Mulsant, B. H., Rajji, T. K., Uchida, H., Graff-Guerrero, A., \& Mamo, D. C. (2011). Treatment resistant schizophrenia and response to antipsychotics: a review. Schizophrenia research,133(1-3), 54-62. https://doi.org/10.1016/j.schres.2011.09.016

Swets, M., Dekker, J., van Emmerik-van Oortmerssen, K., Smid, G. E., Smit, F., de Haan, L., \& Schoevers, R. A. (2014). The obsessive compulsive spectrum in schizophrenia, a meta-analysis and meta-regression exploring prevalence rates. Schizophrenia research, 152(2-3), 458-468. https://doi.org/10.1016/j.schres.2013.10.033
Tang, W. K., \& Ungvari, G. S. (2003). Efficacy of electroconvulsive therapy in treatment-resistant schizophrenia: a prospective open trial. Progress in neuro-psychopharmacology \& biological psychiatry, 27(3), 373-379. https:// doi.org/10.1016/S0278-5846(02)00354-8

Taylor D. M. (2017). Clozapine for Treatment-Resistant Schizophrenia: Sti11 the Gold Standard?. CNS drugs, 31(3), 177-180. https://doi.org/10.1007/ s40263-017-0411-6

Taylor, D. M., \& Smith, L. (2009), Augmentation of clozapine with a second antipsychotic - a meta-analysis of randomized, placebo-controlled studies. Acta Psychiatrica Scandinavica, 119: 419-425. https://doi.org/10.1111/j.1600-0447.2009.01367.x

Taylor, D., Paton, C., Kapur, S. (2015). The Maudsley prescribing guidelines in psychiatry. John Wiley \& Sons.

Temmingh, H., \& Stein, D. J. (2015). Anxiety in Patients with Schizophrenia: Epidemiology and Management. CNS drugs, 29(10), 819-832. https:// doi.org/10.1007/s40263-015-0282-7

Tsai, G. E., Yang, P., Chung, L. C., Tsai, I. C., Tsai, C. W., \& Coyle, J. T. (1999). D-serine added to clozapine for the treatment of schizophrenia. American Journal of Psychiatry, 156(11), 1822-1825. https://doi. org/10.1176/ajp.156.11.1822

Tsuang, M. T., \& Faraone, S. V. (1995). The case for heterogeneity in the etiology of schizophrenia. Schizophr Res; 17(2):161-175. doi:10.1016/09209964(95)00057-s

Turkington, D., Kingdon, D., Turner, T., \& Insight into Schizophrenia Research Group (2002). Effectiveness of a brief cognitive-behavioural therapy intervention in the treatment of schizophrenia. The British journal of psychiatry: the journal of mental science, 180, 523-527. https://doi. org/10.1192/bjp.180.6.523

Umbricht, D. S., Wirshing, W. C., Wirshing, D. A., McMeniman, M., Schooler, N. R., Marder, S. R., \& Kane, J. M. (2002). Clinical predictors of response to clozapine treatment in ambulatory patients with schizophrenia. The Journal of clinical psychiatry, 63(5), 420-424. https://doi. org/10.4088/jcp.v63n0508

Uno, Y., \& Coyle, J. T. (2019). Glutamate hypothesis in schizophrenia. Psychiatry and clinical neurosciences, 73(5), 204-215. https://doi.org/10.1111/ pcn. 12823

Upthegrove, R., Marwaha, S., Birchwood, M. (2017). Depression and Schizophrenia: Cause, Consequence, or Trans-diagnostic Issue?. Schizophr Bull, 43(2):240-244. doi:10.1093/schbul/sbw097

Ure, J. A., Corral, R., Wainwright, E. (2018). Schizophrenia and Brain Networks. Neuro Neurosurg, 1(1):1-10. doi: 10.15761/NNS.1000102

Valiengo, L., Goerigk, S., Gordon, P. C., Padberg, F., Serpa, M. H., Koebe, S., Santos, L., Lovera, R., Carvalho, J. B., van de Bilt, M., Lacerda, A., Elkis, H., Gattaz, W. F., \& Brunoni, A. R. (2020). Efficacy and Safety of Transcranial Direct Current Stimulation for Treating Negative Symptoms in Schizophrenia: A Randomized Clinical Trial. JAMA psychiatry, 77(2), 121-129. https://doi.org/10.1001/jamapsychiatry.2019.3199

Valmaggia, L. R., van der Gaag, M., Tarrier, N., Pijnenborg, M., \& Slooff, C. J. (2005). Cognitive-behavioural therapy for refractory psychotic symptoms of schizophrenia resistant to atypical antipsychotic medication. Randomised controlled trial. The British journal of psychiatry : the journal of mental science, 186, 324-330. https://doi.org/10.1192/bjp.186.4.324

van der Gaag, M., Nieman, D. H., Rietdijk, J., Dragt, S., Ising, H. K., Klaassen, R. M., Koeter, M., Cuijpers, P., Wunderink, L., \& Linszen, D. H. (2012). Cognitive behavioral therapy for subjects at ultrahigh risk for developing psychosis: a randomized controlled clinical trial. Schizophrenia bulletin, 38(6), 1180-1188. https://doi.org/10.1093/schbul/sbs105

Van Sant, S. P., \& Buckley, P. F. (2011). Pharmacotherapy for treatment-refractory schizophrenia. Expert opinion on pharmacotherapy, 12(3), 411434. https://doi.org/10.1517/14656566.2011.528200

Varese, F., Smeets, F., Drukker, M., Lieverse, R., Lataster, T., Viechtbauer, W., Read, J., van Os, J., \& Bentall, R. P. (2012). Childhood adversities increase the risk of psychosis: a meta-analysis of patient-control, prospective- and cross-sectional cohort studies. Schizophrenia bulletin, 38(4), 661-671. https://doi.org/10.1093/schbul/sbs050 
Vaygggsoğlu, S., Yağcioğlu, A. E. A., Yağcgğoğlu, S., Karahan, S., Karcgğ, O., Gürel, Ş. C., \& Yazgg̊̊̊, M. K. (2013). Lamotrigine augmentation in patients with schizophrenia who show partial response to clozapine treatment. Schizophrenia Research, 143(1), 207-214. https://doi.org/10.1016/j. schres.2012.11.006

Veerman, S. R. T., Schulte, P. F. J., Smith, J. D., \& De Haan, L. (2016). Memantine augmentation in clozapine-refractory schizophrenia: A randomized, double-blind, placebo-controlled crossover study. Psychological Medicine, 46(9), 1909-1921. https://doi.org/10.1017/S0033291716000398

Veerman, S. R., Schulte, P. F., Begemann, M. J., Engelsbel, F., \& de Haan, L. (2014). Clozapine augmented with glutamate modulators in refractory schizophrenia: a review and metaanalysis. Pharmacopsychiatry, 47(6), 185-194. https://doi.org/10.1055/s-0034-1383656

Ventura, J., Hellemann, G. S., Thames, A. D., Koellner, V., \& Nuechterlein, K. H. (2009). Symptoms as mediators of the relationship between neurocognition and functional outcome in schizophrenia: A meta-analysis. Schizophr Res, 113(3), 189-199. https://doi.org/10.1016/j.schres.2009.03.035

Verdoux, H., \& Quiles, C. (2020). Educational needs and psychoeducation interventions in clozapine users: a narrative review. Acta psychiatrica Scandinavica, 142(2), 96-108. https://doi.org/10.1111/acps.13172

Verma, M., Sahoo, S., Nehra, R., \& Grover, S. (2020). Does clozapine improves cognition in patients with treatment resistant schizophrenia?: An exploratory study. Schizophrenia Research, 218(1), 315-317. https://doi. org/10.1097/nmd.0000000000000066

Vita, A., Minelli, A., Barlati, S., Deste, G., Giacopuzzi, E., Valsecchi, P., Turrina, C., \& Gennarelli, M. (2019). Treatment-Resistant Schizophrenia: Genetic and Neuroimaging Correlates. Frontiers in pharmacology, 10, 402. https://doi.org/10.3389/fphar.2019.00402

Wagner, E., Löhrs, L., Siskind, D., Honer, W. G., Falkai, P., \& Hasan, A. (2019). Clozapine augmentation strategies - a systematic meta-review of available evidence. Treatment options for clozapine resistance. Journal of psychopharmacology, 33(4), 423-435. https://doi.org/10.1177/0269881118822171

Walton, M. E., \& Bouret, S. (2019). What Is the Relationship between Dopamine and Effort?. Trends in neurosciences, 42(2), 79-91. https://doi.org/10.1016/j.tins.2018.10.001

Wang, W., Pu, C., Jiang, J., Cao, X., Wang, J., Zhao, M., \& Li, C. (2015). Efficacy and safety of treating patients with refractory schizophrenia with antipsychotic medication and adjunctive electroconvulsive therapy: a systematic review and meta-analysis. Shanghai archives of psychiatry, 27(4), 206-219. https://doi.org/10.11919/j.issn.1002-0829.215093

Wernicke, C. (1899). Krankenvorstellungen aus der Psychiatrischen Klinik in Breslau. Schletter.

Wimberley, T., Støvring, H., Sørensen, H. J., Horsdal, H. T., MacCabe, J. H., \& Gasse, C. (2016). Predictors of treatment resistance in patients with schizophrenia: a population-based cohort study. The lancet. Psychiatry, 3(4), 358-366. https://doi.org/10.1016/S2215-0366(15)00575-1
World Health Organization. (2019). ICD-11 Reference Guide. (2020, 29.de septiembre) https://icd.who.int/browse11/content/ refguide.ICD11 en/ html/index.html\#2.45.06.

Wunderink, L., Nienhuis, F. J., Sytema, S., Slooff, C. J., Knegtering, R., \& Wiersma, D. (2007). Guided discontinuation versus maintenance treatment in remitted first-episode psychosis: relapse rates and functional outcome. The Journal of clinical psychiatry, 68(5), 654-661. https://doi. org/10.4088/jcp.v68n0502

Yamamori, H., Hashimoto, R., Fujita, Y., Numata, S., Yasuda, Y., Fujimoto, M., Ohi, K., Umeda-Yano, S., Ito, A., Ohmori, T., Hashimoto, K., \& Takeda, M. (2014). Changes in plasma D-serine, L-serine, and glycine levels in treatment-resistant schizophrenia before and after clozapine treatment. Neuroscience letters, 582, 93-98. https://doi.org/10.1016/j.neulet.2014.08.052

Yi, Z., Fan, X., Wang, J. J., Liu, D., Freudenreich, O., Goff, D., \& Henderson, D. C. (2012). Rosiglitazone and cognitive function in clozapine-treated patients with schizophrenia: A pilot study. Psychiatry Research, 200(2-3), 79-82. https://doi.org/10.1016/j.psychres.2012.05.020

Zahn, T. P., Pickar, D., \& Haier, R. J. (1994). Effects of clozapine, fluphenazine, and placebo on reaction time measures of attention and sensory dominance in schizophrenia. Schizophrenia Research, 13(2), 133-143. https://doi.org/10.1016/0920-9964(94)90094-9

Zheng, W., Cao, X. L., Ungvari, G. S., Xiang, Y. Q., Guo, T., Liu, Z. R., Wang, Y. Y., Forester, B. P., Seiner, S. J., \& Xiang, Y. T. (2016). Electroconvulsive Therapy Added to Non-Clozapine Antipsychotic Medication for Treatment Resistant Schizophrenia: Meta-Analysis of Randomized Controlled Trials. PloS one, 11(6), e0156510. https://doi.org/10.1371/journal. pone. 0156510

Zhuo, K., Tang, Y., Song, Z., Wang, Y., Wang, J., Qian, Z., Li, H., Xiang, Q., Chen, T., Yang, Z., Xu, Y., Fan, X., Wang, J., \& Liu, D. (2019). Repetitive transcranial magnetic stimulation as an adjunctive treatment for negative symptoms and cognitive impairment in patients with schizophrenia: a randomized, double-blind, sham-controlled trial. Neuropsychiatric disease and treatment, 15, 1141-1150. https://doi.org/10.2147/NDT.S196086

Zink M. (2014). Comorbid Obsessive-Compulsive Symptoms in Schizophrenia: Insight into Pathomechanisms Facilitates Treatment. Advances in medicine, 2014, 317980. https://doi.org/10.1155/2014/317980

Zisook, S., McAdams, L. A., Kuck, J., Harris, M. J., Bailey, A., Patterson, T. L., Judd, L. L., \& Jeste, D. V. (1999). Depressive symptoms in schizophrenia. The American journal of psychiatry, 156(11), 1736-1743. https://doi. org/10.1176/ajp.156.11.1736

Zoccali, R., Muscatello, M. R., Bruno, A., Cambria, R., Micò, U., Spina, E., \& Meduri, M. (2007). The effect of lamotrigine augmentation of clozapine in a sample of treatment-resistant schizophrenic patients: A double-blind, placebo-controlled study. Schizophrenia Research, 93(1-3), 109-116. https://doi.org/10.1016/j.schres.2007.02.009 